JANAINA HARDER

\title{
A percepção do informante frente à funcionalidade do idoso com Doença de Alzheimer
}

Dissertação apresentada à Faculdade de Medicina da Universidade de São Paulo para obtenção do título de Mestre em Ciências.

Programa de Psiquiatria.

Orientadora: Prof. ${ }^{a}{ }^{-}{ }^{\mathrm{a}}$.Tânia Corrêa de Toledo Ferraz Alves

São Paulo 2018 


\section{Dados Internacionais de Catalogação na Publicação (CIP)}

Preparada pela Biblioteca da

Faculdade de Medicina da Universidade de São Paulo

Creprodução autorizada pelo autor

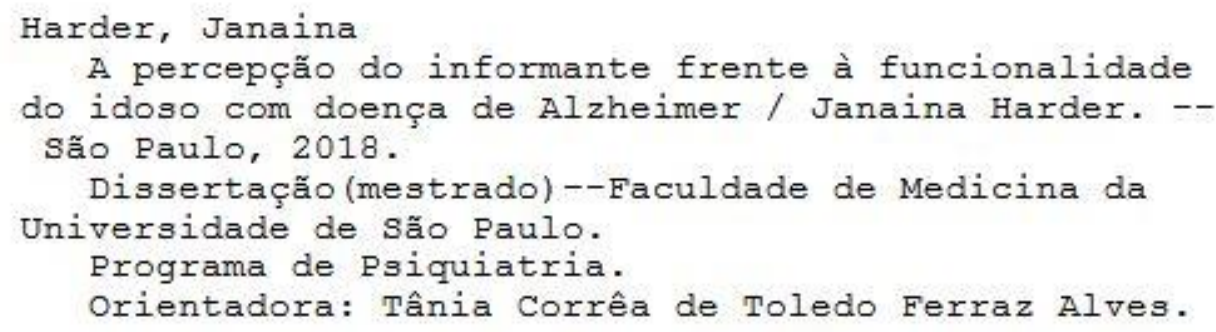

Descritores: 1.Doença de Alzheimer 2. Função executiva 3.Terapia ocupacional 4.Atividades cotidianas 5.Estresse psicológico 6. Cuidadores 7. Diagnóstico 8. Demência

$\mathrm{USP} / \mathrm{FM} / \mathrm{DBD}-106 / 18$ 
"......Não é sobre chegar no topo do mundo e saber que venceu. É sobre escalar e sentir que o caminho te fortaleceu..." (Ana Vilela) 
Primeiramente agradeço imensamente a Deus por guiar meus passos e me fortalecer nesta jornada;

A minha querida orientadora Tânia Alves que com sua imensa sabedoria me ensinou o que é pesquisa e com seu exemplo me ensinou o que é amor pela pesquisa e pela profissão;

Agradeço aos meus pais que sempre me apoiaram e que ensinaram-me o valor da vida, da luta e da persistência, que em sua simplicidade da vida me ensinaram o que os livros não nos ensinam: o amor incondicional

Agradeço meu marido Cassiano que com sua paciência, aguentou minhas ausências e angustias ao longo destes anos.

Ao meu filho Murilo que eu amo muito por fazer-me rir quando mais precisei e que me acolheu com seus abraços e beijinhos;

A equipe de profissionais que cooperaram com esse trabalho, sem vocês seria impossível continuar;

A companheira de jornada, Patrícia Buchain, muito obrigada pela compreensão e auxilio em todo este percurso;

Ao serviço de Terapia Ocupacional e em especial a Alexandra que acreditou nos meu profissionalismo e acolheu-me na instituição; sabedorias;

Ao PROTER e toda a equipe que auxiliou-me compartilhando suas

A Alessandra Moraes que pacientemente parou seu trabalho para socorrerme sempre que precisei;

A minha estatística Creuza que com seu profissionalismo, ajudou-me muito;

Ao Prof. Dr. Cássio Bottino (in memoria) que permitiu-me fazer parte desta equipe maravilhosa;

Ao CEREDIC que proporcionou esta parceria tão importante para nossa pesquisa;

Ao CNPq que auxiliou-me com bolsa de estudo durante essa trajetória;

Enfim, agradecer para mim foi um grande desafio, assim como foi todo este percurso até chegar até aqui. Foram muitos conhecimentos, muitas pessoas e muito aprendizado ao longo destes anos, que, com certeza, posso afirmar que tudo isso valeu a pena. Portanto, quero agradecer imensamente a todos que direta ou indiretamente fizeram parte desta história. 
Esta dissertação está de acordo com as normas em vigor no momento desta publicação:

Referências: adaptado de International Committe of Medical Journals Editors (Vancouver).

Universidade de São Paulo, Faculdade de Medicina. Serviço de Biblioteca e Documentação. Guia de apresentação de dissertações, teses e monografias. Elaborado por Annelise Carneiro da Cunha, Maria Julia de A. L. Freddi, Maria Crestana, Marinalva de Souza Aragão, Suely Campos Cardoso, Valéria Vilhena. $3^{\text {a }}$ ed. São Paulo: Serviço de Biblioteca e Documentação; 2011.

Abreviaturas dos títulos dos periódicos de acordo com List of Journals Indexed in Index Medicus. 
Lista de abreviaturas e Siglas

Lista de Figuras

Lista de Tabelas

Resumo

Abstract

1. INTRODUÇÃO

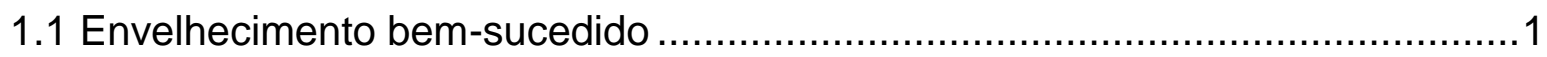

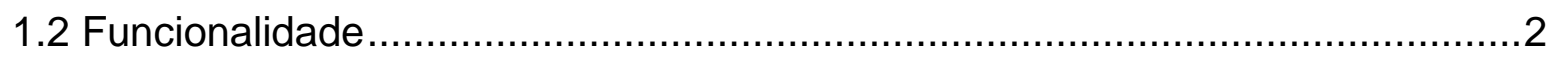

1.3 Doença de Alzheimer e funcionalidade ............................................... 5

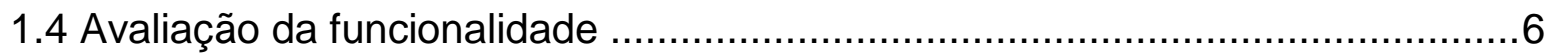

1.5 Percepção da funcionalidade pelo cuidador /informante ............................. 10

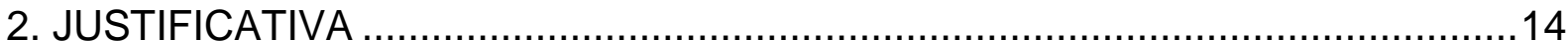

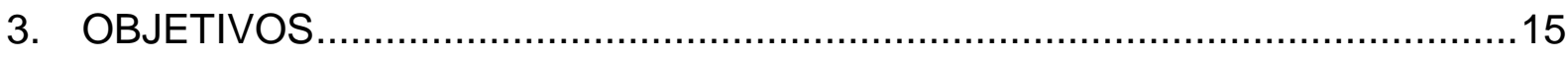

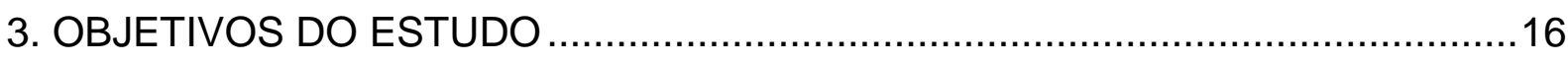

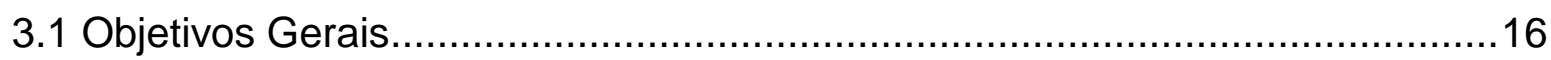

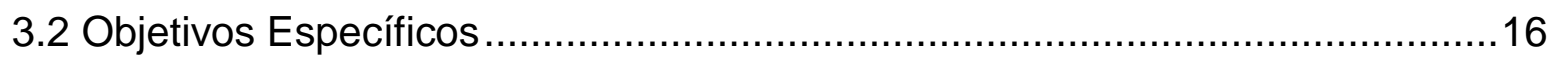

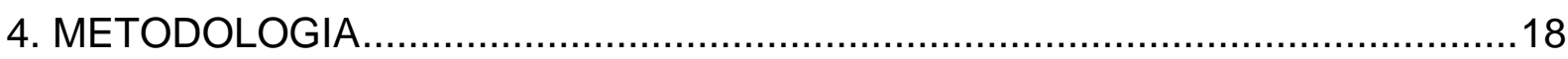

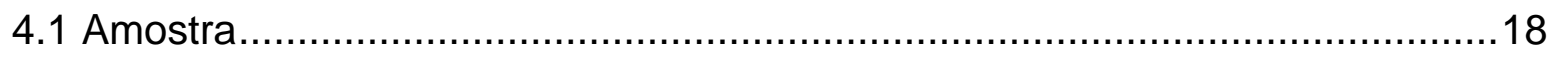

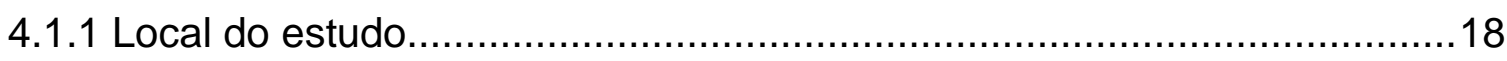

4.1.2 Cálculo da amostra ........................................................................

4.1.3 Critérios de Inclusão ................................................................. 19

4.1.4 Critérios de exclusão ..................................................................20

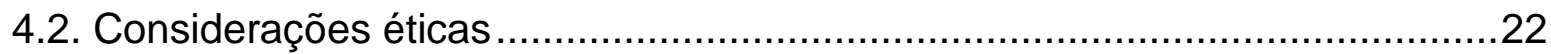

4.3. Descrição dos Instrumentos e Avaliações ............................................23

4.3.1 Avaliação cognitiva, clínica e demográfica .......................................23

4.3.1.1 Ficha de identificação individual ...............................................23 
4.3.1.2 Teste Cognitivo de Cambridge (CAMCOG) (Roth et al., 1986) ..............23

4.3.1.3 Mini Exame do Estado Mental (MEEM) (Folstein et al., 1975)..............23

4.3.1.4 Clinical Dementia Rating (CDR) (Hughes et al., 1982) ........................24

4.3.1.5 Escala de Hamilton para Depressão (HAM-D) (Hamilton, 1960) ...........24

4.3.1.6 Mini International Neuropsychiatric Interview (M.I.N.I.)(DSM IV) (Amorim,

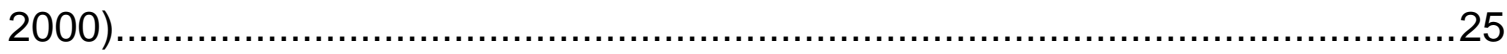

4.3.1.7 Avaliação Cognitiva de Montreal (MoCA) (Nasreddine et al., 2005) ......25

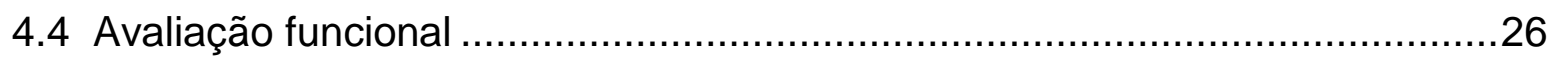

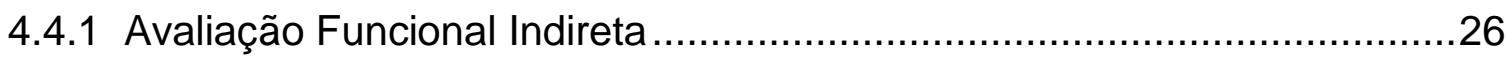

4.4.1.1 Escala de Atividades Instrumentais da Vida Diária (Lawton e Brody,

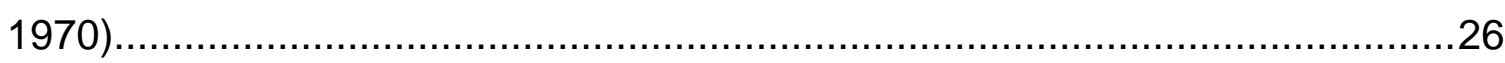

4.4.1.2 Questionário de Atividades funcionais de Pfeffer (FAQ) (Pfeffer et al.,

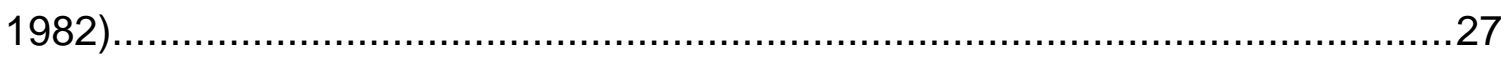

4.4.1.3 Bayer - Activities of Daily Living (B-ADL) (Hindmarch et al. 1998) ........27

4.4.1.4 Informant Questionnaire on Cognitive Decline-IQCODE.......................28

4.4.2 Avaliação Funcional Direta .......................................................29

4.4.2.1 Direct Assessment Functional State (DAFS-BR) ................................29

4.5 Avaliação de sintomas psiquiátricos .......................................................

4.5.1 Avaliação do estresse cuidador (Zarit Burden Interview)(Zarit e Zarit, 1983)

4.5.2 Caregiver Burden Inventary (CBI) (Novak e Guest, 1989) .......................30

4.5.3 Inventário de Depressão de Beck (BDI)(Beck et al., 1961).....................31

4.5.4 Inventário de Ansiedade de Beck (BAI) (Beck et al., 1988) .....................31

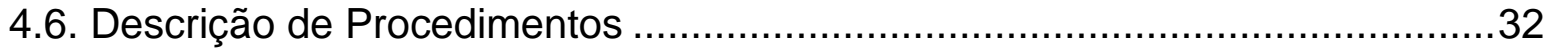

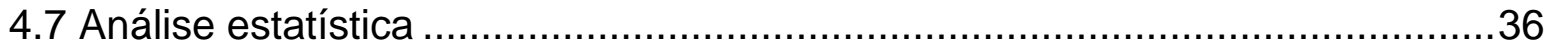

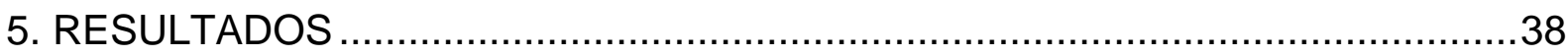

5.1 Análises de correlações entre as avaliações indireta e direta......................45

5.2 Análises de Sensibilidades e Especificidades.........................................50 


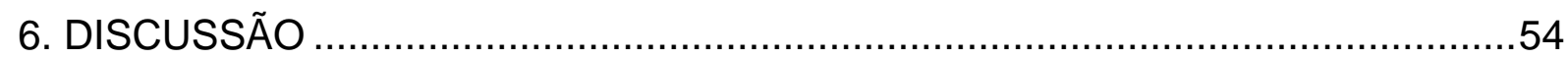

7. CONCLUSÃO

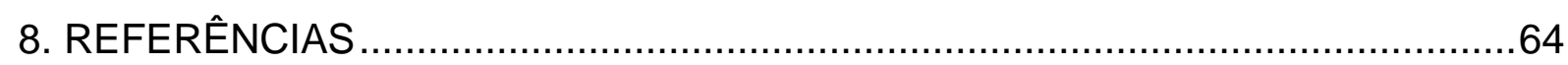

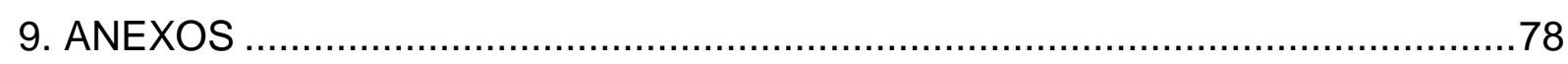

Anexo A - Termo de Consentimento Livre e Esclarecido - Casos e Controles......78

Anexo B - Termo de Consentimento Livre Esclarecido -Cuidador..........................81

Anexo C - APROVAÇÃO DA COMISSÃO DE ÉTICA …...................................84

Anexo D- DAFS-BR - Direct Assessment of Functional Status-Revised ................88

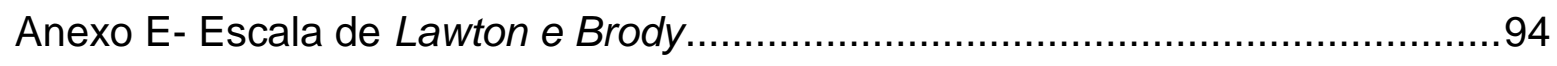

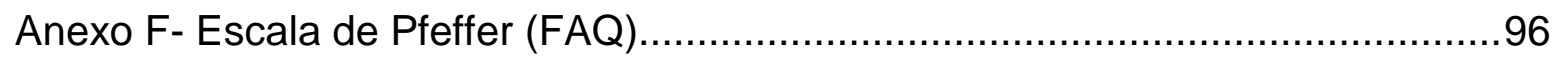

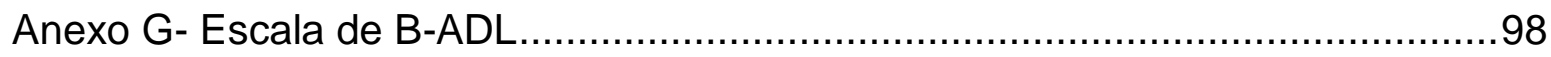

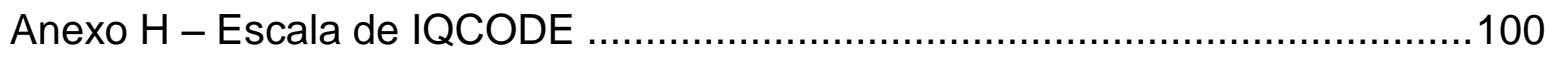

Anexo I - ARTIGO SUBMETIDO - Influence of emotional aspects in informant's

perception of the functionality of the elderly individual with Alzheimer's Disease 102 


\section{LISTAS}

\section{LISTA DE ABREVIATURAS E SIGLAS}

AAVD

ABVD

ADL-Q

ADRDA

AIVD

ANOVA

AVD

B-ADL

BADLS

BAI

BDI

CAMCOG

CAMDEX-R

CBI

CCL

CDR

CEREDIC

CID-10

CIF

D.P.
Atividades Avançadas de Vida Diária

Atividades Básicas de Vida Diária

Activities of Daily Living Questionnaire

Alzheimer's Disease and Related Disorders Association

Atividades instrumentais de vida diária

Análise de Variância a um fator

Atividades de Vida Diária

Bayer - Activities of Daily Living

Bristol Activities of Daily Living Scale

Inventário de Ansiedade de Beck

Inventário de Depressão de Beck

Teste Cognitivo de Cambridge

Cambridge Examination for Mental Disorders of the

Elderly

Caregiver Burden Inventary

Comprometimento Cognitivo Leve

Clinical Dementia Rating

Centro de Referência dos Estudos Cognitivos do Idoso

Classificação Internacional de Doenças

Classificação Internacional de Funcionalidade

Desvio Padrão 
DA

DAD

DAFS-BR

DFT

DSM-4

DSM-5

EFPT

FAQ

HAM-D

IBGE

IQCODE

M.I.N.I.

MEEM

MoCA

NINCDS

OMS

OTDL-R

PROTER

RTI-E

SPSS
Doença de Alzheimer

Disability Assessment for Dementia

Direct Assessment Functional State

Demência Fronto-temporal

Manual Diagnóstico e Estatístico de Transtornos

Mentais 4⿳亠丷a EDIÇÃO

Manual Diagnóstico e Estatístico de Transtornos

Mentais 5a EDIÇÃO

Executive Functional Performance

Questionário de Atividades funcionais de Pfeffer

Escala de Hamilton para Depressão

Instituto Brasileiro de Geografia e Estatísticas

Informant Questionnaire on Cognitive Decline in the

Elderly

Mini International Neuropsychiatric Interview

Mini-Exame do Estado Mental

Avaliação Cognitiva de Montreal

National Institute of Neurological and Communicative

Disorders and Stroke

Organização Mundial de Saúde

Revised Observed Tasksof Daily Living

Programa Terceira Idade

Routine Task Inventary Expanded

Package for Social Science 


\section{LISTA FIGURAS}

Figura 1. Interação entre os componentes da CIF. 3

Figura 2. Fluxograma da seleção da amostra do presente estudo .......................................... 21

Figura 3. Fluxograma da Organização do Processo de Avaliações: ........................................... 33

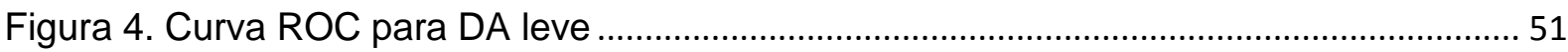

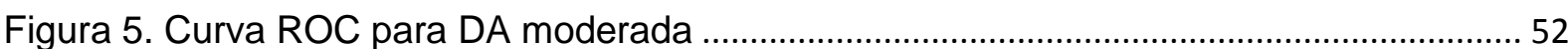




\section{LISTA DE TABELAS}

Tabela 1. Escala de avaliações funcionais diretas ................................................................. 7

Tabela 2. Escala de avaliações funcionais indiretas ................................................................ 8

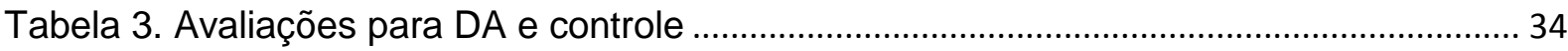

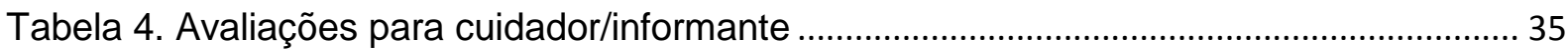

Tabela 5. Caracterização demográfica da amostra segundo grupos (DA leve,DA moderada e

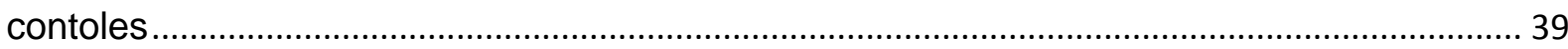

Tabela 6. Caracterização cognitiva e funcional dos sujeitos....................................................... 40

Tabela 7. Caracterização demográfica dos cuidadores/informantes, segundo os grupos dos respectivos pacientes

Tabela 8. Perfil cognitivo e emocional dos cuidadores/informantes, segundo os grupos dos respectivos pacientes

Tabela 9. Coeficiente de correlação das avaliações indiretas e direta ( $n=81$ pacientes) ....... 45

Tabela 10. Coeficiente de correlação entre questões indiretas e os domínios. 46

Tabela 11. Coeficiente de correlações de correlação de fatores emocionais do informante com escalas funcionais para o grupos de controle, DA leve e DA moderada

Tabela 12. Coeficiente de correlação entre os domínios das escalas CBI e DAFS-BR para os grupos de controle, DA leve e DA moderada 49

Tabela 13. Valor da Acurácia (dado pela área) dos instrumentos estudados para DA leve.. 50 Tabela 14. Valor da Acurácia (dado pela área) dos instrumentos estudados para DA moderada. 


\section{RESUMO}

Harder J. A percepção do informante frente à funcionalidade do idoso com doença de Alzheimer [dissertação]. São Paulo: Faculdade de Medicina, Universidade de São Paulo; 2018.

Introdução: Para muitos idosos a manutenção das habilidades funcionais é tão importante quanto a própria ausência de doença. No início do declínio cognitivo. a perda funcional relatada por familiares é importante para diagnóstico inicial das demências. A distorção da percepção da funcionalidade do idoso pode comprometer a terapêutica de modo a postergar o início do tratamento. Objetivo: $O$ presente estudo tem como objetivo comparar a avaliação da funcionalidade direta realizada com o idoso com a avaliação indireta realizada com o informante, e investigar se fatores emocionais como estresse, ansiedade e depressão do cuidador/informante podem interferir nesta avaliação. Metodologia: É um estudo controlado transversal, que avaliou a funcionalidade de 41 sujeitos com DA leve e moderada (CDR 1 e 2) e a de 40 sujeitos controles (CDR 0 ) emparelhados para faixa etária. Foram aplicadas avaliações indiretas da funcionalidade (IQCODE, FAQ, B-ADL, Lawton e Brody) preenchidas pelos familiares e o idoso foi avaliado de forma direta pela DAFS-BR. Investigou-se o perfil dos familiares e cuidadores, bem como se apresentavam sintomas depressivos, ansiosos, estresse e sobrecarga. A análise estatística foi realizada por meio da Análise de Variância a um fator com comparações múltiplas pelo teste de Bonferroni. As correlações foram avaliadas por meio do coeficiente de correlação de Pearson. Resultados: Com relação ao perfil cognitivo e emocional dos informantes/cuidadores observou-se que não há diferença significativa entre os grupos em relação aos sintomas depressivos, ansiosos e cognitivos. Observam-se diferenças entre os grupos em relação ao estresse do cuidador (Zarit e CBI $\mathrm{p}<0,001)$. $\mathrm{Na}$ análise de correlações entre as avaliações indiretas e direta observamse correlações significativas de todas as escalas, com boa sensibilidade e especificidade para DA leve e moderada. Entretanto, ao avaliar correlações dos sintomas depressivos, ansiosos e estresse do cuidador/informante com os escores das escalas indiretas nos diferentes grupos, observamos que nos controles e DA leve a performance do IQCODE foi o que mais se aproximou da avaliação direta e foi menos influenciado por esses sintomas. Já na DA moderada todos os questionários indiretos foram pouco influenciados pelos sintomas emocionais. Conclusão: A presença de sintomas emocionais influencia a avaliação indireta em quadros leves de declínio cognitivo, sendo nesses casos preferível uma avaliação direta. Já nos moderados, a avaliação indireta sofre menor influência do estresse do cuidador, uma vez que os prejuízos são mais evidentes.

Descritores: doença de Alzheimer; função executiva; terapia ocupacional; atividades cotidianas; estresse psicológico; cuidadores; diagnóstico; demência 
Harder J. Influence of emotional aspects in informant's perception of the functionality of the elderly individual with Alzheimer's disease [dissertation]. São Paulo: "Faculdade de Medicina, Universidade de São Paulo"; 2018

Background: For many senior individuals maintaining functional abilities is as important as the absence of disease itself. At the onset of cognitive decline, the functional loss reported by relatives is very important for the initial diagnosis of dementia. However, a distorted perception of the functionality of the elderly individual may compromise therapy by postponing the start of treatment. Objective: The objective of this study is to compare the direct functional assessment of the elderly with the functional indirect evaluation by the informant and to investigate whether caregiver/informant emotional factors, such as stress, anxiety and depression, interfere in this evaluation. Method: We adopt a controlled cross-sectional approach to evaluate the functionality of 41 subjects with mild to moderate (CDR 1 and 2) Alzheimer's Disease (AD) and 40 control subjects (CDR 0) matched for age. Indirect evaluations of functionality (the Informant Questionnaire on Cognitive Decline IQCODE, the Pfeffer Functional Activities Questionnaire - FAQ, Bayer Activities of Daily Living Scale - B-ADL, the Lawton and Brody Instrumental Activities of Daily Living Scale) were answered by family members. The elderly individuals were directly evaluated using the Direct Assessment of Functional State (DAFS-BR). The cognitive profile of the family members and caregivers was investigated, as well as the presence of depressive, anxiety, and burden symptomatology. Statistical analysis was performed based on single-factor analysis of variance (ANOVA) with multiple comparisons using the Bonferroni test. Correlations were assessed using the Pearson correlation coefficient. Results: Regarding the cognitive and emotional profile of the informants/caregivers, no significant difference between the groups was observed in relation to depression and anxiety or cognitive symptoms. However, we observed differences between the groups in relation to the caregiver's buden ( $p<$ $0.001)$. In the analysis of correlations between indirect and direct evaluations, we observed significant correlations for all scales, with good sensitivity and specificity for mild and moderate AD. However, when assessing the correlations of the depressive, anxiety and stress symptoms of the caregiver/informant with the scores of the indirect scales for the different groups, we observed that in the control and mild AD groups, IQCODE was the indirect assessment that most closely approximated to the direct evaluation and was less influenced by these symptoms. In moderate $A D$, all indirect questionnaires were little influenced by emotional symptoms. Conclusion: The presence of emotional symptoms influences the indirect evaluation of mild conditions of cognitive decline, in which case direct evaluation is preferable. In moderate cases, indirect evaluation is less influenced by caregiver stress because the impairment is more evident.

Descriptors: Alzheimer disease; executive function; occupational therapy; activities of daily living; stress, psychological; caregivers; diagnosis; dementia 
1. INTRODUÇÃO 


\section{INTRODUÇÃO}

A população idosa vem crescendo exponencialmente e representa hoje 20,6 milhões de brasileiros, com expectativa de atingir 19\% da população total brasileira (Carvalho e Rodríguez-Wong, 2008) A mudança da pirâmide populacional relacionase a diversos fatores, entre eles o aumento da expectativa de vida e as mudanças nas taxas de natalidade e mortalidade (Gomes e Pamplona, 2015). O aumento da prevalência de demências na América Latina sugere que em 2050 o número de indivíduos ultrapasse 7,8 milhões de pessoas (Custodio et al., 2017). No Brasil, a incidência é de 13,8 a cada mil habitantes com mais de 65 anos e, destes, 7,7 são diagnosticados com Doença de Alzheimer (DA) (Nitrini et al., 2004). Assim como no Brasil e na América Latina, a DA é a demência de maior prevalência mundial (Nitrini et al., 2004; Boff et al., 2015; Custodio et al., 2017). Desta maneira, investigar e compreender melhor os aspectos da funcionalidade dos idosos se torna importante para se obter uma melhor qualidade de vida e auxiliar no envelhecimento bemsucedido (Costa, 2006; Burton et al., 2009; Trindade et al., 2017).

\subsection{Envelhecimento bem-sucedido}

A busca pela conquista de um envelhecimento saudável ultrapassa o desejo de ausências de patologias. Para muitos idosos, a manutenção das habilidades funcionais torna-se mais importante do que a própria ausência de doença (WHO, 2015) Assim sendo, para considerar que um envelhecimento é "bem-sucedido" é necessário observar vários aspectos, entre eles, a funcionalidade, a cognição, o emocional, o bem-estar e a qualidade de vida. Diante disso, preservar a cognição, controlar e estabilizar doenças e incapacidades, associadas à boa capacidade funcional e à interação ativa na comunidade, são fatores considerados importantes nesse processo de envelhecimento (Rowe e Kahn, 1987; Fuchs et al., 2013; Dash et al., 2016).

A manutenção da funcionalidade destaca-se por estar relacionada à capacidade de lidar com as perdas ocorridas no envelhecimento e de ocupar-se com trabalhos e atividades agradáveis em faixas etárias mais avançadas (Ramos, 2003). 
Autores como Lara et al. (2015) tendem a caracterizar aspectos físicos e cognitivos que influenciam a capacidade funcional, como biomarcadores importantes tanto para o envelhecimento saudável como para o início de processos demenciais.

No processo de envelhecimento natural funções cognitivas como velocidade de processamento, memória de trabalho, atenção dividida, funções executivas e memória episódica tendem a declinar. Memória semântica, memória autobiográfica, processos emocionais e memória implícita mantêm-se mais preservadas com o avançar da idade (Dash et al., 2016).

Em contraponto, o processo de declínio da funcionalidade abrange trajetórias individuais e distintas que podem diferenciar de acordo com o estilo de vida de cada indivíduo. Idosos com ausência de patologias, com o estilo de vida saudável e com boas reservas cognitivas (ou seja, idosos que ao longo de sua vida praticaram exercícios cognitivos e físicos, que tiveram bom engajamento social, alimentação balanceada entre outros) podem manter-se ativos e independentes ao longo de todo seu envelhecimento. (Nyberg et al., 2012; Fjell et al., 2014).

Em idosos com demências ou desordens cognitivas o declínio da funcionalidade pode ser insidioso e tênue, comprometendo inicialmente as atividades avançadas de vida diária (AAVD) e atividades instrumentais de vida diária (AIVD) e, à medida que a doença vai avançando, a funcionalidade declina em paralelo, comprometendo por fim as atividades básicas de vida diária (ABVD). (Cornelis et al., 2017).

Assim, compreender a funcionalidade e seu impacto nas atividades diárias torna-se imprescindível tanto para diagnósticos como para o tratamento precoce das demências.

\subsection{Funcionalidade}

Para compreender a funcionalidade em um aspecto amplo e dinâmico, o presente estudo sugere como definição a Classificação Internacional de Funcionalidade (CIF). (Farias e Buchalla, 2005), que a descrevem como sendo a interação dinâmica entre as funções e as estruturas do corpo (olhos: visão; ouvidos: audição; cérebro: memória; etc), as atividades (execução de uma tarefa, ação de um indivíduo), a participação (envolvimento numa situação de vida real) e fatores ambientais e sociais ( ambiente físico e social em que a pessoa conduz a vida). 
O diagrama abaixo, descrito pela $\mathrm{CIF}$, permite compreender a dimensão da funcionalidade relacionada à saúde do indivíduo.

Figura 1. Interação entre os componentes da CIF

\section{Condição de saúde \\ (transtorno ou doença)}

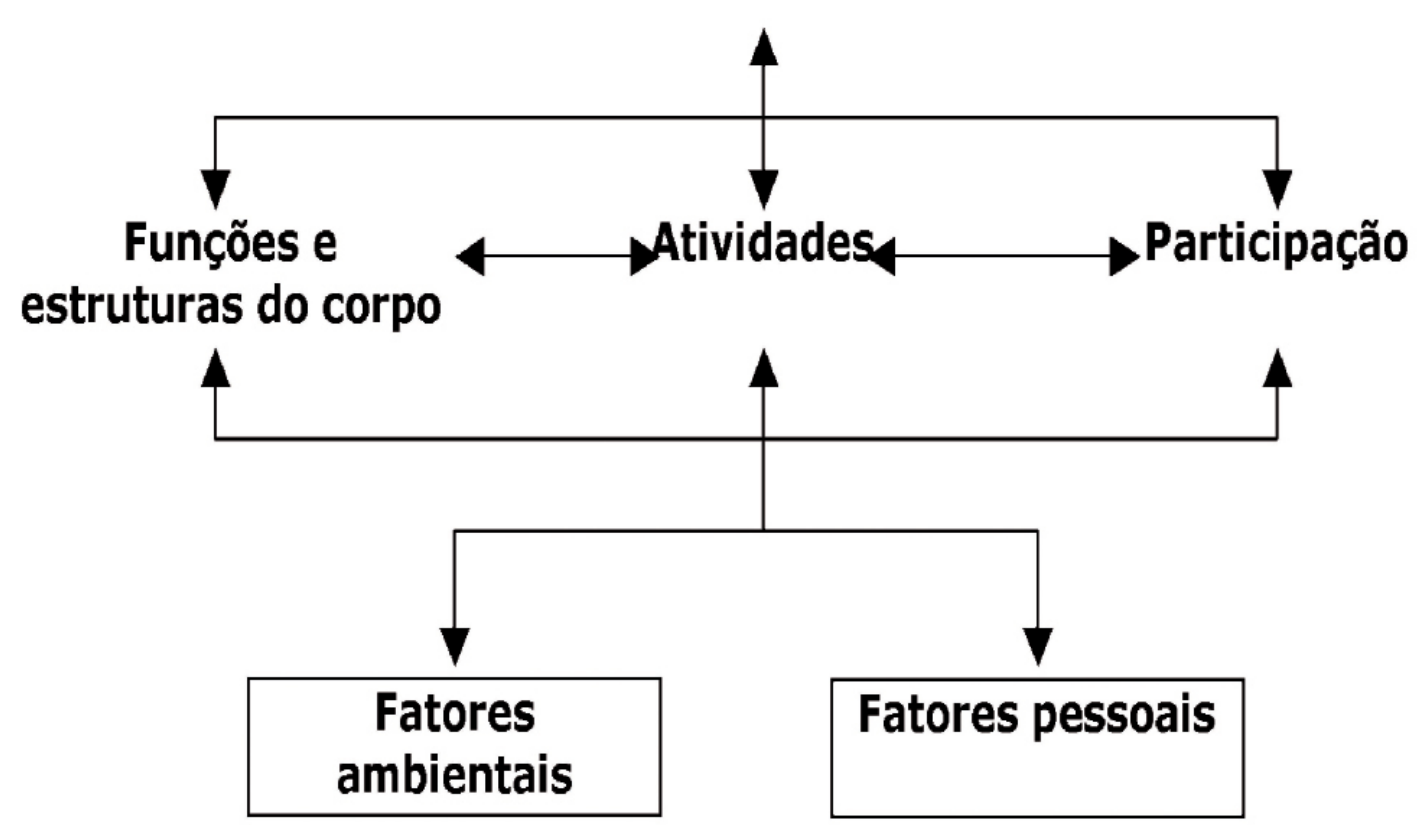

Fonte: CIF. OMS 2004

$\mathrm{Na}$ tentativa de unificar e padronizar as nomenclaturas, a CIF surge para auxiliar os profissionais da saúde a responder às reais necessidades que englobam, não só a patologia, como também as complexas mudanças que uma doença pode acarretar tanto no âmbito físico, como no psíquico e no social do indivíduo. Farias e Buchalla (2005) afirmam que a CIF se baseia no modelo biopsicossocial e que a avaliação do indivíduo incorpora o contexto de vida no qual ele está inserido. Os autores sugerem que o modelo da CIF substitua o enfoque negativo da deficiência e incapacidade por uma visão mais global, na qual, mesmo com a presença de alterações estruturais que o corpo possa apresentar, o indivíduo possa manter sua funcionalidade e independência nas atividades de vida diária (AVD). 
As atividades de vida diária se dividem em atividades avançadas, instrumentais e básicas. As AAVD são consideradas as atividades intencionais que exigem um funcionamento físico, mental e social; estas permitem o desenvolvimento de múltiplos papéis no decorrer da vida, os exemplos mais comuns são viajar ou planejar viagens, participar em grupos ou movimentos comunitários, dirigir e planejar eventos (Dias et al, 2014). As AIVD são as tarefas também de alta complexidade cognitiva e que são necessárias para a manutenção da vida em comunidade como, por exemplo, atividades de organização e controle do orçamento, utilização de telefone, realização de compras, planejamento e preparo de refeições, administração de medicamentos, capacidade de caminhar e orientar-se em locais usuais, organização de sua rotina, entre outras. As ABVD envolvem as atividades de autocuidado e higiene pessoal, como, por exemplo, banho, alimentação e locomoção.

Caporicci e Neto (2011) em um estudo comparativo de idosos saudáveis ativos e inativos, por meio da avaliação das AVD e da medição de qualidade de vida, sugerem que a realização das AVD de forma independente e segura é um dos fatores determinantes para a expectativa de uma vida ativa e uma melhor qualidade de vida.

Por outro, lado é preciso levar em conta que o ambiente e as interações que o indivíduo faz com ele também determinarão a independência funcional do idoso. A adaptação ao ambiente ou aos recursos oferecidos serão decisivos para determinar como o idoso realizará as atividades que considerar relevantes. Desta forma, é importante que familiares ou acompanhantes identifiquem a melhor maneira de auxiliar o idoso a realizar suas atividades, ao invés de assumi-las em seu lugar (Silva Talmelli et al., 2010).

No processo de envelhecimento, as demências são comumente citadas como sendo uma das patologias senis que, em sua maioria, trazem mudanças multifatoriais, que ocasionam não apenas alterações na estrutura cerebral, mas também mudanças significativas nas AVD e alteram o estilo de vida do idoso e de seus familiares. (Cornelis et al., 2017). 


\subsection{Doença de Alzheimer e funcionalidade}

De início insidioso e progressão lenta, a DA usualmente acomete regiões hipocampais e áreas corticais associativas tendo na sua fisiopatologia a presença de placas neuríticas com predomínio amiloide e emaranhados neurofibrilares (Association, 2014). Clinicamente, pode-se observar um declínio da memória recente, principalmente episódica, progredindo para desorientação espacial, alterações das funções executivas, visuoespaciais e, concomitantemente, comprometimento das funcionalidades nas atividades diárias (Caramellia e Barbosa, 2002; Pereira et al., 2010).

$\mathrm{Na}$ fase inicial da DA os principais comprometimentos funcionais estão relacionados a AAVD e a AIVD, que são as atividades mais complexas do ponto de vista cognitivo, pois exigem, geralmente, o desempenho de mais de uma função cognitiva, física e social (Dias et al., 2014).

Apesar de notório, o declínio funcional nas AAVD no início da DA tem sua avaliação menos citada pela literatura, visto que possuem alta influência de gênero e cultura e dificultam a padronização da avaliação. (Dias et al., 2014; Canon et al., 2016). Porém o prejuízo das AAVD já podem ser considerados indicadores importantes para futuros prejuízos funcionais (Dias et al., 2014; Sposito et al., 2016) e podem ser vistos nos quadros de comprometimento cognitivo leve (CCL), principalmente em CCL amnésticos (Cunha et al., 2015; Marshall et al., 2017). Com a progressão do quadro demencial, as AIVD se tornam mais comprometidas e já nas fases inicias da DA, a organização de finanças e usos de telefones e o manejo de sua própria medicação podem ser tarefas difíceis de serem realizadas de forma independente (Jekel et al., 2015; Vallejo et al., 2017). Assim, nos quadros de DA moderadas e graves o comprometimento das ABVD são mais evidentes e as atividades de autocuidado e higiene pessoal como, por exemplo, banho, alimentação e locomoção precisam ser auxiliadas por um cuidador (Mlinac e Feng, 2016; Ferreira, 2017). Desta forma, pode-se concluir que com o avançar da doença e com os acometimentos cognitivos consequentes, a funcionalidade tende a declinar em paralelo tornando o idoso com DA cada vez mais dependente de cuidados.

Avaliar a funcionalidade como preditor de piora evolutiva e como auxílio diagnóstico se mostra importante, para que tanto o idoso quanto seus familiares determinem o grau de independência e possam auxiliar os profissionais de saúde no 
melhor planejamento terapêutico (Caramellia e Barbosa, 2002; Marra et al., 2007; Hopkins et al., 2017).

\subsection{Avaliação da funcionalidade}

A avaliação da funcionalidade foi inicialmente proposta por Lawton e Brody (1970) como uma tentativa de mensurar os diferentes graus de complexidade e de dependência no qual as pessoas se enquadram, numa variedade de áreas tais como: qualidade do autocuidado, atitudes em relação a si mesmo e ao estado emocional e integridade física.

Atualmente a importância da avaliação funcional está contemplada nos critérios internacionais diagnósticos, tais como o National Institute of Neurological and Communicative Disorders and Stroke (NINCDS) e a Alzheimer's Disease and Related Disorders Association (ADRDA) (Mckhann et al., 1984). no Manual Diagnóstico e Estatístico de Transtornos Mentais 5a Edição (DSM-5) (Association, 2014), e a utilização de escalas ou questionários de avaliações funcionais são consideradas essenciais para os diagnósticos e/ou estadiamentos das demências (Nitrini et al., 2005a; Paixão Jr e Reichenheim, 2005; Chaves et al., 2011; Dias et al., 2014).

A avaliação da funcionalidade pode ocorrer de forma direta ou indireta, (Bravell et al., 2011; Lima-Silva et al., 2015; Mlinac e Feng, 2016). Na avaliação direta a funcionalidade é mensurada através da observação do examinador em um ambiente terapêutico próximo da vida diária do idoso. Enquanto que na avaliação indireta são aplicados escalas e questionários a informantes que convivem com o idoso.

Chaves et al. (2011), na tentativa de identificar qual a melhor maneira de avaliar o declínio funcional e cognitivo no envelhecimento, realizaram revisão sistemática da literatura que identifica os principais instrumentos utilizados na avaliação da funcionalidade, os quais se aplicam no próprio idoso ou em informante. Estes autores recomendam o uso das escalas Informant Questionnaire on Cognitive Decline in the Elderly (IQCODE), Direct Assessment Funcional State Review (DAFSR), Disability Assessment for Dementia (DAD), Activities of Daily Living Questionnaire (ADL-Q) e Bayer Activities of Daily Living (B-ADL) para avaliação de AIVD na DA, porque apresentam boas evidências fornecidas por estudos que 
possibilitam a medida de testes apropriados de acuraria diagnóstica. Almeida $M$ al. (2016) destacam as escalas de Atividades Instrumentais de Vida Diária de Lawton e Brody, o Índice de Katz, o Questionário de Atividades Funcionais de Pfeffer, Disability Assessment for Dementia, e o Índice de Barthel como as mais estudadas na literatura. Hopkins et al. (2017) também enfatizam a importância da escala Atividades Instrumentais de Vida Diária de Lawton e Brody como um bom instrumento devido às suas propriedades psicométricas e à facilidade de aplicação clínica. Bentvelzen et al. (2017) realizaram uma revisão sistemática com o intuito de auxiliar pesquisadores e clínicos a padronizar e orientar os pontos positivos e negativos de instrumentos de avalições em demência, dentre estes destacaram as avaliações B-ADL e IQCODE, como sendo excelentes instrumentos para auxiliar no diagnóstico com boas evidências psicométricas e aplicabilidade em diferentes contextos clínicos.

As tabelas 1 e 2 descrevem alguns dos principais instrumentos utilizados para avaliar a funcionalidade. Entre as citadas, na tabela 2 encontram-se 9 avaliações indiretas com adaptações transculturais, 7 com validação para a população brasileira e 1 direta adaptada e validada para a população brasileira.

Tabela 1. Escala de avaliações funcionais diretas

\begin{tabular}{|c|c|c|c|c|c|}
\hline & ABVD & AIVD & $\begin{array}{l}\text { Adaptação } \\
\text { transcultural }\end{array}$ & $\begin{array}{l}\text { Validação } \\
\text { brasileira }\end{array}$ & Comentários \\
\hline \multicolumn{6}{|c|}{ Avaliações Diretas } \\
\hline DAFS-BR & Sim & Sim & Sim & Sim & $\begin{array}{l}\text { Vários estudos literatura nacional } \\
\text { e internacional(Pereira et al., } \\
2010 \text { ). Apresenta como } \\
\text { particularidade a identificação de } \\
\text { CCL e Demência (Pereira et al. } \\
2010 \text { ). }\end{array}$ \\
\hline EFPT & Não & Sim & Sim & Sim & $\begin{array}{l}\text { Avalia funções executivas } \\
\text { através de tarefas ecológicas do } \\
\text { dia a dia (Neubern, 2018) }\end{array}$ \\
\hline RTI-E & Sim & Sim & $\begin{array}{c}\text { Em } \\
\text { andamento }\end{array}$ & $\begin{array}{c}\text { Em } \\
\text { andamento }\end{array}$ & $\begin{array}{llr}\text { Em processo de tradução e } & \text { a } \\
\text { validação, } & \text { possui } & \text { a } \\
\text { particularidade de contemplar } \\
\text { questões indiretas para o } \\
\text { cuidador. }\end{array}$ \\
\hline
\end{tabular}

Nota: ABVD: Atividades básicas de Vida Diária, AIVD: Atividades Instrumentais de Vida Diária; 
Tabela 2. Escala de avaliações funcionais indiretas

\begin{tabular}{|c|c|c|c|c|c|}
\hline & ABVD & AIVD & $\begin{array}{l}\text { Adaptação } \\
\text { transcultural }\end{array}$ & $\begin{array}{l}\text { Validação } \\
\text { brasileira }\end{array}$ & Comentários \\
\hline \multicolumn{6}{|c|}{ Avaliações Indiretas } \\
\hline $\begin{array}{l}\text { Escala de } \\
\text { atividades } \\
\text { instrumentais } \\
\text { (Lawton e } \\
\text { Brody, 1970) }\end{array}$ & Não & Sim & $\begin{array}{l}\text { Sim; (Lopes Dos } \\
\text { Santos e Virtuoso } \\
\text { Júnior, 2008) }\end{array}$ & $\begin{array}{l}\text { Sim; (Lopes } \\
\text { Dos Santos e } \\
\text { Virtuoso } \\
\text { Júnior, 2008) }\end{array}$ & $\begin{array}{l}\text { Bons resultados em estudos de } \\
\text { confiabilidade e muito citado na } \\
\text { literatura nacional e internacional } \\
\text { (Almeida M L et al., 2016) }\end{array}$ \\
\hline $\begin{array}{l}\text { Escala de } \\
\text { Atividades de } \\
\text { vida diária(Katz } \\
\text { et al., 1963) }\end{array}$ & Sim & Não & $\begin{array}{l}\text { Sim; (Lino et al., } \\
\text { 2008) }\end{array}$ & $\begin{array}{l}\text { Sim; (Lino et } \\
\text { al., 2008) }\end{array}$ & $\begin{array}{l}\text { Por não analisar AIVD é pouco } \\
\text { utilizada em demências iniciais } \\
\text { (Almeida } \mathrm{ML} \text { et al 2016) }\end{array}$ \\
\hline $\begin{array}{l}\text { Índice Barthel } \\
\text { (Mahoney e } \\
\text { Barthel, 1965) }\end{array}$ & Sim & Não & $\begin{array}{ll}\text { Sim } ; & \text { (Moura } \\
\text { Minosso } & \text { et al., } \\
2010) & \end{array}$ & $\begin{array}{l}\text { Sim (Moura } \\
\text { Minosso et al., } \\
2010)\end{array}$ & $\begin{array}{l}\text { Não há estudos com aplicação } \\
\text { em pacientes com DA (Chaves et } \\
\text { al., 2011) }\end{array}$ \\
\hline $\begin{array}{l}\text { FAQ (Pfeffer } \\
\text { et al., 1982) }\end{array}$ & Não & Sim & $\begin{array}{l}\text { Sim (Chaves et } \\
\text { al., 2011; Dutra et } \\
\text { al., 2015) }\end{array}$ & $\begin{array}{l}\text { Sim (Chaves } \\
\text { et al., 2011; } \\
\text { Dutra et al., } \\
\text { 2015) }\end{array}$ & $\begin{array}{l}\text { Bastante utilizada em pesquisa } \\
\text { para diagnosticar diferentes } \\
\text { demências. (Almeida ML et al } \\
\text { 2016) }\end{array}$ \\
\hline $\begin{array}{l}\text { FIM (Granger } \\
\text { et al., 1986) }\end{array}$ & Sim & Não & $\begin{array}{l}\text { Sim; (Riberto et } \\
\text { al., 2016) }\end{array}$ & $\begin{array}{l}\text { Não para } \\
\text { demências } \\
\text { (Canon e } \\
\text { Novelli, 2012) }\end{array}$ & $\begin{array}{l}\text { Pouco são os estudos com } \\
\text { demências (Chaves et al., 2011; } \\
\text { Canon e Novelli, 2012) }\end{array}$ \\
\hline $\begin{array}{l}\text { IQCODE (Jorm } \\
\text { e Jacomb, } \\
\text { 1989) }\end{array}$ & Não & Sim & $\begin{array}{l}\text { Sim: (Sanchez e } \\
\text { Lourenço, 2009) }\end{array}$ & $\begin{array}{l}\text { Sim (Sanchez } \\
\text { e Lourenço, } \\
2009)\end{array}$ & $\begin{array}{l}\text { Bastante utilizada em pesquisa. } \\
\text { Boa aplicação clínica (Perroco et } \\
\text { al., 2008; Bentvelzen et al., 2017) }\end{array}$ \\
\hline $\begin{array}{l}\text { DAD (Gauthier } \\
\text { L et al., 1994) }\end{array}$ & Sim & Sim & $\begin{array}{l}\text { Sim;(Carthery- } \\
\text { Goulart et al., } \\
\text { 2007) }\end{array}$ & $\begin{array}{l}\text { Sim; (Bahia et } \\
\text { al., 2010) }\end{array}$ & $\begin{array}{l}\text { Por ser um modelo muito recente } \\
\text { ainda há poucas citações na } \\
\text { literatura (Canon et al., 2016) }\end{array}$ \\
\hline $\begin{array}{l}\text { BADLS (Bucks } \\
\text { et al., 1996) }\end{array}$ & Sim & Sim & Não & Não & $\begin{array}{l}\text { Não há adaptação para a } \\
\text { população brasileira (Chaves et } \\
\text { al., 2011) }\end{array}$ \\
\hline $\begin{array}{l}\text { B-ADL } \\
\text { (Hindmarch et } \\
\text { al., 1998) }\end{array}$ & Sim & Sim & $\begin{array}{l}\text { Sim MAPI- } \\
\text { Reseach Institute } \\
\text { (Mapi, 1999) }\end{array}$ & Não & $\begin{array}{l}\text { Bons resultados em estudos de } \\
\text { confiabilidade (Folquitto et al., } \\
\text { 2007) }\end{array}$ \\
\hline $\begin{array}{l}\text { ADL-Q } \\
\text { (Johnson et } \\
\text { al., 2004) }\end{array}$ & Sim & Sim & $\begin{array}{l}\text { Sim; (Medeiros e } \\
\text { Guerra, 2009) }\end{array}$ & $\begin{array}{l}\text { Sim; } \\
\text { (Medeiros e } \\
\text { Guerra, 2009) }\end{array}$ & $\begin{array}{l}\text { Boa aplicação clínica mas não } \\
\text { apresenta estudos brasileiros com } \\
\text { acuraria no diagnóstico de DA } \\
\text { (Chaves et al., 2011) }\end{array}$ \\
\hline
\end{tabular}

Nota: ABVD: Atividades básicas de Vida Diária, AIVD: Atividades Instrumentais de Vida Diária; FIM: Functional Independence Measure; IQCODE: Informant Questionnaire on Cognitive Decline in the Elderly; DAD: Disability Assessment for Dementia; BADLS: Bristol Activities of Daily Living Scale; B-ADL:Bayer Activitiesof Daily Living Scale; ADL-Q: Activities of Daily Living Questionnaire; FAQ-Questionário de Atividades Funcionais de Pfeffer 
Atualmente temos apenas validadas e adaptadas à população brasileira as escalas - DAFS-BR (Direct Assessment Functional States) (Pereira et al., 2010) e EFPT(Executive Functional Performance Test) (Neubern, 2018). Há outras avaliações validadas para diferentes realidades culturais, como é o caso RTI-E (Routine Task Inventary Expanded), em processo de validação no Brasil e Kettle Test e OTDL-R (Revised Observed Tasksof Daily Living) (Katz, 2011). A dificuldade no uso das avaliações diretas é o tempo de aplicação, bem como a necessidade de profissional treinado.

A maioria das avaliações adaptadas e validadas para a população brasileira são as avaliações indiretas (tabela 2), nas quais as questões sobre a funcionalidade do idoso são direcionadas a informantes (familiares ou cuidadores). As vantagens destes métodos se dão pela praticidade e rapidez de aplicação. Em média a duração das avaliações funcionais é de 20 minutos por questionário, podem ser aplicadas por profissionais de saúde após um treinamento fácil e rápido e são mais práticas para aplicação clínica. Não há consenso se essas avaliações indiretas conseguem identificar prejuízos iniciais, visto que dependem de informantes. Nessa direção, Burton et al. (2009) sugerem que o diagnóstico de perda da funcionalidade. detectada em análises mais indiretas, é muito sutil para ser inferido por questionários respondidos por informantes. Jefferson et al. (2008) também apontam que, apesar de vários estudos reconhecerem a existência do comprometimento funcional, poucas pesquisas se propuseram a analisar qual seria a melhor forma de identificar déficits precoces nas AIVD e quais são suas correlações cognitivas. Além disso, temos que considerar a possibilidade de erros de percepção do cuidador/informante, pois tal percepção pode depender de vários fatores, dentre eles o convívio com o idoso, o estado de humor do familiar (estresse ou depressão do cuidador), a capacidade cognitiva e a sua escolaridade para ideal compreensão das perguntas e resposta. (Zanetti et al., 1999; Argüelles et al., 2001; Bressan et al., 2007; Mlinac e Feng, 2016; Lin et al., 2017).

Assim sendo, as escalas indiretas poderiam estar sujeitas a uma distorção da real capacidade do paciente, pois, levando em consideração a complexidade dos papéis sociais e familiares desempenhados pelos idosos, e mesmo que as ações tenham a intenção de minimizar a sobrecarga de atividades do idoso, nota-se que por vezes os familiares de idosos com DA tendem a incorporar e a assumir funções cotidianas anteriormente realizadas pelo idoso como, por exemplo, o gerenciamento 
financeiro ou o planejamento da rotina diária (Bressan et al., 2007), o que pode impactar negativamente na vida independente e na postura ativa deste idoso. (Pereira J K et al., 2014).

\subsection{Percepção da funcionalidade pelo cuidador /informante}

Apesar da dificuldade no consenso acerca da definição do papel de cuidador, alguns autores relatam que este é quem oferece suporte físico e psicológico e fornece ajuda prática e direta quando necessário (Garrido e Menezes, 2004; Cruz e Hamdan, 2008).

No contexto nacional e internacional, os cuidadores de idosos são em sua maioria do gênero feminino, esposa ou filhas de idosos (Cruz e Hamdan, 2008; Novelli et al., 2010; Marigliano et al., 2015; Souza et al., 2016; Gutierrez et al., 2017). No início, quando há um cuidador principal responsável, ele assume de forma integral o papel de cuidar, o que pode acarretar em inúmeras sobrecargas (Cruz e Hamdan, 2008; Gutierrez et al., 2017).

O termo burden (responsabilidade, carga, peso, impacto), proveniente da língua inglesa, tem recebido bastante atenção da literatura e, no presente contexto, é utilizado para descrever os aspectos negativos associados ao cuidado de um paciente dependente. Esses aspectos dizem respeito à presença de problemas, dificuldades ou eventos adversos que afetam significativamente a vida dos responsáveis, principalmente nos âmbitos físico, financeiro e emocional (Silva Falcão e Nobre Ferro Bucher-Maluschke, 2009). A sobrecarga de cuidado pode diferenciar de pessoa para pessoa dependendo de suas características interpessoais e de sua relação com o idoso com demência. Viñas-Diez et al. (2017) descrevem a diferença entre o estresse do cuidador correlacionando-o ao grau de parentesco e convivência no mesmo domicílio. Os autores concluíram que as esposas são em sua maioria idosas, com menor grau de escolaridade e geralmente assumem o papel de cuidar sozinhas; a princípio, têm menos sobrecarga quanto ao cuidado, mas à medida que o idoso torna-se mais dependente físico e cognitivamente, a sobrecarga também tende a ser maior. $O$ mesmo estudo afirma que no grupo de filhos que convivem com o idoso com demência no mesmo domicílio, há maior sobrecarga física e impacto na vida social quando comparados aos filhos cuidadores que não moram junto com os idosos com DA. Com o mesmo 
enfoque, o autor Yu et al. (2015) descrevem os comprometimentos cognitivos, os declínios funcionais e os problemas comportamentais, como sendo os principais preditores de estresse do cuidador. Cruz e Hamdan (2008) relatam que cuidadores de idosos com demência apresentam um pior julgamento sobre a própria saúde, sentem-se mais estressados e com a vida afetiva e social mais limitadas do que cuidadores de idosos sem demência.

A distorção de percepção da realidade, o exagero ou a depreciação de um atributo, evento ou sensação, são erros cognitivos associados a pessoas com níveis de estresses consideráveis (Bahls, 1999). Assim como sentimentos de incerteza, ansiedade, depressão, conflitos intrafamiliares, dificuldades financeiras, dentre outros, também podem levar o informante a distorcer o relato acerca do desempenho funcional do idoso (Zanetti et al., 1999; Argüelles et al., 2001; Bressan et al., 2007).

Nesta direção, Razani et al. (2007) estudaram a correlação entre a real performance nas AVD de pacientes com demência inicial e o relato de seus cuidadores, assim como a sobrecarga emocional que o papel de cuidador pode acarretar e concluíram que esta sobrecarga tende a subestimar a real funcionalidade de idosos. Informantes que passam maior quantidade de tempo com o idoso e apresentam graus de parentesco mais próximos avaliam com menor precisão sua efetiva funcionalidade.

Vale notar que a distorção da percepção do outro pode ocorrer em direções opostas dependendo de características regionais e culturais. Bressan et al. (2007) evidenciaram que, ao contrário dos americanos e europeus que tendem a superestimar as habilidades nas AIVD, os brasileiros subestimam tais atividades. Esses autores ressaltam que tal distorção pode estar relacionada ao fato de que muitos cuidadores realizam as atividades pelos idosos e não com os idosos e podem não ter muita clareza da real capacidade do idoso. Cruz V T et al. (2004) também afirmam que familiares inseridos em um contexto cultural mais protetor tendem a minimizar o impacto da demência nas AIVD, principalmente no que se refere à tentativa de proteger a imagem do doente podendo, assim, retardar o início do tratamento.

No Brasil, poucos estudos foram feitos para correlacionar a funcionalidade do idoso em ABVD e AIVD e o relato de seus cuidadores. Santos e Melo Borges (2015) compararam a percepção de familiares de idosos brasileiros 
com DA leve e moderada, frente à percepção da funcionalidade pelos idosos, e concluiu que idosos com DA subestimam suas próprias dificuldades em realizar as atividades de vida diária e, conforme a DA progride, há piora progressiva da consciência da percepção de sua funcionalidade.

O estresse do cuidador/informante do idoso pode fazer com que, ao responder questionários de funcionalidade indiretos, mascarem algumas informações, o que pode levar a uma terapêutica mais tardia. Porém, uma avaliação exclusivamente direta também pode não ser a melhor forma de obter bons resultados sobre a real funcionalidade do idoso, visto que pode ser influenciada por variáveis pontuais e transitórias do momento. A combinação de uma escala direta e indireta para o direcionamento profissional e para a fidedignidade dos fatos pode ser a melhor alternativa para uma real avaliação funcional e na definição do tratamento acerca da funcionalidade de DA, visto que intervir terapeuticamente o mais precoce possível pode ser mais eficaz e pontual, acarretando na manutenção da independência por mais tempo, melhorando, com isso, a qualidade de vida dos idosos e seus familiares (Bravell et al., 2011; Mlinac e Feng, 2016). 
2. JUSTIFICATIVA 


\section{JUSTIFICATIVA}

Com o real aumento da expectativa de vida e a constante preocupação com o desempenho funcional do idoso, investigar a funcionalidade e a percepção do cuidador e/ou familiar do idoso se torna fundamental para a melhor compreensão dos quadros de declínios cognitivos e demenciais. Considerando que a percepção distorcida do desempenho funcional e seus possíveis vieses de interpretação podem comprometer a terapêutica postergando o início do tratamento e aumentando riscos domiciliares. A subavaliação da funcionalidade pode trazer preocupações importantes quanto à segurança, pois, ao subestimar o comprometimento do desempenho funcional do idoso, os familiares podem não tomar precauções necessárias em sua segurança domiciliar e social. Além disso, o estresse do cuidador pode gerar impacto em sua saúde física e emocional.

O presente estudo tem como objetivo comparar a avaliação da funcionalidade direta realizada com o idoso com a avaliação da funcionalidade indireta realizada com o informante, além de investigar se fatores cognitivos e emocionais como estresse, ansiedade e depressão do cuidador/informante podem interferir na capacidade de avaliação do idoso. É importante que haja novas pesquisas que enfoquem de maneira aprofundada os motivos das possíveis distorções de percepção relatadas por informante, pois podem ser úteis para a compreensão dos melhores instrumentos a serem utilizados, a fim de que se obtenha um diagnóstico mais precoce e fidedigno, além de fornecer orientações e esclarecimentos a informantes acerca dos conhecimentos e tratamentos da doença de Alzheimer. 


\section{OBJETIVOS DO ESTUDO}

\subsection{Objetivos Gerais:}

- Caracterizar os perfis da funcionalidade do idoso com Doença de Alzheimer a partir de avaliações direta e indiretas.

\subsection{Objetivos Específicos:}

- Comparar as avaliações direta e indiretas com a finalidade de identificar potenciais vieses de percepção dos cuidadores em pacientes com DA;

- Correlacionar as avaliações direta e indireta nos diferentes domínios da funcionalidade;

- Caracterizar os perfis dos cuidadores do ponto de vista cognitivos e emocionais. 


\section{METODOLOGIA}

Esse é um estudo controlado transversal, que pretende comparar informantes/cuidadores de sujeitos portadores de DA e de controles emparelhados para faixa etária, considerando o ponto de vista funcional, com a finalidade de investigar fatores que possam influenciar a avaliação de idosos.

\subsection{Amostra}

Grupo DA:

-40 sujeitos portadores de DA (leve ou moderada) e seus cuidadores, divididos em:

26 sujeitos portadores de DA leve e seus cuidadores;

14 sujeitos portadores de DA moderada seus cuidadores.

Grupo Controle:

-41 sujeitos idosos e seus respectivos informantes.

\subsubsection{Local do estudo}

Para o presente estudo foram convidados a participar voluntariamente os pacientes que fazem parte do ambulatório de psiquiatria geriátrica do Programa Terceira Idade - PROTER, do Instituto de Psiquiatria do Hospital das Clínicas da Faculdade de Medicina de São Paulo, do Centro de Referência dos Estudos Cognitivos do Idoso (CEREDIC) ou idosos que foram encaminhados de outras clínicas. Os sujeitos controles foram idosos saudáveis da comunidade, familiares ou cuidadores de pacientes. A coleta de dados foi realizada no Instituto de Psiquiatria do Hospital das Clínicas da Faculdade de Medicina de São Paulo.

\subsubsection{Cálculo da amostra}

O cálculo amostral foi baseado na avaliação da funcionalidade e da percepção do cuidador mensurada pelos instrumentos IQCODE, Escala de Atividades Instrumentais de Vida Diária de Lawton e Brody, FAQ e B-ADL. No 
artigo de Folquitto. et al (2007) é apresentada a comparação dos escores da BADL para os três grupos de Clinical Dementia Rating (CDR) de forma semelhante a este estudo. Para o cálculo do tamanho amostral utilizamos as informações dos valores de média e desvio-padrão para cada grupo de CDR contidas neste estudo (Folquito et al. 2007) e obtivemos um tamanho de efeito igual a 1,92. Baseado em um nível de significância de $5 \%$ com uso da Análise de Variância a um fator (ANOVA), poder de $80 \%$, calculamos através do programa G*Power versão 3.1 (Faul et al., 2007), que um mínimo de 9 sujeitos em cada um dos 3 grupos permitiu as inferências do presente projeto. Para a execução desta pesquisa utilizamos 41 sujeitos para o grupo controle, 40 sujeitos para o grupo com DA, divididos em 26 sujeitos para o grupo de DA leve e 14 casos para o de DA moderada, o que nos forneceu poder de teste de 0,99 para as análises dos instrumentos B-ADL, IQCODE e Escala de Atividades Instrumentais de Lawton e Brody. Para o instrumento FAQ utilizamos teste não-paramétrico que não nos permite o cálculo do valor do poder.

\subsubsection{Critérios de Inclusão}

Foram considerados para o estudo os pacientes com DA que atendem aos seguintes critérios:

1- Idosos com idade acima de 60 anos;

2-Pacientes com diagnóstico de DA;

3- Sujeitos com no mínimo 4 anos de escolaridade;

4- Pacientes que contam com os cuidados de outra pessoa identificada (cuidadores/ informante).

Para os sujeitos saudáveis (Controles) foram considerados:

1-Sujeitos acima de 60 anos emparelhados para idade com informante identificado;

2- Sujeitos com no mínimo 4 anos de escolaridade;

3- Sujeitos que contem com parentes e/ou conhecidos próximos que possam fornecer informações sobre o cotidiano desses idosos. 


\subsubsection{Critérios de exclusão}

Foram excluídos do estudo os sujeitos que atenderam aos seguintes critérios:

1- Deficiências auditivas ou visuais não corrigidas e disfuncionais;

2- História ou evidência clínica de outras doenças neurológicas (doença de Parkinson, epilepsia), de acidente vascular cerebral e/ou doenças sistêmicas ou cerebrais graves (infecções, neoplasias, doenças hepáticas, renais ou metabólicas);

3- História ou evidência clínica de outra doença psiquiátrica, que não depressão comórbida a DA (dependência de álcool ou drogas, esquizofrenia, transtorno afetivo bipolar).

Para o grupo controle foram excluídos os sujeitos que apresentavam transtorno psiquiátrico maior. 
Figura 2. Fluxograma da seleção da amostra do presente estudo

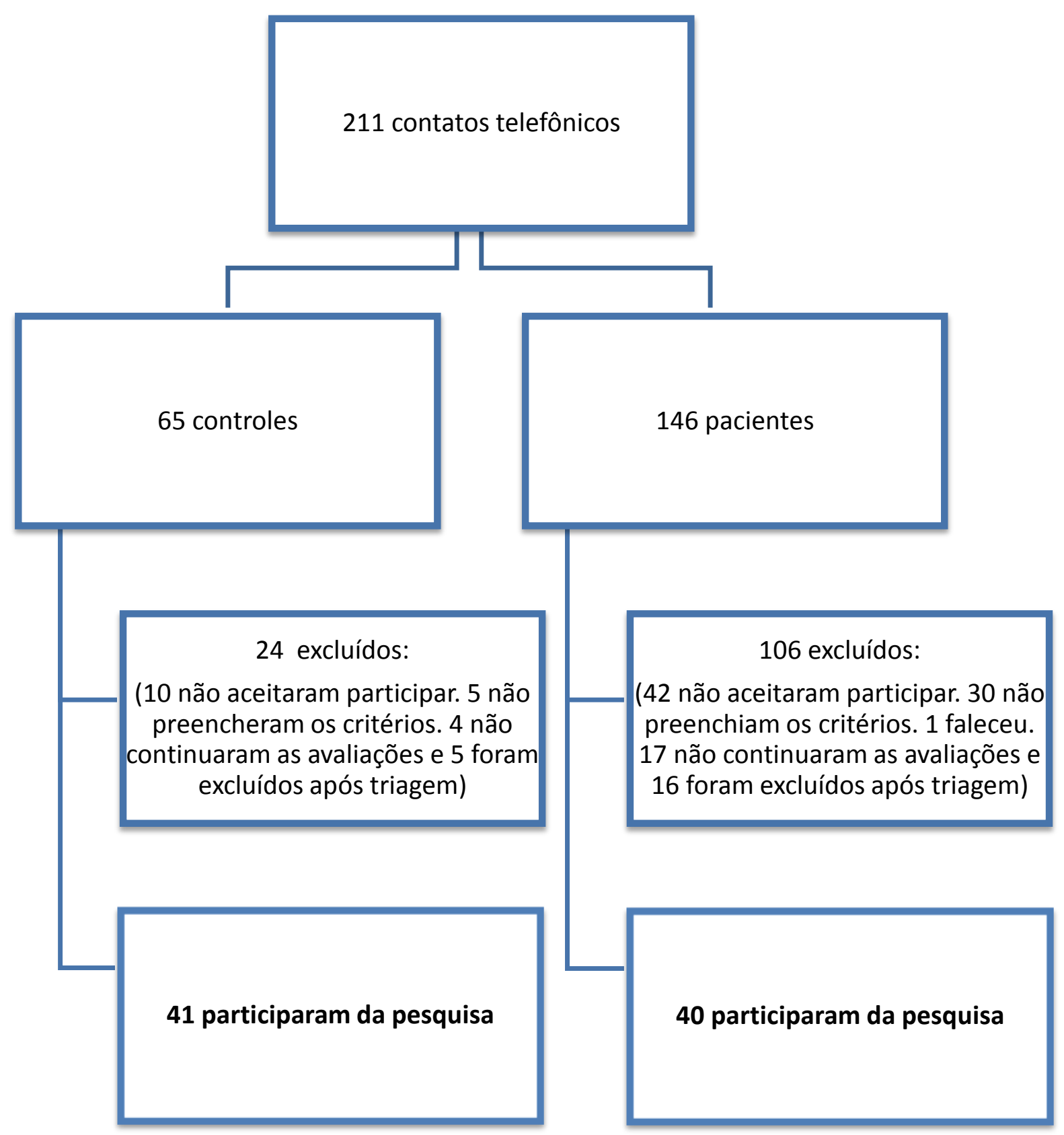




\subsection{Considerações éticas}

O presente estudo foi aprovado pelo comitê de ética (CAAE: 25866714.3.0000.0068) e se trata de um subprojeto do estudo "Funcionalidade e Qualidade de Vida na Doença de Alzheimer", aprovado pelo Comitê de Ética em Pesquisa do Hospital das Clinicas da Faculdade de Medicina da USP (CAPPesq). Todas as escalas e entrevistas estão contempladas no projeto original cuja pesquisadora responsável é a orientadora da presente pesquisa. Todos os sujeitos da amostra foram convidados a participar e receberam, por escrito, informações detalhadas sobre a natureza, métodos e objetivos do estudo. Após o esclarecimento de todas as dúvidas, foi solicitada a assinatura de termo de consentimento informado. A não-concordância em participar não acarretou em prejuízos para seu tratamento. Para idosos com déficit cognitivo que os impedia de compreender o termo de consentimento, este foi lido e assinado por um familiar ou responsável legal. Somente após a assinatura do Consentimento Pós-Informado pelos familiares e/ou pacientes, na presença da investigadora e de uma testemunha, os sujeitos foram incluídos no estudo. Por se tratar de um estudo observacional, e não envolver nenhum procedimento invasivo ou exame complementar, não houve risco significativo de natureza psíquica ou física para os participantes. 


\subsection{Descrição dos Instrumentos e Avaliações}

\subsubsection{Avaliação cognitiva, clínica e demográfica}

\subsubsection{Ficha de identificação individual}

Incluindo dados demográficos e clínicos e informações sobre medicações em uso atual.

\subsubsection{Teste Cognitivo de Cambridge (CAMCOG) (Roth et al., 1986)}

O Teste Cognitivo de Cambridge (CAMCOG) faz parte de um instrumento de avaliação mais abrangente chamado Cambridge Examination for Mental Disorders of the Elderly (CAMDEX-R), que teve sua primeira versão adaptada e traduzida para a população brasileira por Bottino et al. (2001), e tem como objetivo auxiliar no diagnóstico de síndromes demenciais avaliando variadas funções cognitivas. É um instrumento de rastreio com duração média de 30 minutos, tem como pontuação máxima 107 pontos e quanto maior a pontuação, melhor o desempenho do indivíduo. Apresenta oito subescalas de diferentes domínios (orientação, linguagem, memória, atenção, concentração, praxia, percepção e pensamento abstrato). O teste conta com alguns itens de testes de rastreamento como o Mini-Exame do Estado Mental (MEEM), o Teste Mental Abreviado de Hodkinson, o teste de fluência verbal categoria animais e o teste do desenho do relógio. Podem ser analisados os escores total, domínios ou sub testes. É descrita nota de corte de 79/80. (Paradela et al., 2009)

\subsubsection{Mini Exame do Estado Mental (MEEM) (Folstein et al., 1975)}

Adaptado e validado para a população brasileira por Bertolucci et al. (1994), sendo um dos instrumentos de rastreio cognitivo mais utilizado no Brasil e pela literatura internacional (Brucki et al., 2003; Canedo, 2014), tem como objetivo quantificar a presença de déficit cognitivo. É composto por sete categorias de funções cognitivas que totalizam 30 pontos. Bertolucci et al. 
(1994) afirmam que a pontuação pode receber influência da escolaridade e sugere como nota de corte $\geq 25$ para sujeitos normais, de 24 a 21 DA leve e de 20 a 10 DA moderada.

Brucki et al. (2003) também ressaltam que a escolaridade pode influenciar a performance do indivíduo nos resultados do teste e, seu estudo sugere uma nota de corte de 20 pontos para indivíduos analfabetos, 25 para aqueles que possuem de 1 a 4 anos de escolaridade, 27 para os que têm de 5 a 8 anos de escolaridade e 28 para idosos que possuem de 9 a 11 anos de escolaridade.

MEEM é um excelente instrumento de rastreio, porém é sempre importante a utilização de testes complementares para um diagnóstico mais preciso.

\subsubsection{Clinical Dementia Rating (CDR) (Hughes et al., 1982)}

Validado para a população brasileira por Montaño e Ramos (2005), permite verificar a gravidade de demências, além de identificar casos questionáveis. Tem como objetivo avaliar a cognição, o comportamento e sua influência nas atividades diárias. O Instrumento é dividido em seis subcategorias: memória, orientação, julgamento ou solução de problemas, relações comunitárias, atividades no lar ou de lazer e cuidados pessoais. A classificação proposta prevê: ausência de demência (CDR 0), questionável demência (CDR 0,5), demência leve (CDR 1), moderada (CDR 2) e grave (CDR3) e não há necessidade de nota de corte estabelecidas pelo desempenho populacional, pois os indivíduos são comparados ao seu próprio desempenho passado (Montaño e Ramos, 2005).

\subsubsection{Escala de Hamilton para Depressão (HAM-D) (Hamilton, 1960)}

Escala de heteroavaliação, aplicada pela observação do entrevistador, avalia a gravidade de sintomas depressivos. Recomenda-se a utilização da escala juntamente com um guia estruturado de entrevista, para aumentar sua acurácia no diagnóstico. No presente trabalho foi utilizada a versão de 31 itens que inclui sintomas atípicos. Os escores podem variar de 0 a 52. Pacientes 
gravemente deprimidos são caracterizados como aqueles que obtém mais de 25 pontos; moderadamente deprimidos aqueles com escores entre 18 e 24 e com depressão leve os de escores entre 7 e 17 (Gallucci Neto et al., 2001).

\subsubsection{Mini International Neuropsychiatric Interview (M.I.N.I.)(DSM IV)} (Amorim, 2000)

A M.I.N.I. foi desenvolvido por pesquisadores do Hospital PitiéSalpêtrière de Paris e da Universidade da Flórida e foi adaptado para a população brasileira por Amorim (2000). Tem como objetivo auxiliar o diagnóstico de transtornos mentais tanto na prática clínica quanto na área de pesquisa por meio de um questionário elaborado com perguntas estruturadas compatíveis com o DSM-III-R/IV e com a CID-10. Sua aplicação dura em torno de 15 minutos e explora de modo padronizado os principais transtornos psiquiátricos do eixo I do DSM IV (Amorim. 2000).

\subsubsection{Avaliação Cognitiva de Montreal (MoCA) (Nasreddine et al., 2005)}

A Avaliação Cognitiva de Montreal (MoCA) foi desenvolvida por Nasreddine et al. (2005) no Canadá e foi traduzida para a população brasileira em 2009 (Sarmento, 2009). É considerada um instrumento de rastreio cognitivo que tem como objetivo auxiliar no diagnóstico de deficiência cognitiva leve. É composta por subdomínios cognitivos, tais como: atenção e concentração, funções executivas, memória, linguagem, habilidades visuoconstrutivas, conceituação, cálculo e orientação. O tempo de aplicação da MoCA é de aproximadamente 20 minutos. $O$ escore total é de 30 pontos, sendo o escore de 25 ou maior considerado normal. (Sarmento, 2009; Cecato et al., 2014) 


\subsection{Avaliação funcional}

\subsubsection{Avaliação Funcional Indireta}

4.4.1.1 Escala de Atividades Instrumentais da Vida Diária (Lawton e Brody, 1970)

Adaptada para a população brasileira em 2008 por Lopes Dos Santos e Virtuoso Júnior (2008), a Escala de Atividades Instrumentais da Vida Diária Lawton e Brody tem como objetivo mensurar a incapacidade do idoso em relação às AIVD. O instrumento é composto por oito tarefas como: utilização de telefone, realização de compras, preparação da alimentação, organização doméstica, lavagem de roupa, uso de transportes, administração de medicamentos e gestão do orçamento. A pontuação máxima é 21 pontos, sendo considerado como independência total os escores de 21 pontos, como dependência parcial entre 21 e 5 pontos e como dependência total escores menores que 5 pontos.

Almeida M L et al. (2016), em um estudo de revisão sistemática, verificaram que a Escala de Atividades Instrumentais da Vida Diária Lawton e Brody foi o instrumento de avaliação de AIVD mais utilizado nos artigos analisados. No estudo de Lopes Dos Santos e Virtuoso Júnior (2008) analisouse a confiabilidade da escala na versão brasileira e observou-se que os índices de correlações interclasse (Ricc) na reprodutividade e objetividade das medidas são consideráveis "quase perfeitos", ou seja, o índice de concordância está entre 0,80 a 1,00, Corroborando com este estudo brasileiro. Araújo et al. (2008), em um estudos de validações para população de Portugal, também sugerem o uso da Escala de Atividades Instrumentais da Vida Diária -Lawton e Brody porque esta, além de apresentar bons resultados psicométricos ( $\alpha$ de Cronbach $=0,94)$, é um instrumento de fácil aplicação e interpretação para o avaliado e o avaliador, além de ter um custo baixo e não necessitar de um treinamento longo por parte do profissional que a utilizará. 
4.4.1.2 Questionário de Atividades funcionais de Pfeffer (FAQ) (Pfeffer et al., 1982)

A FAQ foi traduzida e adaptada para a população brasileira em 2011 por Sanchez et al. (2011). Tem como objetivo avaliar as AIVD em dez habilidades cognitivas: controlar as próprias finanças, fazer compras, esquentar água e apagar o fogo, preparar refeições, manter-se atualizado, prestar atenção em uma notícia e discuti-la, lembrar-se de compromissos, cuidar da própria medicação, manter-se orientado ao andar pela vizinhança e ficar sozinho em casa. As respostas seguem um padrão similar onde (0) é considerado capaz de realizar a tarefa ou nunca fez, mas poderia fazer agora; (1) Faz com dificuldades, ou nunca o fez e agora teria dificuldades; (2) necessita de ajuda e (3) não é capaz. O escore mínimo é 0 e o máximo é 30. Quanto maior a pontuação, maior é a dependência do paciente e escores maiores ou iguais a 6 sugerem dependência no desempenho funcional (Dutra et al., 2015).

Estudos sugerem que a FAQ é um instrumento confiável e estável por apresentar medidas psicométricas satisfatórias ( $\alpha$ de Cronbach=0,95). (Sanchez et al 2011) e boa sensibilidade e especificidade para declínio funcional (75,93\% sensibilidade e $80,36 \%$ de especificidade (Dutra et al. 2015). Jacinto (2008) considerou a escala FAQ o instrumento que apresentou maior eficácia no diagnóstico de declínio cognitivo, assim sendo, essa escala pode ser considerada muito adequada na avaliação do desempenho funcional de idosos brasileiros tanto em estudos de pesquisa como na prática clínica.

\subsubsection{Bayer - Activities of Daily Living (B-ADL) (Hindmarch et al. 1998)}

A B-ADL foi desenvolvida em parceria com o laboratório Bayer e adaptada para diferentes culturas em diversos países. No Brasil, a versão adaptada ao português foi realizada pela "MAPI- Reseach Institute" e está disponível desde maio de 1999. Folquitto et al. (2007) analisaram a aplicabilidade e a eficiência da escala B- ADL em pacientes com demências leve a grave e considerou que houve diferença estatística quando foram comparados grupos controle a pacientes com demência ( $p<0,001)$, como também quando comparados grupos de demência leve com demência 
moderada $(p<0,001)$ e a escala também apresentou alta consistência interna ( $\alpha$ de Cronbach $=0,981$ )

A B-ADL é uma escala composta por 25 questões com resposta que varia entre 1 e 10, em que 1 significa que o idoso em questão nunca apresenta dificuldade para a realização de determinada tarefa e 10 representa o grau máximo de dificuldade para desempenhar a mesma tarefa. A escala ainda conta com as possibilidades, "não sabe" e "não se aplica", para os casos em que não há informação ou em que a dificuldade se relaciona a outro transtorno. As duas primeiras questões estão relacionadas ao autocuidado de uma forma mais global como, por exemplo, fazer suas atividades diárias e cuidar de si mesmo; as questões subsequentes são mais relacionadas a tarefas específicas e às funções cognitivas (Hindmarch et al., 1998). O escore será obtido pela soma dos itens dividida pelo número de questões respondidas. Quanto maior o resultado, maior o grau de prejuízo na funcionalidade. Autores sugerem, para o uso da versão brasileira, 3,12 pontos como sendo a nota de corte mais adequada quanto à especificidade e à sensibilidade (Folquito et al. 2007).

A escala B-ADL é um instrumento rápido e de fácil aplicação, que não exige um treinamento mais específico para o examinador e, dessa forma, é sugerida para pesquisas e prática clínicas (Nitrini et al., 2005b; Folquitto et al., 2007).

\subsubsection{Informant Questionnaire on Cognitive Decline-IQCODE (Jorm e Jacomb, 1989)}

Desenvolvido na Austrália, no idioma inglês, composto, em sua versão original, por 26 questões que avaliam o desempenho atual em diferentes situações da vida diária e comparam com o desempenho anteriormente observado ao longo de um continuum de dez anos. As perguntas estão organizadas em uma escala Likert, com cinco opções: 1 - muito melhor; 2 - um pouco melhor; 3 - não houve mudança; 4 - um pouco pior; 5- muito pior. 0 resultado final é obtido pela soma ponderada dos itens, dividindo-os pelo total de itens da escala. Estudos brasileiros demonstraram um bom índice de confiabilidade ( $\alpha$ de Crombach= 0,94 e CCl=0,92) (Sanchez e Lourenço, 2009) e excelente sensibilidade e especificidade (sensibilidade $=82,4 \%$, 
especificidade $=98,3 \%$ ) quando utilizada uma nota de corte 3,38 para a versão longa (Perroco et al., 2008).

Na prática clínica e na pesquisa o IQCODE conta com um diferencial quando questiona o entrevistado fazendo um comparativo com seu próprio desempenho há dez anos, o que pode facilitar no momento da aplicação e na análise mais detalhada das AIVD. Estudos recentes apontam para a importância da inclusão deste teste para um diagnóstico preciso de DA (Bustamante et al., 2003; Nitrini et al., 2005b; Sanchez et al., 2011).

\subsubsection{Avaliação Funcional Direta}

4.4.2.1 Direct Assessment Functional State (DAFS-BR) (Loewenstein et al., 1989)

Desenvolvida por Loewenstein et al. (1989) e traduzida e adaptada para a população brasileira por Pereira et al. (2010), a DAFS-BR é instrumento capaz de avaliar de forma direta e objetiva a funcionalidade de idosos por meio de seis domínios (orientação temporal, comunicação, habilidades para lidar com dinheiro, habilidades para fazer compras, vestir-se, higiene pessoal e alimentação) e oferece ao profissional treinado a oportunidade de observar de forma direta a realização de atividades similares ao cotidiano de idosos. Pereira et al. 2010 afirmam que a DAFS-BR possui boa sensibilidade e especificidade (100\% e 93,7\%, respectivamente), assim como boa consistência interna ( $\alpha$ de Cronbach $=0,78)$ e correlação moderada e significativa com o IQCODE ( $r=-$ $0,65, p \leq 0,001)$. Assim sendo, demonstrou ser um instrumento bastante eficiente para avaliar a presença de declínios funcionais e sugere uma nota de corte de 86 pontos. (Pereira et al. 2010). 


\subsection{Avaliação de sintomas psiquiátricos}

4.5.1 Avaliação do estresse cuidador (Zarit Burden Interview)(Zarit e Zarit, 1983)

Validada para o contexto brasileiro por Scazufca (2002), a escala avalia a sobrecarga do cuidador/informante por meio de um questionário de 22 perguntas referentes às condições de saúde, bem-estar psicológico, finanças e vida social do cuidador. As questões contam com 5 possibilidades de resposta para cada questão, sendo: 0-nunca, 1-raramente, 2-algumas vezes, 3frequentemente, 4-sempre. O resultado final é a somatória dos pontos obtidos que variam de 0 a 88. A classificação da sobrecarga é considerada de acordo com um crescente gradativo, ou seja, até 21 pontos há ausência de sobrecarga; de 21-40 pontos há sobrecarga moderada; de 41-60 há sobrecarga de moderada a severa e acima de 61 há sobrecarga severa. A avaliação da consistência interna para a população brasileira foi considerada boa, com um $\alpha$ de Cronbach igual a 0,87 (Scazufca, 2002).

\subsubsection{Caregiver Burden Inventary (CBI) (Novak e Guest, 1989)}

Instrumento de origem canadense, desenvolvido por Novak e Guest (1989) e adaptado à população brasileira por Valer (2012), é composto por 24 questões fechadas, que medem o impacto da sobrecarga dos cuidadores e se dividem em cinco domínios: sobrecarga tempo dependente (domínio 1), sobrecarga de vida pessoal (domínio 2), sobrecarga física (domínio 3), sobrecarga emocional (domínio 4) e sobrecarga social (domínio 5). Cada domínio possui 5 questões, com exceção do domínio de sobrecarga física (4 questões), e cada questão recebe pontuação que vai de 0 , discordo totalmente, a 4, concordo totalmente. Quanto maior o escore, maior a sobrecarga do cuidador (Valer et al., 2015). A adaptação do instrumento para a população brasileira demonstrou-se satisfatória com consistência interna muito similar ao instrumento original ( $\alpha$ de Cronbach entre 073 e 0,86), com médias divididas por domínios como: Domínio 1=12,3 pontos (d.p. 5,0); domínio $2=10,00$ (d.p. 
6,0); domínio $3=7,8$ (d.p. 6,1); domínio $4=6,7$ (d.p. 4,9); domínio $5=4,6$ (d.p. 4,3 ) e valor total $=41,8$ (d.p. 20,9) (Valer et al., 2015).

\subsubsection{Inventário de Depressão de Beck (BDI)(Beck et al., 1961)}

Desenvolvido originalmente por Beck et al (1961) e revisado em 1996 para atender aos critérios de episódio de depressão maior do DSM-5, trata-se de uma escala de autorrelato, para levantamentos dos sintomas depressivos. A validação da escala para a população brasileira demonstrou boa aplicabilidade tendo $70 \%$ de sensibilidade e $87 \%$ para especificidade com ponto de corte 10/11 para detectar depressão (Gomes-Oliveira et al., 2012).

$\mathrm{O}$ BDI é formado por 21 questões de múltipla escolha que abrangem componentes cognitivos, afetivos, comportamentais e somáticos da depressão, O escore final é obtido pela somatória de todos os itens que compõe a escala resultando na seguinte normatização, segundo o Centro de Terapia Cognitiva: a) escores menores que 11 pontos - nenhuma depressão ou depressão mínima; b) escores entre 12 e 19 pontos - depressão leve-moderada; c) escores entre 20 e 35 pontos - depressão moderada a grave; d) escores entre 36 a 63 pontos - depressão grave (Gomes-Oliveira, 2012).

\subsubsection{Inventário de Ansiedade de Beck (BAI) (Beck et al., 1988)}

O BAl foi criado por Beck et al. (1988) para mensurar sintomas ansiosos. No Brasil foi traduzido por Cunha (2001) e validado por Quintão et al. (2013). Trata-se de um questionário de autorrelato, com 21 questões de múltipla escolha que discorrem sobre como o indivíduo tem se sentido na última semana, expressas em sintomas comuns de ansiedade (como sudorese e sentimentos de angústia). Cada questão apresenta quatro possíveis respostas e a que se assemelha mais com o estado mental do indivíduo deve ser sinalizada. O escore máximo é de 63 pontos e a classificação varia conforme os seguintes resultados: a) escores de 0 a 7 pontos: grau mínimo de ansiedade; b) escores de 8 a 15 pontos: ansiedade leve; c) escores de 16 a 25 pontos: ansiedade moderada e d) escores de 26 a 63: ansiedade severa (Cunha, 2001). 


\subsection{Descrição de Procedimentos}

Primeiramente realizou-se um contato telefônico no qual, após explicações prévias sobre a pesquisa, efetuou-se o convite para participação, Com a aceitação do idoso, o sujeito e seu cuidador/informante foram convidados a comparecer em dois dias para avaliações de aproximadamente uma hora e meia de duração.

Num primeiro momento foi aplicado pelo médico psiquiatra um protocolo de triagem com o objetivo de confirmação diagnóstica de DA. Realizada a confirmação, o sujeito era avaliado por terapeutas ocupacionais que realizaram as avaliações funcionais. Num segundo momento, foi aplicado ao cuidador/informante mais próximo um questionário contendo seus dados pessoais e demográficos, o termo de consentimento, as avaliações de funcionalidade indireta, sua avaliação de estresse e avaliações de sintomas ansiosos e depressivos. Todas as avaliações foram aplicadas no prazo máximo de uma semana para evitar possíveis alterações quanto ao comportamento e funcionalidade do idoso. Todos os profissionais que participaram da pesquisa receberam um treinamento prévio para a aplicação do protocolo completo.

A análise dos dados foi realizada através da divisão dos grupos a partir dos escores do CDR final, ou seja, controles, DA leve e DA moderada. 
A figura 3 descreve a organização do processo de avaliações aplicadas nos idosos e nos cuidadores/informantes.

Figura 3. Fluxograma da Organização do Processo de Avaliações:

Encaminhamento pelos ambulatórios do Proter e Ceredic e convidados da comunidade

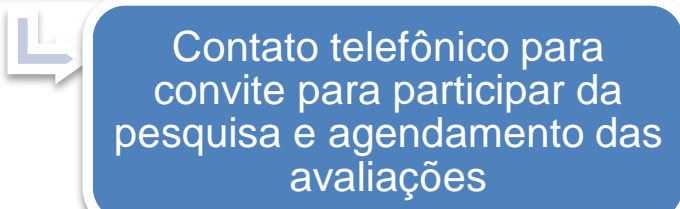

Triagem para confimação diagnóstica e critérios de elegibilidade da pesquisa.

Avaliação de funcionalidade direta com o sujeito e avaliações cognitivas e emocionais e de funcionalidade indireta com o cuidador/informante 
Tabela 3. Avaliações para DA e controle

\begin{tabular}{|c|c|c|}
\hline & Instrumentos & $\begin{array}{l}\text { Valores de referência descritos na } \\
\text { literatura }\end{array}$ \\
\hline \multirow[t]{15}{*}{ Triagem } & Termo de consentimento & \\
\hline & Dados demográficos & \\
\hline & M.I.N.I. & \\
\hline & CAMCOG & $\leq 79 / 80$ \\
\hline & MEEM & $\geq 25$ NORMAL \\
\hline & & $24-21=$ leve \\
\hline & & 20-10 moderada \\
\hline & CDR & $\mathrm{CDR}=0$ ausência de demência \\
\hline & & $\mathrm{CDR}=0.5=$ questionável demência \\
\hline & & $\mathrm{CDR}=1$ = demência leve \\
\hline & & $\mathrm{CDR}=2=$ demência moderada \\
\hline & & $\mathrm{CDR}=3$ = demência grave \\
\hline & Escala de Depressão Hamilton & 7-17 = depressão leve \\
\hline & & 18-24 = depressão moderada \\
\hline & & $>25=$ depressão grave \\
\hline Avaliação & DAFS-BR & Comprometimento funcional $\leq 86$ \\
\hline funcional & & \\
\hline direta & & \\
\hline
\end{tabular}


Tabela 4. Avaliações para cuidador/informante

\begin{tabular}{|c|c|c|}
\hline & Instrumentos & $\begin{array}{l}\text { Valores de referência descritos na } \\
\text { literatura }\end{array}$ \\
\hline Triagem & $\begin{array}{l}\text { Termo de Consentimento } \\
\text { Dados demográficos }\end{array}$ & \\
\hline $\begin{array}{l}\text { Avaliação de rastreio } \\
\text { cognitivo }\end{array}$ & MoCA & $\leq 25$ déficit cognitivo \\
\hline $\begin{array}{l}\text { Avaliação estresse do } \\
\text { cuidador }\end{array}$ & Zarit & $\begin{array}{l}<21 \text { ausência de sobrecarga } \\
21-40 \text { sobrecarga moderada } \\
41-60 \text { sobrecarga moderada a severa } \\
\geq 61 \text { sobrecarga severa }\end{array}$ \\
\hline & $\mathrm{CBI}$ & $\begin{array}{l}\text { Domínio } 1=15,7 \\
\text { Domínio } 2=15,2 \\
\text { Domínio } 3=7,8 \\
\text { Domínio } 4=6,7 \\
\text { Domínio } 5=4,6\end{array}$ \\
\hline Avaliação psiquiátrica & BDI & $\begin{array}{l}\text { <11 mínima } \\
\text { 12-19 leve -moderada } \\
20-35 \text { moderada grave } \\
\text { 36-63 grave }\end{array}$ \\
\hline & BAI & $\begin{array}{l}\text { 0-7 ansiedade mínima } \\
\text { 8-15 ansiedade leve } \\
\text { 16-25 ansiedade moderada } \\
26-63 \text { ansiedade severa }\end{array}$ \\
\hline $\begin{array}{l}\text { Avaliação } \\
\text { funcionalidade }\end{array}$ & $\begin{array}{l}\text { Escala De Atividades } \\
\text { Instrumentais } \mathrm{Da} \text { Vida }\end{array}$ & $\begin{array}{l}\text { Independente }=21 \\
\text { Dependência Parcial 21-5 }\end{array}$ \\
\hline Indireta & $\begin{array}{l}\text { Diária, Lawton e Brody } \\
\text { FAQ } \\
\text { B-ADL }\end{array}$ & $\begin{array}{l}\text { Dependência total }<5 \\
\text { Comprometimento funcional } \geq 6 \\
\text { Comprometimento } \\
\text { Funcional } \geq 3,12\end{array}$ \\
\hline & IQCODE & Comprometimento funcional $\geq 3,38$ \\
\hline
\end{tabular}

Nota: MoCA: Avaliação Cognitiva de Montreal, Zarit: Zarit Burden Interview; CBI: Caregiver burden inventary; BDI: Inventário de depressão de Beck; BAI: Inventário de ansiedade de Beck; FAQ: Questionário de Atividades funcionais de Pfeffer; B-ADL: Bayer - Activities of Daily Living; IQCODE: Informant Questionnaire on cognitive Decline 


\subsection{Análise estatística}

Os dados foram analisados por meio do programa Statistical Package for Social Science (SPSS), versão 22 para Windows. Inicialmente foi realizada a caracterização demográfica dos sujeitos incluídos no estudo. Variáveis contínuas foram apresentadas por meio de médias e desvios-padrão e variáveis categóricas foram apresentadas por frequências absolutas e porcentagens. A avaliação da distribuição normal da presente amostra foi realizada através de Kolmogorov-Smirnov. No caso de distribuição normal das variáveis quantitativas utilizaremos testes paramétricos para comparação de médias (Análise de Variância a um fator com comparações múltiplas pelo teste de Bonferroni), em casos diversos foram utilizados testes não-paramétricos (teste de Kruskal-Wallis com comparações múltiplas pelo teste de Dunn). Para as variáveis qualitativas foi utilizado o teste qui-quadrado ou o teste exato de Fisher. A avaliação de correlações foi realizada por meio do coeficiente de correlação de Pearson. $O$ nível de significância estatístico utilizado foi de $5 \%$ para todas as análises.

Para análise de sensibilidade e especificidade foi utilizada a Curva ROC (Receiver Operating Characteristic) por ser considerada uma forma eficaz de demonstrar a melhor acurácia entre as escalas. A área sob a curva ROC é a medida do desempenho de um teste (índice de exatidão do teste) e acima de 0,70 é considerado desempenho satisfatório. 
5. RESULTADOS 


\section{RESULTADOS}

Foram avaliados 81 sujeitos, sendo 41 controles e 40 pacientes com DA e seus cuidadores/ informantes, com idades entre 63 e 98 anos (média de 76,10 anos com d.p. 7,90 anos e mediana de 76,00 anos). Cinquenta e cinco pacientes $(67,9 \%)$ eram do gênero feminino.

$\mathrm{Na}$ tabela 5 apresenta-se a caracterização demográfica segundo os grupos controle, DA leve e DA moderada.

Entre os sujeitos avaliados, quarenta e um $(50,6 \%)$ foram classificados como saudáveis (controle), 26 (32,1\%) como DA leve e 14 (17,3\%) como DA moderada. Foi observado que não há diferença significativa entre os três grupos em relação a idade, gênero, cor, estado civil, situação de trabalho, tempo de aposentadoria e religião, porém há diferença significativa entre os grupos em relação ao ano de escolaridade (teste de Bonferroni; $p<0,001$ ). $O$ grupo controle apresenta mais anos de estudo do que o grupo DA leve $(p=0,001)$ e não difere do grupo DA moderada $(p=0,365)$. Os grupos de DA não apresentam diferença significativa entre si (teste de Bonferroni; $p=0,500$ ). 
Tabela 5. Caracterização demográfica da amostra segundo grupos (DA leve, DA moderada e Controles)

\begin{tabular}{|c|c|c|c|c|c|}
\hline & & & Grupo & & \\
\hline \multicolumn{2}{|c|}{ Variáveis } & $\begin{array}{c}\text { Controle } \\
(\mathrm{n}=41)\end{array}$ & $\begin{array}{c}\text { DA leve } \\
(\mathrm{n}=26)\end{array}$ & $\begin{array}{c}\text { DA moderada } \\
(\mathrm{n}=14)\end{array}$ & $P$ \\
\hline \multirow[t]{4}{*}{ Idade } & & & & & $0,054^{(3)}$ \\
\hline & $60-69$ & $12(29,3 \%)$ & $5(19,2 \%)$ & $0(0,0 \%)$ & \\
\hline & $70-79$ & $19(46,3 \%)$ & $11(42,3 \%)$ & $5(35,7 \%)$ & \\
\hline & $>=80$ & $10(24,4 \%)$ & $10(38,5 \%)$ & $9(64,3 \%)$ & \\
\hline \multirow[t]{3}{*}{ Gênero } & & & & & $0,580^{(3)}$ \\
\hline & Masculino & $11(26,8 \%)$ & $10(38,5 \%)$ & $5(35,7 \%)$ & \\
\hline & Feminino & $30(73,2 \%)$ & $16(61,5 \%)$ & $9(64,3 \%)$ & \\
\hline \multirow[t]{5}{*}{ Cor } & & & & & $0,695^{(4)}$ \\
\hline & Branco & $34(82,9 \%)$ & $23(88,5 \%)$ & $13(92,9 \%)$ & \\
\hline & Pardo & $2(4,9 \%)$ & $2(7,7 \%)$ & $1(7,1 \%)$ & \\
\hline & Negro & $1(2,4 \%)$ & $1(3,9 \%)$ & $0(0,0 \%)$ & \\
\hline & Asiático & $4(9,8 \%)$ & $0(0,0 \%)$ & $0(0,0 \%)$ & \\
\hline \multicolumn{2}{|c|}{ Estado Civil } & & & & $0,223^{(3)}$ \\
\hline & Com companheiro & $15(36,6 \%)$ & $14(53,9 \%)$ & $4(28,6 \%)$ & \\
\hline & Sem companheiro & $26(63,4 \%)$ & $12(46,1 \%)$ & $10(71,4 \%)$ & \\
\hline \multicolumn{2}{|c|}{ Escolaridade (em anos) } & $11,95 \pm 4,34$ & $7,58 \pm 4,62$ & $9,71 \pm 5,38$ & $<0,001^{(1)}$ \\
\hline \multicolumn{2}{|c|}{ Situação de trabalho } & & & & $0,205^{(4)}$ \\
\hline & Aposentado & $29(70,7 \%)$ & $22(84,6 \%)$ & $14(100,0 \%)$ & \\
\hline & Trabalhando & $6(14,6 \%)$ & $1(3,9 \%)$ & $0(0,0 \%)$ & \\
\hline & Do lar & $6(14,6 \%)$ & $3(11,5 \%)$ & $0(0,0 \%)$ & \\
\hline \multicolumn{2}{|c|}{ Tempo de aposentadoria (em anos) } & $15,13 \pm 12,98$ & $13,85 \pm 9,60$ & $15,36 \pm 12,12$ & $0,995^{(2)}$ \\
\hline \multicolumn{2}{|c|}{ Religião } & & & & $0,910^{(4)}$ \\
\hline & Católica & $3(56,1 \%)$ & $14(53,9 \%)$ & $7(50,0 \%)$ & \\
\hline & Protestante/Evangélica & $3(7,3 \%)$ & $3(11,5 \%)$ & $3(21,4 \%)$ & \\
\hline & Espírita & $9(22,0 \%)$ & $6(23,1 \%)$ & $3(21,4 \%)$ & \\
\hline & Judaica & $0(0,0 \%)$ & $1(3,9 \%)$ & $0(0,0 \%)$ & \\
\hline & Outra & $3(7,3 \%)$ & $1(3,9 \%)$ & $0(0,0 \%)$ & \\
\hline & Nenhuma & $3(7,3 \%)$ & $1(3,9 \%)$ & $1(7,1 \%)$ & \\
\hline
\end{tabular}

Nota: (1) nível descritivo de probabilidade da Análise de Variância a um fator, (2) nível descritivo de probabilidade do teste não-paramétrico de Kruskal-Wallis,(3) nível descritivo de probabilidade do teste qui-quadrado, (4) nível descritivo de probabilidade do teste exato de Fisher. 
A Tabela 6 descreve o perfil cognitivo dos sujeitos avaliados e sua funcionalidade de acordo com escalas direta e indireta.

Tabela 6. Caracterização cognitiva e funcional dos sujeitos

\begin{tabular}{lcccc}
\hline \multicolumn{5}{c}{ Grupos } \\
\hline Variáveis & $\begin{array}{c}\text { Controle } \\
(\mathrm{n}=41)\end{array}$ & $\begin{array}{c}\text { DA leve } \\
(\mathrm{n}=26)\end{array}$ & $\begin{array}{c}\text { DA moderada } \\
(\mathrm{n}=14)\end{array}$ & $P$ \\
\hline MEEM & $27,44 \pm 2,25$ & $22,12 \pm 3,88$ & $15,93 \pm 2,73$ & $<0,001^{(1)}$ \\
CAMCOG & $92,85 \pm 8,37$ & $69,69 \pm 11,03$ & $52,36 \pm 10,00$ & $<0,001^{(1)}$ \\
DAFS-BR & $96,41 \pm 7,39$ & $74,23 \pm 10,54$ & $58,29 \pm 10,05$ & $<0,001^{(1)}$ \\
B-ADL & $1,29 \pm 0,90$ & $4,96 \pm 2.00$ & $6,64 \pm 2,10$ & $<0,001^{(1)}$ \\
Lawton-Brody & $20,12 \pm 1,74$ & $13,73 \pm 3,14$ & $10,93 \pm 2,65$ & $<0,001^{(1)}$ \\
IQCODE & $2,71 \pm 0,78$ & $3,35 \pm 0,56$ & $3,64 \pm 0,50$ & $<0,001^{(1)}$ \\
FAQ & $0,46 \pm 1,29$ & $12,04 \pm 7,76$ & $23,75 \pm 5,76$ & $<0,001^{(2)}$
\end{tabular}

Nota: MEEM: Mini Exame do Estado Mental, CAMCOG: Teste Cognitivo Cambridge DAFS-BR: Direct Assessment Functional State FAQ: Questionário de Atividades funcionais de Pfeffer; B-ADL: Bayer - Activities of Daily Living; IQCODE: Informant Questionnaire on cognitive Decline; Lawton-Brody: Escala de Atividades Instrumentais de Lawton e Brody, (1) nível descritivo de probabilidade da Análise de Variância a um fator, (2) nível descritivo de probabilidade do teste não-paramétrico de Kruskal-Wallis.

Houve diferença significativa entre os grupos em relação a MEEM $(p<0,001)$, CAMCOG $(p<0,001)$, DAFS-BR $(p<0,001)$, B-ADL $(p<0,001)$, Escala de Atividades Instrumentais de Lawton e Brody $(p<0,001)$, IQCODE $(p<0,001)$ e FAQ $(p<0,001)$, caracterizando, assim, os casos como DA leve, moderada e os grupo controle.

Em relação à funcionalidade, observamos que o grupo controle apresentou em todas as formas de avaliação (direta e indireta) a preservação de todas as AIVD, enquanto que o grupo com DA leve e moderada apresentou pior desempenho indicando prejuízo das AIVD progressivos. Nenhum grupo apresentou prejuízo das ABVD.

Foi possível observar pelo MEEM, CAMCOG, DAFS-BR e a Escala de Atividades Instrumentais de Lawton e Brody que os três grupos diferem entre si (teste de Bonferroni; $\mathrm{p}<0,001$ ) pois o grupo controle apresenta valor significativamente maior do que os outros dois grupos de DA e o grupo de DA leve apresenta valor significativamente maior do que o do grupo de DA moderada. 
Já em relação ao IQCODE, observou-se que o grupo controle apresenta valor significativo menor do que os outros dois grupos de DA (teste de Bonferroni; DA leve: $p=0,001$ e DA moderada: $p<0,001$ ), porém não se observou diferença significativa entre os grupos de DA leve e moderada $(p=0,567)$. Em relação a $B-A D L$, observou-se que os três grupos diferem entre si (teste de Bonferroni; $p<0,001$ ), com o grupo controle apresentando valor significativamente menor do que os outros dois grupos de DA e o grupo DA leve apresentando valor significativamente menor do que o do grupo DA moderada.

Em relação a $F A Q$, observou-se que os três grupos diferem entre si (teste de Dunn $\mathrm{p}<0,001$ ), com 0 grupo controle apresentando valor significativamente menor do que os outros dois grupos de DA e o grupo de DA leve apresentando valor significativamente menor do que o do grupo de DA moderada.

A tabela 7 apresenta a caracterização demográfica dos cuidadores/ informantes dos sujeitos dos grupos controle, DA leve e DA moderada. 
Tabela 7. Caracterização demográfica dos cuidadores/informantes, segundo os grupos dos respectivos pacientes.

\begin{tabular}{|c|c|c|c|c|c|}
\hline \multirow[b]{2}{*}{ Variáveis } & & \multicolumn{3}{|c|}{ Grupo de cuidador/informante dos grupos } & \multirow[b]{2}{*}{$P$} \\
\hline & & $\begin{array}{c}\text { Controle } \\
(n=41)\end{array}$ & $\begin{array}{c}\text { DA leve } \\
(n=26)\end{array}$ & $\begin{array}{c}\text { DA moderada } \\
(n=14)\end{array}$ & \\
\hline Idade & & $58,05 \pm 14,52$ & $57,58 \pm 11,89$ & $56,36 \pm 12,31$ & $0,920^{(1)}$ \\
\hline Gênero & & & & & $0,563^{(3)}$ \\
\hline & $\begin{array}{l}\text { Masculino } \\
\text { Feminino }\end{array}$ & $\begin{array}{l}11(26,8 \%) \\
30(73,2 \%)\end{array}$ & $\begin{array}{c}5(19,2 \%) \\
21(80,8 \%)\end{array}$ & $\begin{array}{c}2(14,3 \%) \\
12(85,7 \%)\end{array}$ & \\
\hline Cor & $\begin{array}{l}\text { Branco } \\
\text { Pardo } \\
\text { Negro } \\
\text { Asiático }\end{array}$ & $\begin{array}{c}31(75,6 \%) \\
5(12,2 \%) \\
0(0,0 \%) \\
5(12,2 \%)\end{array}$ & $\begin{array}{c}23(88,5 \%) \\
1(3,9 \%) \\
1(3,9 \%) \\
1(3,9 \%)\end{array}$ & $\begin{array}{c}9(64,3 \%) \\
5(35,7 \%) \\
0(0,0 \%) \\
0(0,0 \%)\end{array}$ & $0,050^{(4)}$ \\
\hline Estado C & $\begin{array}{l}\text { vil } \\
\text { Com companheiro } \\
\text { Sem companheiro }\end{array}$ & $\begin{array}{l}19(46,3 \%) \\
22(53,7 \%)\end{array}$ & $\begin{array}{c}17(65,4 \%) \\
9(34,6 \%)\end{array}$ & $\begin{array}{l}8(57,1 \%) \\
6(42,9 \%)\end{array}$ & $0,304^{(3)}$ \\
\hline Escolaric & $\begin{array}{l}\text { de } \\
\text { Primário } \\
\text { Colegial } \\
\text { Técnico } \\
\text { Superior } \\
\text { Pós-graduação }\end{array}$ & $\begin{array}{c}5(12,2 \%) \\
3(7,3 \%) \\
0(0,0 \%) \\
20(48,8 \%) \\
13(31,7 \%)\end{array}$ & $\begin{array}{c}3(11,5 \%) \\
7(26,9 \%) \\
1(3,9 \% \%) \\
11(42,3 \%) \\
4(15,4 \%)\end{array}$ & $\begin{array}{c}3(21,4 \%) \\
3(21,4 \%) \\
0(0,0 \%) \\
3(21,4 \%) \\
5(35,7 \%)\end{array}$ & $0,136^{(4)}$ \\
\hline Situação & $\begin{array}{l}\text { Ap trabalho } \\
\text { Aposentado } \\
\text { Trabalhando } \\
\text { Do lar } \\
\text { Desempregado }\end{array}$ & $\begin{array}{c}19(46,3 \%) \\
19(46,3 \%) \\
3(7,4 \%) \\
0(0,0 \%)\end{array}$ & $\begin{array}{c}8(30,8 \%) \\
15(57,7 \%) \\
2(7,7 \%) \\
1(3,8 \%)\end{array}$ & $\begin{array}{c}4(28,6 \%) \\
9(64,3 \%) \\
1(7,1 \%) \\
0(0,0 \%)\end{array}$ & $0,640^{(4)}$ \\
\hline Tempo d & aposentadoria (em anos) & $10,70 \pm 8,72$ & $15,40 \pm 15,53$ & $11,00 \pm 3,46$ & $0,827^{(2)}$ \\
\hline Grau de & $\begin{array}{l}\text { arentesco } \\
\text { Cônjuge } \\
\text { Filho } \\
\text { Outro } \\
\text { Não é parente }\end{array}$ & $\begin{array}{c}10(24,4 \%) \\
14(34,1 \%) \\
10(24,4 \%) \\
7(17,1 \%)\end{array}$ & $\begin{array}{c}8(30,8 \%) \\
16(61,5 \%) \\
2(7,7 \%) \\
0(0,0 \%)\end{array}$ & $\begin{array}{c}3(21,4 \%) \\
8(57,1 \%) \\
1(7,1 \%) \\
2(14,3 \%)\end{array}$ & $0,058^{(4)}$ \\
\hline Mora con & o idoso & $15(36,6 \%)$ & $12(46,2 \%)$ & $11(78,6 \%)$ & $0,025^{(3)}$ \\
\hline Frequênc & $\begin{array}{l}\text { a que encontra o idoso } \\
\text { Diária } \\
\text { Semanal } \\
\text { Quinzenal } \\
\text { Mensal } \\
\text { Outro }\end{array}$ & $\begin{array}{c}18(43,9 \%) \\
15(36,6 \%) \\
1(2,4 \%) \\
5(12,2 \%) \\
2(4,9 \%)\end{array}$ & $\begin{array}{c}16(61,5 \%) \\
7(26,9 \%) \\
1(3,8 \%) \\
1(3,8 \%) \\
1(3,8 \%)\end{array}$ & $\begin{array}{c}13(92,9 \%) \\
1(7,1 \%) \\
0(0,0 \%) \\
0(0,0 \%) \\
0(0,0 \%)\end{array}$ & $0,141^{(4)}$ \\
\hline Religião & $\begin{array}{l}\text { Católica } \\
\text { Protestante/Evangélica } \\
\text { Espirita } \\
\text { Judaica } \\
\text { Outra } \\
\text { Nenhuma }\end{array}$ & $\begin{array}{c}24(58,5 \%) \\
7(17,1 \%) \\
4(9,8 \%) \\
0(0,0 \%) \\
1(2,4 \%) \\
5(12,2 \%)\end{array}$ & $\begin{array}{c}15(57,7 \%) \\
1(3,9 \%) \\
4(15,4 \%) \\
1(3,9 \%) \\
4(15,4 \%) \\
1(3,9 \%)\end{array}$ & $\begin{array}{l}6(42,9 \%) \\
2(14,3 \%) \\
3(21,4 \%) \\
0(0,0 \%) \\
0(0,0 \%) \\
3(21,4 \%)\end{array}$ & $0,158^{(4)}$ \\
\hline
\end{tabular}

Nota:(1):nível descritivo de probabilidade da Análise de Variância a um fator, (2) nível descritivo de probabilidade do teste não-paramétrico de Kruskal-Wallis, (3) nível descritivo de probabilidade do teste qui-quadrado, (4) nível descritivo de probabilidade do teste exato de Fisher. 
Foram avaliados 81 cuidadores/informantes com idade entre 22 e 80 anos (média de 57,60 anos com d.p. 13, 21 anos e mediana de 59,00 anos). Sessenta e três $(77,8 \%)$ cuidadores/informantes eram do sexo feminino. Não houve diferença significante entre os três grupos em relação a idade, gênero, cor, estado civil, escolaridade, situação de trabalho, tempo de aposentadoria e religião. Há diferença significativamente estatística entre os grupos em relação a morar com o idoso (teste qui-quadrado, $\mathrm{p}=0,025$ ). Pela partição do quiquadrado observamos que os grupos controle e DA leve não apresentam diferenças significativas $(p=0,444)$ e apresentam porcentagem significativamente menor de casos quando comparados ao grupo DA moderada $(p=0,009)$.

Na Tabela 8 foi analisado o perfil dos cuidadores/informantes em relação a cognição, sintomas depressivos, sintomas de ansiedade e estresses relacionado a função de cuidar.

Tabela 8. Perfil cognitivo e emocional dos cuidadores/informantes, segundo os grupos do respectivo paciente.

\begin{tabular}{lcccc}
\hline & \multicolumn{4}{c}{ Grupo de cuidador/informante dos grupos } \\
\hline Variáveis & $\begin{array}{c}\text { Controle } \\
(n=41)\end{array}$ & $\begin{array}{c}\text { DA leve } \\
(n=26)\end{array}$ & $\begin{array}{c}\text { DA moderada } \\
(n=14)\end{array}$ & $P$ \\
\cline { 2 - 5 } & & & & \\
Zarit & $8,51 \pm 10,74$ & $28,19 \pm 16,99$ & $30,14 \pm 13,13$ & $<0,001^{(2)}$ \\
BDI & $7,98 \pm 9,06$ & $8,73 \pm 8,48$ & $9,50 \pm 8,75$ & $0,224^{(2)}$ \\
BAI & $5,78 \pm 6,27$ & $9,92 \pm 12,56$ & $8,50 \pm 7,41$ & $0,608^{(2)}$ \\
MoCA & $25,39 \pm 2,80$ & $24,00 \pm 3,59$ & $23,21 \pm 4,84$ & $0,084^{(1)}$ \\
CBI & $5,20 \pm 10,41$ & $27,00 \pm 24,41$ & $36,21 \pm 18,88$ & $<0,001^{(2)}$ \\
CBI - tempo dependente & $0,95 \pm 1,90$ & $6,73 \pm 6,17$ & $11,57 \pm 4,57$ & $<0,001^{(2)}$ \\
CBI - vida pessoal & $0,88 \pm 2,29$ & $7,38 \pm 6,34$ & $8,71 \pm 7,08$ & $0,001^{(2)}$ \\
CBI - físico & $1,15 \pm 2,73$ & $4,42 \pm \pm, 13$ & $7,57 \pm 7,64$ & $<0,001^{(2)}$ \\
CBI -social & $1,20 \pm 3,03$ & $4,77 \pm 6,09$ & $6,29 \pm 5,12$ & $0,002^{(2)}$ \\
CBI - emocional & $1,05 \pm 2,66$ & $4,19 \pm 4,87$ & $2,07 \pm 2,56$ & $<0,001^{(2)}$ \\
\hline
\end{tabular}

Nota: MoCA: Avaliação Cognitiva de Montreal, Zarit: ZaritBurden Interview; CBI: Caregiver burden inventary; BDI: Inventário de depressão de Beck; BAl: Inventário de ansiedade de Beck; (1) nível descritivo de probabilidade da Análise de Variância a um fator, (2) nível descritivo de probabilidade do teste não-paramétrico de Kruskal-Wallis, (3) nível descritivo de probabilidade do teste qui-quadrado, (4) nível descritivo de probabilidade do teste exato de Fisher.

Observou-se que não há diferença significativa entre os grupos em relação aos sintomas depressivos (BDI), aos sintomas de ansiedade (BAI) e aos aspectos cognitivos (MoCA), porém há diferença entre os grupos em relação ao estresse do cuidador (Zarit $p<0,001$ e CBI $p<0,001$ ). 
Quando observamos o estresse do cuidador avaliado pela Zarit nota-se que o grupo controle apresenta valor significativamente menor do que os dos outros dois grupos de DA (teste de Dunn; $p<0,001$ ), porém os grupos de DA leve e DA moderada não apresentam diferenças significativas entre si $(p=1,000)$. O mesmo ocorre quando avaliado o estresse do cuidador pelo $C B I$ total, observou-se que o grupo controle apresenta valor significativamente menor do que os grupos de DA (teste de Dunn $p<0,001$ ), porém os grupos DA leve e DA moderada não apresentam diferenças significativas entre si $(p=0,585)$.

Em relação ao domínio da $\mathrm{CBI}$, quanto ao tempo dependente, observouse que o grupo controle apresenta valor significativamente menor do que os grupos de DA (teste de Dunn; $p<0,001$ ), porém os grupos DA leve e DA moderada não apresentam diferenças significativas entre si $(p=0,086)$.

Em relação ao domínio da $\mathrm{CBI}$ de vida pessoal (através do teste de Dunn), observou -se que o grupo controle apresenta valor significativamente menor do que os dos outros dois grupos de DA $(p<0,001)$, porém os grupos DA leve e DA moderada não apresentam diferenças significativas entre si $(p=1,000)$.

Em relação ao domínio da $\mathrm{CBI}$ de aspectos físicos, observou-se que o grupo controle apresenta valor significativamente menor do que os dos outros dois grupos de DA (teste de Dunn; DA leve: $p=0,031$ e DA moderada: $p=$ 0,001). Os grupos DA leve e moderada não apresentam diferenças significativas entre si $(p=0,464)$.

Em relação ao domínio $\mathrm{CBI}$ de vida social, observou-se que o grupo controle apresenta valor significativamente menor do que os dos outros dois grupos de DA (teste de Dunn; DA leve: $p=0,061$ e DA moderada: $p<0,001$ ), porém os grupos DA leve e DA moderada não apresentam diferenças significativas entre si $(p=0,468)$.

Em relação ao domínio $\mathrm{CBI}$ de aspectos emocionais, observou-se que o grupo controle apresenta valor significativamente menor do que o do grupo de DA leve (teste de Dunn; $p=0,002$ ) e não apresenta diferença significativa do grupo DA moderada $(p=0,282)$. Os grupos $D A$ leve e moderada não apresentam diferenças significantes entre si $(p=0,930)$. 
5.1 Análises de correlações entre as avaliações indireta e direta

A tabela 9 apresenta a correlação da variável DAFS-BR e a Escala de Atividades Instrumentais de Lawton e Brody, FAQ, B-ADL e IQCODE.

Tabela 9. Coeficiente de correlação das avaliações indiretas e direta $(n=81$ pacientes)

\begin{tabular}{lcc}
\hline & DAFS-BR & \\
\hline & $\boldsymbol{R}$ & $\boldsymbol{P}$ \\
Lawton- Brody & 0,835 & $<0,001$ \\
FAQ & $-0,834$ & $<0,001$ \\
B-ADL & $-0,772$ & $<0,001$ \\
IQCODE & $-0,445$ & $<0,001$
\end{tabular}

Nota: $r=$ coeficiente de correlação de Pearson; $p=$ significância; DAFS-BR: Direct Assessment Funcional State, IQCODE: Informant Questionnaire on Cognitive Decline in the Elderly; B-ADL: Bayer Activities of Daily Living Scale; FAQ-Questionário de Atividades Funcionais de Pfeffer; Lawton-Brody: Escala de atividades instrumentais Lawton e Brody

Apesar de todas as correlações serem significativas, observou-se que a Escala de Atividades Instrumentais de Lawton e Brody, B-ADL e FAQ possuem uma correlação forte com a DAFS-BR, a correlação da IQCODE, no entanto, é moderada.

As escalas indiretas foram separadas pelas questões individuais e correlacionadas com os domínios da DAFS-BR (orientar-se temporalmente, comunicar-se, lidar com dinheiro, fazer compras, vestir-se e manter higiene pessoal). As escalas indiretas que não apresentam questões referentes a um determinado domínio não foram correlacionadas.

A Tabela 10 apresenta as correlações entre os domínios da DAFS-BR e as questões das escalas indiretas. 
Tabela 10 . Coeficiente de correlação entre questões indiretas e os domínios da DAFS-BR

\begin{tabular}{lllc}
\multicolumn{2}{c}{ da DAFS-BR } & $\mathrm{R}$ & $\mathrm{P}$ \\
\hline DAFS-BR (Orientação temporal) & & & \\
& IQCODE & $-0,701$ & $<0,001$ \\
DAFS-BR (Comunicação) & & & \\
& IQCODE & $-0,451$ & $<0,001$ \\
& Lawton-Brody & 0,566 & $<0,001$ \\
& B-ADL & $-0,455$ & $<0,001$
\end{tabular}

DAFS-BR (Lidar com dinheiro)

$\begin{array}{lcc}\text { IQCODE } & -0,564 & <0,001 \\ \text { FAQ } & -0,672 & <0,001 \\ \text { Lawton-Brody } & 0,654 & <0,001 \\ \text { B-ADL } & -0,069 & 0,545 \\ \text { B-ADL } & -0,309 & <0,001\end{array}$

DAFS-BR (Fazer compras)

$\begin{array}{lcc}\text { FAQ } & -0,773 & <0,001 \\ \text { Lawton-Brody } & 0,716 & <0,001 \\ \text { B-ADL } & -0,743 & <0,001\end{array}$

DAFS-BR (Vestir-se e Higiene)
B-ADL
$-0,356$
0,001
$B-A D L$
$-0,363$
0,001

Nota: $r$ = coeficiente de correlação de Pearson; $p=$ nível descritivo de probabilidade: DAFS-BR: Direct Assessment Funcional State, IQCODE: Informant Questionnaire on Cognitive Decline in the Elderly; B-ADL: Bayer Activities of Daily Living Scale; FAQ-Questionário de Atividades Funcionais de Pfeffer; Lawton-Brody: Escala de atividades instrumentais Lawton-Brody

Observou-se que há semelhanças significativas em todas as correlações avaliadas, com exceção da correlação entre DAFS-BR (Lidar com dinheiro) e B-ADL (contar o dinheiro sem errar).

Também foram analisados os fatores emocionais do cuidador/informante e as escalas de funcionalidades direta e indireta. A tabela 11 apresenta a análise de correlação do estresse, ansiedade e depressão dos grupos e as avaliações direta e indiretas dos respectivos sujeitos. 
Tabela 11. Coeficiente de correlações de correlação de fatores emocionais do informante com escalas funcionais para os grupos controle, DA leve e moderada.

\begin{tabular}{|c|c|c|c|c|c|c|c|c|c|c|c|c|c|c|c|c|}
\hline & & \multicolumn{5}{|c|}{ Controle $(n=41)$} & \multicolumn{5}{|c|}{ DA Leve $(n=26)$} & \multicolumn{5}{|c|}{ DA Moderada $(n=14)$} \\
\hline & & $\begin{array}{c}\text { DAFS- } \\
B R\end{array}$ & IQCODE & $B-A D L$ & LAWTON & $F A Q$ & $\begin{array}{c}\text { DAFS- } \\
B R\end{array}$ & IQCODE & $B-A D L$ & LAWTON & $F A Q$ & $\begin{array}{c}\text { DAFS- } \\
B R\end{array}$ & IQCODE & $\begin{array}{c}B- \\
A D L\end{array}$ & LAWTON & $F A Q$ \\
\hline \multirow[t]{2}{*}{ Zarit } & $\mathrm{R}$ & $-0,040$ & 0,666 & 0,795 & $-0,523$ & 0,522 & $-0,068$ & 0,474 & 0,452 & $-0,341$ & 0,209 & $-0,189$ & 0,223 & 0,376 & $-0,354$ & 0,259 \\
\hline & $p$ & 0,803 & $<0,001$ & $<0,001$ & $<0,001$ & $<0,001$ & 0,741 & 0,014 & 0,020 & 0,088 & 0,306 & 0,517 & 0,442 & 0,185 & 0,214 & 0,371 \\
\hline \multirow[t]{2}{*}{ BDI } & $\mathrm{R}$ & 0,037 & 0,138 & 0,528 & $-0,520$ & 0,576 & $-0,022$ & 0,337 & 0,277 & $-0,366$ & 0,208 & 0,150 & $-0,132$ & 0,355 & $-0,517$ & 0,261 \\
\hline & $p$ & 0,819 & 0,388 & $<0,001$ & $<0,001$ & $<0,001$ & 0,916 & 0,092 & 0,170 & 0,066 & 0,308 & 0,608 & 0,653 & 0,213 & 0,058 & 0,368 \\
\hline \multirow[t]{2}{*}{$\mathrm{BAI}$} & $\mathrm{R}$ & 0,215 & 0,227 & 0,436 & $-0,308$ & 0,335 & $-0,224$ & 0,390 & 0,368 & $-0,514$ & 0,605 & 0,204 & $-0,042$ & $-0,237$ & $-0,446$ & $-0,115$ \\
\hline & $p$ & 0,177 & 0,154 & 0,004 & 0,050 & 0,032 & 0,271 & 0,049 & 0,065 & 0,007 & 0,001 & 0,485 & 0,887 & 0,414 & 0,110 & 0,695 \\
\hline \multirow[t]{2}{*}{ CBI total } & $\mathrm{R}$ & $-0,096$ & 0,491 & 0,822 & $-0,650$ & 0,713 & $-0,229$ & 0,176 & 0,460 & $-0,569$ & 0,430 & 0,144 & 0,176 & 0,420 & $-0,496$ & 0,223 \\
\hline & $p$ & 0,552 & 0,001 & $<0,001$ & $<0,001$ & $<0,001$ & 0,259 & 0,547 & 0,018 & 0,002 & 0,028 & 0,624 & 0,547 & 0,134 & 0,071 & 0,444 \\
\hline \multirow{4}{*}{$\begin{array}{l}\text { CBI } \\
\text { (tempo } \\
\text { dependente) } \\
\text { CBI } \\
\text { (vida pessoal) }\end{array}$} & $\mathrm{R}$ & $-0,425$ & 0,132 & 0,349 & $-0,348$ & 0,327 & $-0,427$ & 0,448 & 0,611 & $-0,759$ & 0,708 & $-0,088$ & 0,448 & 0,040 & $-0,200$ & 0,048 \\
\hline & $p$ & 0,006 & 0,409 & 0,025 & 0,026 & 0,037 & 0,030 & 0,108 & 0,001 & $<0,001$ & $<0,001$ & 0,766 & 0,108 & 0,891 & 0,493 & 0,871 \\
\hline & $\mathrm{R}$ & $-0,184$ & 0,469 & 0,736 & $-0,581$ & 0,630 & $-0,260$ & 0,150 & 0,492 & $-0,576$ & 0,424 & 0,140 & 0,150 & 0,538 & $-0,618$ & 0,361 \\
\hline & $p$ & 0,248 & 0,002 & $<0,001$ & $<0,001$ & $<0,001$ & 0,200 & 0,609 & 0,011 & 0,002 & 0,031 & 0,634 & 0,609 & 0,047 & 0,019 & 0,205 \\
\hline \multirow{2}{*}{$\begin{array}{l}\mathrm{CBI} \\
\text { (fisico) }\end{array}$} & $\mathrm{R}$ & $-0,111$ & 0,476 & 0,755 & $-0,620$ & 0,644 & $-0,105$ & 0,102 & 0,293 & $-0,385$ & 0,309 & 0,116 & 0,102 & 0,288 & $-0,388$ & 0,158 \\
\hline & $p$ & 0,491 & 0,002 & $<0,001$ & $<0,001$ & $<0,001$ & 0,611 & 0,729 & 0,146 & 0,052 & 0,124 & 0,693 & 0,729 & 0,317 & 0,171 & 0,589 \\
\hline \multirow{2}{*}{$\begin{array}{l}\text { CBI } \\
\text { (emocional) }\end{array}$} & $\mathrm{R}$ & 0,065 & 0,277 & 0,668 & $-0,538$ & 0,695 & $-0,210$ & 0,104 & 0,245 & $-0,432$ & 0,355 & 0,297 & 0,104 & 0,216 & $-0,180$ & $-0,063$ \\
\hline & $p$ & 0,689 & 0,079 & $<0,001$ & $<0,001$ & $<0,001$ & 0,302 & 0,723 & 0,227 & 0,028 & 0,075 & 0,302 & 0,723 & 0,457 & 0,538 & 0,830 \\
\hline \multirow{2}{*}{$\begin{array}{l}\text { CBI } \\
\text { (social) }\end{array}$} & $\mathrm{R}$ & 0,134 & 0,620 & 0,804 & $-0,542$ & 0,562 & $-0,003$ & $-0,425$ & 0,324 & $-0,213$ & 0,082 & $-0,109$ & $-0,425$ & 0,253 & $-0,079$ & 0,216 \\
\hline & $p$ & 0,405 & $<0,001$ & $<0,001$ & $<0,001$ & $<0,001$ & 0,987 & 0,130 & 0,107 & 0,295 & 0,689 & 0,712 & 0,130 & 0,383 & 0,789 & 0,457 \\
\hline
\end{tabular}

Nota: $r=$ coeficiente de correlação de Pearson, $p$ = nível descritivo de probabilidade, Zarit: Zarit Burden Interview; BDI:Inventário de Depressão de Beck; BAI: Inventário de Ansiedade de Beck; CBI:

Caregiver Burden Inventary; DAFS-BR: Direct Assessment Funcional State, IQCODE: Informant Questionnaire on Cognitive Decline in the Elderly; Lawton: Escala de atividades instrumentais de

Lawton e Brody, B-ADL: Bayer Activities of Daily Living Scale; FAQ:Questionário de Atividades Funcionais de Pfeffer 
Observou-se que no grupo controle o estresse do informante (Zarit e $\mathrm{CBI}$ ) apresenta correlação significativa com as avaliações IQCODE, B-ADL, Escala de Atividades Instrumentais de Lawton e Brody e a FAQ. O mesmo ocorre com os domínios de $\mathrm{CBI}$, com exceção da relação entre IQCODE e CBI, tempo dependente e emocional. Sintomas depressivos do informante (BDI) apresentam correlação significativa e moderada com as avaliações B-ADL, Escala de Atividades Instrumentais de Lawton e Brody e FAQ e sintomas de ansiedade apresentam correlação significativa com as avaliações B-ADL (correlação moderada) e FAQ (correlação fraca).

Com relação ao grupo de DA leve, pode-se observar que o estresse do cuidador avaliado pelo escore total da Zarit apresenta correlação significativa e moderada com as avaliações IQCODE e B-ADL, assim como o escore total do $\mathrm{CBI}$ também apresenta correlação significativa e moderada com as avaliações IQCODE, B-ADL. Escala de Atividades Instrumentais de Lawton e Brody e FAQ. Os sintomas de ansiedade apresentam somente correlações com as avaliações IQCODE (correlação fraca), Escala de Atividades Instrumentais de Lawton e Brody (correlação moderada) e FAQ (correlação moderada). O domínio de tempo dependente da escala $\mathrm{CBI}$ apresenta correlação moderada com as avaliações DAFS-BR, B-ADL, Escala de Atividades Instrumentais de Lawton e Brody e FAQ e o domínio de vida social do $\mathrm{CBI}$ apresenta correlação moderada com as avaliações IQCODE, B- ADL, FAQ e Escala de Atividades Instrumentais de Lawton e Body. O domínio emocional do CBI apresentou correlação moderada apenas com as avaliações IQCODE e Escala de Atividades Instrumentais de Lawton e Body.

Já no grupo de DA moderada, a única correlação significativa e moderada foi a do domínio de vida pessoal do $C B I$ com as escalas B-ADL e Escala de Atividades Instrumentais de Lawton e Brody.

Nas Tabelas 12 foram correlacionados os domínios da escala CBI com os domínios da escala DAFS para os grupos controle, DA leve e DA moderada respectivamente. 
Tabela 12. Coeficiente de correlação entre os domínios das escalas CBI e DAFS-BR para os grupos de controle, DA leve e moderada

\begin{tabular}{|c|c|c|c|c|c|c|c|c|c|c|c|c|c|c|c|c|}
\hline & & \multicolumn{6}{|c|}{ Controle $(n=41)$} & \multicolumn{5}{|c|}{ DA Leve $(n=26)$} & \multicolumn{4}{|c|}{ DA Moderada $(n=14)$} \\
\hline & & $\begin{array}{l}\text { DAFS } \\
\text { O.T }\end{array}$ & $\begin{array}{l}\text { DAFS } \\
\text { Com. }\end{array}$ & $\begin{array}{l}\text { DAFS } \\
\text { Dinh. }\end{array}$ & $\begin{array}{l}\text { DAFS } \\
\text { compras }\end{array}$ & $\begin{array}{l}\text { DAFS } \\
\text { vestir/ } \\
\text { H.P. }\end{array}$ & $\begin{array}{l}\text { DAFS } \\
\text { O.T }\end{array}$ & $\begin{array}{l}\text { DAFS } \\
\text { Com. }\end{array}$ & $\begin{array}{l}\text { DAFS } \\
\text { Dinh. }\end{array}$ & $\begin{array}{l}\text { DAFS } \\
\text { compras }\end{array}$ & $\begin{array}{l}\text { DAFS } \\
\text { vestir/ } \\
\text { H.P. }\end{array}$ & $\begin{array}{l}\text { DAFS } \\
\text { O.T }\end{array}$ & $\begin{array}{l}\text { DAFS } \\
\text { Com. }\end{array}$ & $\begin{array}{l}\text { DAFS } \\
\text { Dinh. }\end{array}$ & $\begin{array}{l}\text { DAFS } \\
\text { compras }\end{array}$ & $\begin{array}{l}\text { DAFS } \\
\text { vestir/ } \\
\text { H.P. }\end{array}$ \\
\hline \multirow{2}{*}{$\begin{array}{l}\text { CBI Tempo } \\
\text { dependencia }\end{array}$} & $\mathrm{R}$ & 0,053 & 0,148 & $-0,334$ & $-0,638$ & - & $-0,156$ & $-0,189$ & $-0,296$ & $-0,411$ & - & $-0,232$ & \multirow{2}{*}{$\begin{array}{l}- \\
0,234 \\
0,421\end{array}$} & 0,124 & $-0,124$ & $-0,298$ \\
\hline & $p$ & 0,741 & 0,355 & 0,033 & $<0,001$ & - & 0,447 & 0,356 & 0,141 & 0,037 & - & 0,424 & & 0,674 & 0,674 & 0,302 \\
\hline CBI vida & $\mathrm{R}$ & 0,110 & $-0,036$ & $-0,191$ & $-0,283$ & - & $-0,133$ & $-0,099$ & $-0,274$ & $-0,315$ & - & $-0,268$ & 0,489 & 0,407 & $-0,388$ & $-0,078$ \\
\hline pessoal & $\mathrm{p}$ & 0,493 & 0,823 & 0,232 & 0,073 & - & 0,516 & 0,632 & 0,176 & 0,117 & - & 0,355 & 0,076 & 0,149 & 0,171 & 0,791 \\
\hline \multirow[t]{2}{*}{ CBI fisico } & $\mathrm{R}$ & 0,153 & 0,008 & $-0,097$ & $-0,188$ & - & $-0,014$ & 0,117 & $-0,092$ & $-0,285$ & - & $-0,238$ & 0,433 & 0,402 & $-0,350$ & 0,103 \\
\hline & $p$ & 0,340 & 0,962 & 0,546 & 0,238 & - & 0,947 & 0,571 & 0,655 & 0,158 & - & 0,413 & 0,122 & 0,155 & 0,220 & 0,726 \\
\hline \multirow[t]{2}{*}{ CBI Emocional } & $\mathrm{R}$ & 0,101 & 0,107 & 0,119 & $-0,129$ & - & $-0,314$ & 0,009 & $-0,259$ & $-0,146$ & - & 0,017 & 0,595 & 0,409 & $-0,265$ & 0,204 \\
\hline & $\mathrm{p}$ & 0,529 & 0,507 & 0,457 & 0,421 & - & 0,118 & 0,965 & 0,201 & 0,478 & - & 0,953 & 0,025 & 0,147 & 0,359 & 0,485 \\
\hline \multirow[t]{2}{*}{ CBI Social } & $\mathrm{R}$ & 0,140 & 0,093 & 0,022 & 0,066 & - & 0,075 & $-0,074$ & $-0,103$ & $-0,002$ & - & $-0,284$ & 0,281 & $\begin{array}{l}- \\
0.083\end{array}$ & $-0,409$ & $-0,083$ \\
\hline & $p$ & 0,383 & 0,562 & 0,893 & 0,680 & - & 0,716 & 0,718 & 0,618 & 0,993 & - & 0,325 & 0,331 & 0,779 & 0,147 & 0,779 \\
\hline
\end{tabular}

NOTA: DAFS-BR: Functional Direct State Assessment, DAFS OT,: Dafs Dominio Orientação Temporal; DAFS Com.: Dafs Dominio Comunicação; DAFS dinh. : Dafs Dominio lidar com finanças DAFS compras: Dafs Dominio lidar com compras; DAFS Vestir/H.P.: Dafs Dominio vesti-se e higiene pessoal; $r=$ coeficiente de correlação de Pearson, $p=$ nível descritivo de probabilidade, CBI: Caregiver Burden Inventary; 
No grupo controle, observou-se que os domínios da DAFS-BR Lidar com dinheiro e Fazer compras apresentam correlação negativa com o domínio CBI do Tempo dependente (correlação fraca e moderada respectivamente)

No grupo DA leve há uma única correlação significativa e negativa entre o domínio da DAFS-BR Fazer compras, e o domínio da CBI Tempo dependente (correlação moderada). E no grupo DA moderada o domínio da DAFS-BR Comunicação apresenta correlação positiva com o domínio da CBI Emocional (correlação moderada).

\subsection{Análises de Sensibilidades e Especificidades}

Com o objetivo de se avaliar o valor preditivo dos instrumentos estudados em relação ao comprometimento funcional dos sujeitos, foi construída a curva ROC, utilizando o consenso clínico como padrão ouro.

As tabelas 13 e 14 apresentam o valor da acurácia dos instrumentos para DA leve e DA moderada, respectivamente.

Tabela 13. Valor da Acurácia (dado pela área) dos instrumentos estudados para DA Leve

\begin{tabular}{|c|c|c|c|c|c|}
\hline \multirow[b]{2}{*}{ Variável } & \multirow[b]{2}{*}{ Área } & \multirow[b]{2}{*}{ Erro padrão } & \multirow[b]{2}{*}{$\mathrm{P}$} & \multicolumn{2}{|c|}{$\begin{array}{c}\text { Intervalo de } \\
\text { Confiança a } 95 \%\end{array}$} \\
\hline & & & & $\begin{array}{l}\text { Limite } \\
\text { Inferior }\end{array}$ & $\begin{array}{l}\text { Limite } \\
\text { Superior }\end{array}$ \\
\hline DAFS-BR & 0,945 & 0,035 & $<0,001$ & 0,000 & 1,000 \\
\hline B-ADL & 0,971 & 0,017 & $<0,001$ & 0,931 & 1,000 \\
\hline $\mathrm{FAQ}$ & 0,967 & 0,026 & $<0,001$ & 0,000 & 1,000 \\
\hline Lawton-Brody & 0,961 & 0,020 & $<0,001$ & 0,922 & 1,000 \\
\hline IQCODE & 0,908 & 0,044 & $<0,001$ & 0,822 & 0,994 \\
\hline
\end{tabular}

Nota: área= Acurácia do instrumento; $p=$ nível descritivo de probabilidade: DAFS-BR: Direct Assessment Funcional State, IQCODE: Informant Questionnaire on Cognitive Decline in the Elderly; B-ADL: Bayer Activities of Daily Living Scale; FAQ-Questionário de Atividades Funcionais de Pfeffer; Lawton - Brody: Escala de atividades instrumentais de Lawton e Brody 
Figura 4. Curva ROC para DA leve

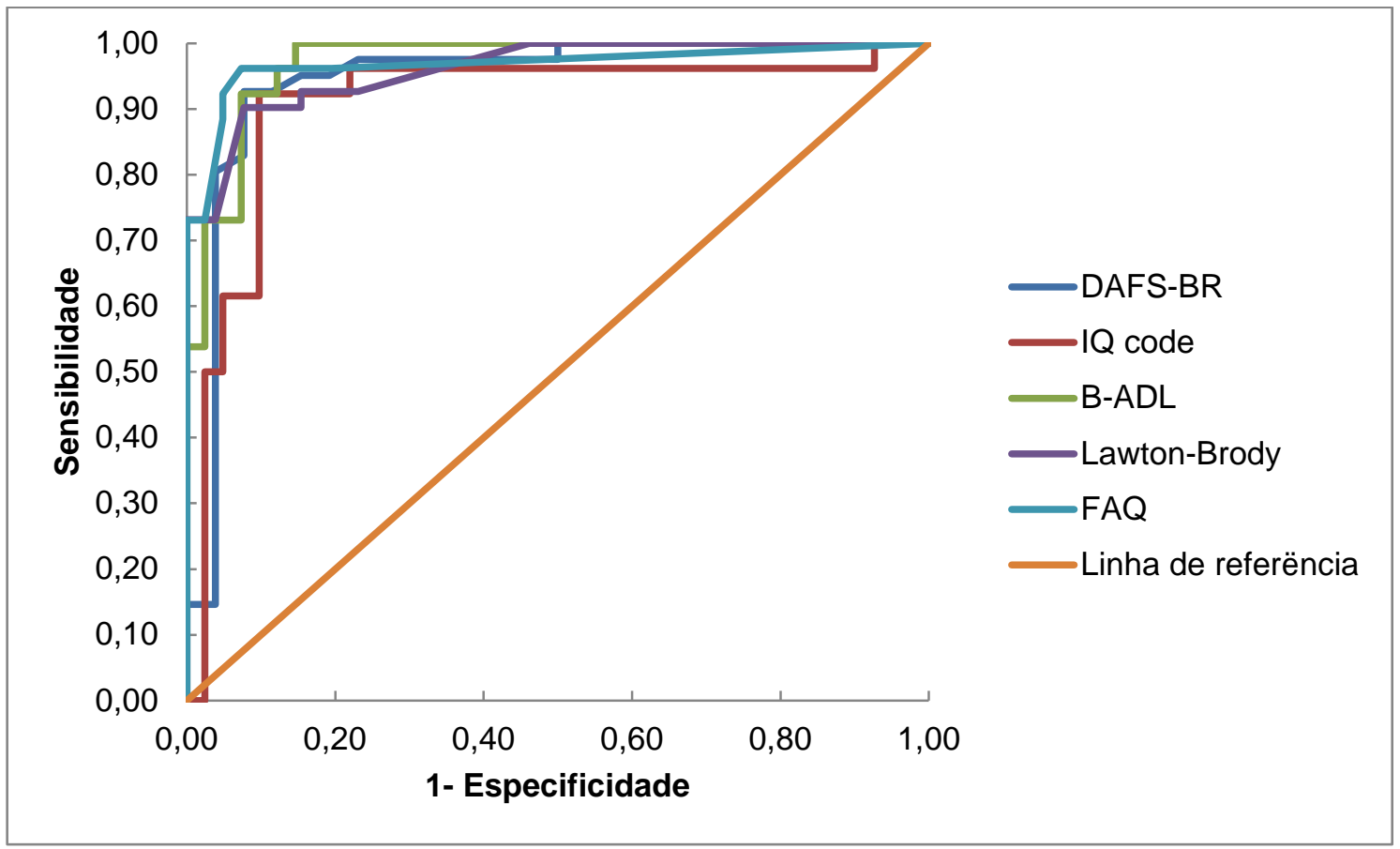

$\mathrm{Na}$ tabela 13 e na figura 2 observou-se que todos os instrumentos apresentam excelente acurácia para identificar DA leve, A DAFS-BR apresenta a maior acurácia, seguido das escalas indiretas B-ADL, FAQ, Escala de Atividades Instrumentais de Lawton e Brody e IQCODE.

$\mathrm{Na}$ tabela 14 e na figura 3 observou-se que todos os instrumentos apresentam excelente acurácia para identificar paciente DA moderada, O FAQ apresenta a maior acurácia, seguido das escalas DAFS-BR, Escala de Atividades Instrumentais de Lawton e Brody, B-ADL e IQ CODE. 
Tabela 14. Valor da Acurácia (dado pela área) dos instrumentos estudados para DA moderada

\begin{tabular}{lcccccc}
\hline & & & & \multicolumn{2}{c}{$\begin{array}{c}\text { Intervalo de } \\
\text { Confiança a } 95 \%\end{array}$} \\
\cline { 5 - 7 } Variável & Área & Erro padrão & $p$ & & \multicolumn{3}{c}{$\begin{array}{c}\text { Limite } \\
\text { Inferior }\end{array}$} & $\begin{array}{c}\text { Limite } \\
\text { Superior }\end{array}$ \\
\hline FAQ & 1,000 & 0,000 & $<0,001$ & 1,000 & 1,000 \\
DAFS-BR & 0,999 & 0,002 & $<0,001$ & 0,000 & 1,000 \\
Lawton-Brody & 0,997 & 0,004 & $<0,001$ & 0,000 & 1,000 \\
B-ADL & 0,988 & 0,011 & $<0,001$ & 0,000 & 1,000 \\
IQ code & 0,950 & 0,029 & $<0,001$ & 0,873 & 1,000
\end{tabular}

Nota: área= Acurácia do instrumento; $p=$ nível descritivo de probabilidade: DAFS-BR: Direct Assessment Funcional State, IQCODE: Informant Questionnaire on Cognitive Decline in the Elderly; B-ADL: Bayer Activitiesof Daily Living Scale; FAQ-Questionário de Atividades Funcionais de Pfeffer; Lawton - Brody: Escala de atividades instrumentais Lawton-Brody

Figura 5. Curva ROC para DA moderada

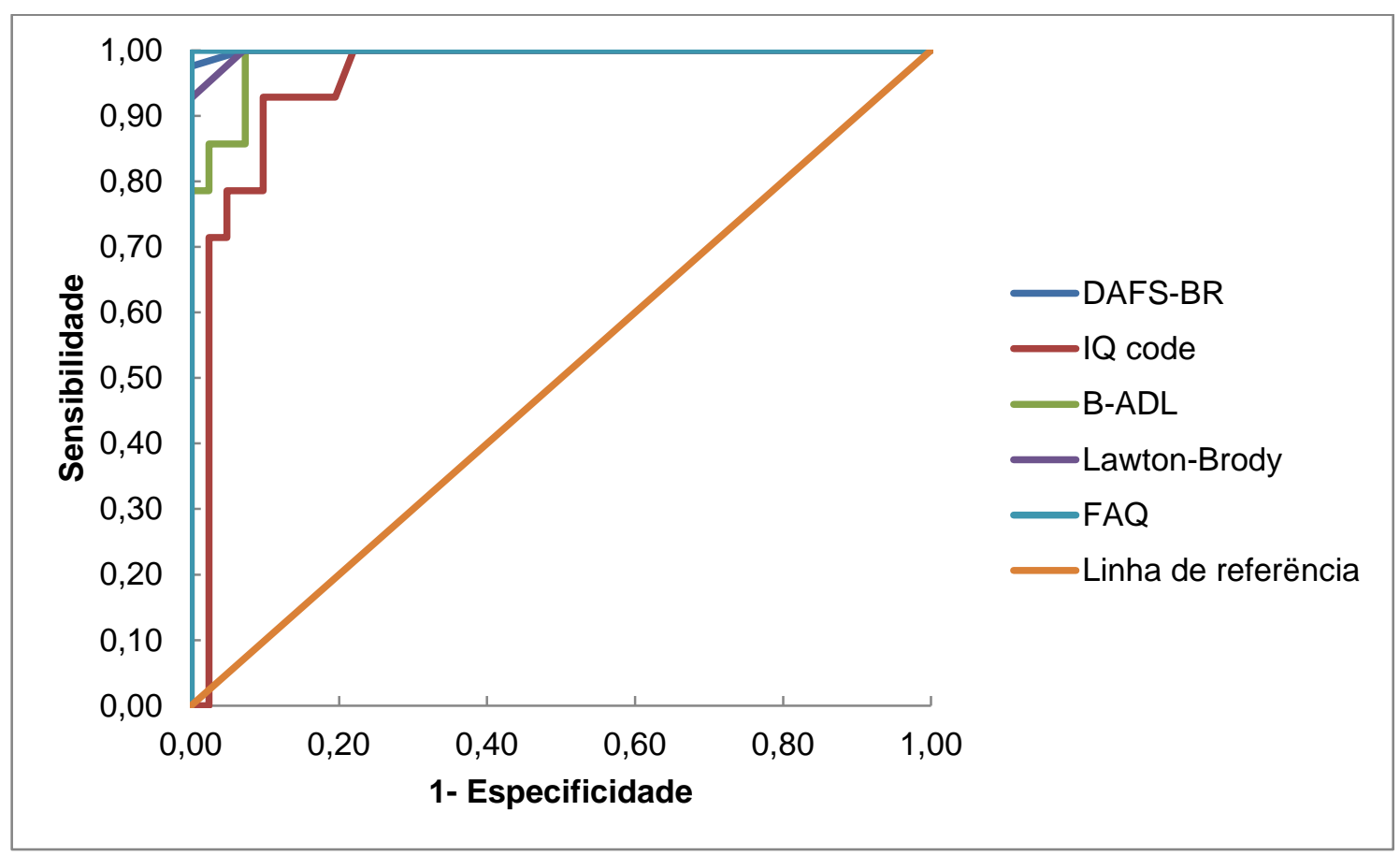


6. DISCUSSÃO 


\section{DISCUSSÃO}

O presente estudo teve como objetivo comparar as avaliações de funcionalidade indiretas com a avaliação de funcionalidade direta, DAFS-BR, correlacionando-as nos diferentes domínios, a fim de identificar, assim, os possíveis vieses de percepção dos cuidadores frente à funcionalidade de pacientes com DA leve e moderada, além de caracterizar o perfil demográfico dos idosos e o perfil emocional e cognitivos dos respectivos cuidadores/informantes. O nosso principal achado na comparação da funcionalidade por meio de avaliações indiretas em relação à avaliação direta foi identificar que a presença de sintomas depressivos, ansiosos e estresse influenciam o preenchimento das escalas indiretas principalmente em controles e DA leve. Com a progressão da DA, a avaliação do cuidador/informante sobre as AIVD vai perdendo a relação com sintomas emocionais e se aproximam da avaliação direta. Apesar desta possível influência ao avaliar a sensibilidade e a especificidade, todas as escalas indiretas apresentam bons resultados em DA leve e moderada.

No presente estudo, ao correlacionar as avaliações indiretas com a avaliação direta, DAFS-BR, concluímos que todas as avaliações possuem correlações significativas. Nossos achados vão ao encontro da literatura, na qual Pereira et al. (2010) observaram uma correlação significativa entre a DAFS-BR e IQCOCE ( $r=0,61, p<0,001)$. A diferença entre as escalas indiretas se faz nas perguntas, como o IQCODE que solicita a comparação do próprio indivíduo com sua funcionalidade há dez anos, enquanto as demais questionam o desempenho atual dos indivíduos nas AIVD. A DAFS-BR é uma avaliação direta com tarefas ecológicas do dia a dia, a qual solicita que 0 indivíduo as realize diante do examinador, permitindo a observação do seu desempenho em cada AVD.

Com o objetivo de aprofundar as análises das correlações entre as diferentes escalas, realizamos um estudo de correlação entre os domínios da DAFS-BR e as questões correspondentes das avaliações indiretas.

Observou-se também que todas as avaliações indiretas possuem pelo menos uma pergunta que se correlaciona com algum domínio da DAFS-BR, 
mas nenhuma delas contempla todos os domínios. O único domínio que foi avaliado em todas as escalas, DAFS-BR e indiretas, foi o financeiro, que é apontado como uma importante dificuldade no início das demências e que pode ser um fator considerável para perda de independência do idoso. É interessante notar que esse foi o único domínio que em uma das escalas não apresentou correlação (DAFS-BR lidar com dinheiro x B-ADL). A escala B-ADL questiona se 0 idoso saberia contar 0 dinheiro sem errar $e \quad 0$ cuidador/informante deve pontuar na escala de 0 a 10 o grau de dificuldade que este sujeito possui, já no domínio da DAFS-BR, relacionado ao lidar com o dinheiro, o sujeito tem que identificar as moedas, contá-las, fazer cálculos mentais para trocos, preencher um cheque e calcular o saldo bancário, o que torna essa tarefas mais complexa.

Mlinac e Feng (2016) afirmam que a perda funcional na DA é progressiva e inicia-se com o acometimento das AIVD, principalmente as dificuldades de lidar com finanças e manejar suas medicações. Costa et al. (2006) analisaram as perdas funcionais em uma população de idosos de Minas Gerais e relatou que entre as AIVD avaliadas pela Escala de Atividades Instrumentais de Lawton e Brody, as três tarefas nas quais os idosos tinham mais dependência e necessitavam de ajuda foram: manuseio de dinheiro $(73,9 \%)$, uso de meios de transporte $(72,5 \%)$ e trabalho doméstico $(40,6 \%)$, Souza Mendes et al. (2015) realizaram estudos com idosos institucionalizados e observaram que $66,27 \%$ destes idosos eram independentes nas ABVD (principalmente alimentação e continência) e 52,18\% nas AIVD, destacaram o uso do telefone como sendo a tarefa de maior nível de dependência. Arrighi et al. (2013) analisaram 341 idosos saudáveis e com diagnósticos de CCL, DA e concluíram que tarefas como cuidar das suas próprias finanças e medicamentos, atividades de lazer e tarefas domésticas são as AIVD que apresentam maiores níveis de dependência em idosos com CCL e DA leve. No estudo de Fagundes et al. (2017) as AVD foram analisadas por meio da escala DAD em uma população com diferentes tipos e demência e observaram que o comprometimento da funcionalidade, independentemente do tipo de demência, é hierárquico e acomete na maioria dos casos inicialmente as AIVD e com a progressão das demências há um comprometimento das ABVD 
subsequentemente. Segundo este estudo, dentre as AIVD inicialmente comprometidas, destacam-se as tarefas de usar medicação, organizar sua saída fora de casa e usar transportes.

Quando correlacionamos o desempenho do indivíduo avaliado pela DAFS-BR com o escore obtido nas escalas indiretas preenchidas pelos cuidadores/informantes, observamos a presença de correlação significativa em todas as escalas. Da mesma forma obtivemos boa sensibilidade e especificidade para DA leve e moderada. Não encontramos em nenhum grupo correlação significativa entre sintomas emocionais e avaliação da funcionalidade direta. Entretanto, ao correlacionar os mesmos sintomas emocionais dos cuidadores/informantes com os escores das escalas indiretas no grupo controle, obtivemos correlações significativas, sendo que o IQCODE foi o que mostrou menor correlação e mais se aproximou da avaliação direta da funcionalidade. Esse fato pode ser explicado pela forma em que se questiona no IQCODE a comparação da funcionalidade atual com a passada (Perroco et al., 2008). No grupo DA leve também observamos correlações entre escalas indiretas e sintomas emocionais, mas em menor quantidade, sugerindo que a progressão da doença possa levar a uma estimativa mais acurada da perda da funcionalidade pelo cuidador/informante. Essa hipótese pode ser reforçada quando no grupo de DA moderada todas as escalas indiretas se mostram semelhantes ao avaliado pela DAFS-BR. É possível sugerir que conforme o prejuízo da funcionalidade se agrava e contempla diferentes domínios, sintomas emocionais do cuidador/informante interfiram menos na percepção de cada domínio. Uma limitação do nosso estudo foi não ter incluído escalas indiretas que avaliam a ABVD, de forma que não é possível avaliar se o mesmo ocorre nestes casos.

Essas observações sugerem que escalas indiretas apresentam menor influência conforme ocorre a progressão da demência. Em casos de DA leve e de CCL a utilização destas escalas pode apresentar um viés em função de sintomas emocionais do cuidador/informante, de forma que, nesses casos, avaliações diretas podem ser preferíveis (Pereira et al. 2010). O uso combinado da DAFS-BR e uma escala de funcionalidade indireta poderiam fornecer ao profissional maiores detalhes acerca da funcionalidade do indivíduo 
(Bravell et al., 2011). As avaliações indiretas e diretas são complementares e oferecem ao profissional e cuidador/informante dados sobre a funcionalidade para um diagnóstico mais fidedigno e um bom direcionamento terapêutico. Nossos achados são corroborados com a literatura, na qual Razani et al. (2007) sugerem que a sobrecarga do cuidador leva a uma subestimação real da funcionalidade de idosos, na mesma direção. Argüelles et al. (2001) sugerem que o estresse e a depressão influenciem a percepção da funcionalidade. No nosso estudo isso foi observado principalmente no grupo controle e DA leve, o que sugere que essa influência não seja tão significativa em relação às AIVD na DA moderada, visto que, neste caso, os prejuízos são mais evidentes.

Com o objetivo de avaliar com qual tipo de estresse se correlaciona os domínios avaliados pela DAFS-BR, esse estudo correlacionou o estresse avaliado pelos domínios da escala CBI (sobrecarga tempo dependente, sobrecarga de vida pessoal, sobrecarga física, sobrecarga emocional e sobrecarga social) com os domínios da DAFS-BR (orientação temporal, comunicação, habilidade em lidar com dinheiro, habilidade em fazer compras e vestir-se e higiene pessoal) e concluiu-se que quando se observa o grupo controle e DA leve há correlações negativas entre lidar com dinheiro e sobrecarga quanto ao tempo de dependência, ou seja, quanto maior a dificuldade do sujeito de lidar com dinheiro ou fazer compras segundo a DAFS$\mathrm{BR}$, maior é o estresse do cuidador com relação ao tempo que ele desprende ao cuidado deste idoso. Já com o avançar da demência, na fase moderada da $\mathrm{DA}$, a sobrecarga está mais correlacionada a fatores emocionais e à dificuldade de comunicação na DAFS-BR, aqui os achados apontam para quanto maior a independência na comunicação, maior o estresse emocional. Esse item, na DAFS-BR, refere-se a falar ao telefone e enviar correspondência, habilidades que se mantêm somente nos casos mais preservados de DA moderada, de forma que conforme a gravidade progride o familiar é menos exposto a essa situação. Nossos achados assemelham-se a literatura que afirma que 0 estresse do cuidador pode estar correlacionado ao tempo de cuidado e a maior dependência das AVD. (Cruz e Hamdan, 2008; Yu et al., 2015; Cesário et al., 2017). Küçükgüçlü et al. (2017) compararam cuidadores de DA e de Demência 
Fronto-temporal (DFT) e os domínios de maior estresse do cuidador pela escala $\mathrm{CBI}$ e concluíram que em ambos os tipos de demência o fator que mais afeta a sobrecarga dos cuidadores é o declínio no desempenho das AVD e sintomas neuropsicológicos, 0 que afeta principalmente 0 domínio de sobrecarga quanto ao tempo de dependência aos cuidados.

Em relação à nossa amostra de pacientes e controles, não houve diferença significativa entre os três grupos em relação a idade, gênero, cor, estado civil, situação de trabalho, tempo de aposentadoria e religião. Com relação à idade, observou-se que no grupo controle 19 sujeitos (46,3\%) tinham entre 70-79 anos, no grupo DA leve, $11(42,3 \%)$ estavam nesta mesma faixa etária e no grupo de DA moderada, a maioria, 9 sujeitos (64,3\%), possuía mais de 80 anos. Esses achados são congruentes com a observação do aumento da incidência e progressão da DA com o envelhecimento (Herrera Jr et al., 2002; Burlá et al., 2013). Com relação ao gênero, encontrou-se predominância feminina nos três grupos, o que vai ao encontro da pirâmide populacional, que demonstra um predomínio de mulheres em relação a homens após os 60 anos (Carvalho e Rodríguez-Wong, 2008). Outros estudos também apresentaram maior predominância do gênero feminino, tais como o de Marra et al. (2007) e Herrera Jr et al. (2002). este último observou 1.656 idosos selecionados randomicamente com idades a partir de 65 anos na cidade de Catanduva, no interior do estado de São Paulo, e concluiu que idade, gênero e baixa escolaridade possuem associações significativas com 0 aumento de prevalência de demência na população.

Quanto à escolaridade, apesar da diferença significativa entre grupo controle e grupo DA leve, quando comparamos os grupos DA leve e moderado isso não se mantém. A escolaridade é um fator protetor reconhecido para DA (Herrera Jr et al., 2002; Bottino et al., 2008; Nitrini et al., 2009). Essa diferença apresenta uma influência potencial especialmente nas avaliações cognitivas, que podem ser dependentes da escolaridade. Entretanto, nas funcionais, objeto deste estudo, são menos influenciadas. Apesar da limitação da diferença da idade entre os grupos, a definição de demência foi realizada pelo CDR, levando em conta possíveis influências da escolaridade. Finalmente, quanto ao perfil cognitivo e funcional, todos os testes avaliados apresentaram 
diferenças estatísticas entre os grupos de controle e DA, como realmente se esperava, caracterizando a perda funcional e cognitiva inerente do avançar da demência.

Em relação ao perfil do cuidador, é interessante notar que uma grande maioria era do gênero feminino (77\%), de diferentes faixas etárias (de 22 a 80 anos, com mediana de 59 anos), o que sugere que as mulheres tendem a assumir o papel de cuidadoras com mais frequência, sendo em geral esposas ou filhas. Observamos também que nos grupos controle e DA leve a maioria dos cuidadores/informantes não reside com o idoso, mas convive diariamente com eles, já na DA moderada a grande maioria mora com o idoso assistido e, assim, podemos inferir que à medida que a necessidade de auxílio aumenta, há maior necessidade de se permanecer mais tempo com esse idoso e, em muitos casos, estar morando na mesma residência pode ser uma alternativa necessária para supervisões e cuidados mais constantes. Os nossos achados foram ao encontro da literatura, na qual Araújo e Fernandes (2015) revisaram a caracterização do perfil do cuidador de idoso e relataram que a maioria dos cuidadores é do sexo feminino (85\%), a idade varia de 26-86 anos (média de 50 anos), $95 \%$ são cuidadores informais, e a estimativa é de que $75 \%$ seja filha ou cônjuge da pessoa idosa e que $80 \%$ residia com o idoso assistido. Estudos como Brigola et al. (2017) caracterizam os cuidadores de idosos num contexto rural do interior paulista e também concluem que a sua maioria é do gênero feminino e com média de $65( \pm 10,4)$ anos de idade. Estudos internacionais também se assemelham aos achados atuais pontuando a prevalência de mulheres como cuidadoras, na faixa etária de 50 e 80 anos e escolaridade que varia de acordo com o nível de desenvolvimento e cultura do seu país (Yu et al., 2015; Custodio et al., 2017; Wolff et al., 2017)

Com relação aos aspectos cognitivos e emocionais dos cuidadores/informantes, o rastreio cognitivo, sintomas depressivos e ansiosos não mostraram diferença entre os grupos. Entretanto observamos diferença entre controle e DA leve e moderada em relação ao estresse do cuidador (Zarit $p<0,001$ e $C B \mid p<0,001)$, mas, ao contrário da literatura, esta amostra não diferenciou maior sobrecarga de estresse entre cuidadores de DA leve e moderada. Uma possível explicação é que apesar de os pacientes com DA 
estarem em diferentes estágios de gravidade, nenhum apresentava comprometimento em ABVD, aspecto que acarreta maiores níveis de estresse do cuidador (Cruz e Hamdan, 2008). A observação de que informantes de controles apresentam menor estresse que os cuidadores de DA vai ao encontro da literatura, na qual estudos recentes observaram que fatores relacionados ao estresse do cuidador podem aumentar com a demência e grau de dependência que o idoso apresenta. A diferença estatística aqui encontrada está relacionada ao grupo controle e aos grupos de DA, demonstrando que o sujeito que convive com o idoso saudável apresenta menos estresse que os cuidadores de DA. O estudo de Pinto e Barham (2014) comparou a percepção do estresse e da qualidade da relação com o idoso, das habilidades sociais e estratégias de enfrentamento de cuidadores de idosos com e sem demência e concluíram que os cuidadores de idosos com demência apresentam maior sobrecarga emocional, maior dificuldade em lidar com críticas justas e menor auto controle (Yu et al., 2015). 


\section{CONCLUSÃO}

No nosso estudo caracterizamos o perfil de funcionalidade dos idosos, observando prejuízos da AIVD nos grupos de DA leve e moderada, sem prejuízo envolvendo as ABVD. O grupo controle mostrou-se independente e preservado para as AIVD.

Nós caracterizamos os cuidadores/informantes, e não observamos diferença entre os informantes do grupo controle e cuidadores de sujeitos com DA do ponto de vista cognitivo, sintomas depressivos e ansiosos. Porém, do ponto de vista de sobrecarga e estresse do cuidador, observamos que os cuidadores dos sujeitos com DA apresentam maior comprometimento do que os informantes dos idosos saudáveis.

A presença de sintomas emocionais influencia a avaliação indireta em quadros leves de declínio cognitivo cujo comprometimento funcional é sutil, Nesses casos, se possível, seria preferível uma avaliação direta. Das avaliações indiretas, a que menos sofreu influência dos fatores emocionais dos cuidadores e mais se aproximou da avaliação direta foi o IQCODE. Em contrapartida, na DA moderada, na qual os prejuízos funcionais são evidentes, as avaliações indiretas sofreram menor influência do estresse do cuidador. 


\section{REFERÊNCIAS}

ALMEIDA M L, M. L. et al. Instrumentos mais utilizados na avaliação da funcionalidade de idosos com demência: uma revisão sistemática. Revista de Atenção à Saúde (antiga Rev. Bras. Ciên. Saúde), v. 14, n. 48, p. 76-85, 2016. ISSN 2359-4330.

AMORIM, P. Mini International Neuropsychiatric Interview (MINI): validação de entrevista breve para diagnóstico de transtornos mentais. Rev Bras Psiquiatr, v. 22, n. 3, p. 106-15, 2000. ISSN 1516-4446.

ARAÚJO, F. et al. Validação da escala de Lawton e Brody numa amostra de idosos não isntitucionalizados. Leal, J., Silva, I. \& Marques, S. Actas do $7^{\circ}$ congresso Nacional de psicologia da saúde. Lisboa: ISPA, 2008. p.217-22.

ARAÚJO, F. N. F. D.; FERNANDES, M. J. P. PERFIL DE CUIDADORES DE IDOSOS NO BRASIL. 2015.

ARGÜELLES, S. et al. Caregivers' judgments of the functional abilities of the Alzheimer's disease patient: impact of caregivers' depression and perceived burden. Journal of Geriatric Psychiatry and Neurology, v. 14, n. 2, p. 91-98, 2001. ISSN 0891-9887.

ARRIGHI, H. M. et al. Longitudinal changes in functional disability in Alzheimer's disease patients. International Psychogeriatrics, v. 25, n. 6, p. 929-937, 2013. ISSN 1041-6102.

ASSOCIATION, A. P. DSM-5: Manual diagnóstico e estatístico de transtornos mentais. Artmed Editora, 2014. ISBN 8582711832.

BAHIA, V. S. et al. Functional disability in Alzheimer disease: a validation study of the Brazilian version of the Disability Assessment for Dementia (DAD-Br). Alzheimer Disease \& Associated Disorders, v. 24, n. 3, p. 291-295, 2010. ISSN 0893-0341.

BAHLS, S.-C. Depressão: uma breve revisão dos fundamentos biológicos e cognitivos. Interação em Psicologia, v. 3, n. 1, 1999. ISSN 1981-8076.

BECK, A. et al. An inventory for measuring clinical anxiety: Psychometrie properties. Journal ofConsulting and Clinical Psychology, v. 56, n. 6, p. 893-897, 1988. 
BECK, A. T. et al. An inventory for measuring depression. Archives of general psychiatry, v. 4, n. 6, p. 561-571, 1961. ISSN 0003-990X.

BENTVELZEN, A. et al. A Comprehensive Review of the Quality and Feasibility of Dementia Assessment Measures: The Dementia Outcomes Measurement Suite. Journal of the American Medical Directors Association, 2017. ISSN 1525-8610.

BERTOLUCCI, P. H. et al. O mini-exame do estado mental em uma populaçäo geral: impacto da escolaridade. Arq. Neuropsiquiatr, v. 52, n. 1, p. 1-7, 1994. ISSN 0004-282X.

BOFF, M. S.; SEKYIA, F. S.; BOTTINO, C. Prevalence of dementia among brazilian population: systematic review. Rev Med (São Paulo), v. 94, n. 3, p. 154-61, 2015.

BOTTINO, C. et al. Validade e confiabilidade da versão brasileira do CAMDEX. Arq Neuropsiquiatr, v. 59, n. Supl 3, p. 20, 2001.

BOTTINO, C. M. et al. Estimate of dementia prevalence in a community sample from São Paulo, Brazil. Dementia and Geriatric Cognitive Disorders, v. 26, n. 4, p. 291-299, 2008. ISSN 1420-8008.

BRAVELL, M. E.; ZARIT, S. H.; JOHANSSON, B. Self-reported activities of daily living and performance-based functional ability: a study of congruence among the oldest old. European Journal of Ageing, v. 8, n. 3, p. 199-209, 2011. ISSN 1613-9372.

BRESSAN, L. A.; VALE, F. D. A. C.; SPECIALI, J. G. The daily life of patients with dementia: a comparative study between the information provided by the caregiver and direct patient assessment. Dementia \& Neuropsychologia, v. 1, n. 3, p. 288-295, 2007. ISSN 1980-5764.

BRIGOLA, A. G. et al. Perfil de saúde de cuidadores familiares de idosos e sua relação com variáveis do cuidado: um estudo no contexto rural. Revista Brasileira de Geriatria e Gerontologia, v. 20, n. 3, 2017. ISSN 1809-9823.

BRUCKI, S. M. et al. Sugestões para o uso do mini-exame do estado mental no Brasil. Arquivos de Neuro-psiquiatria, 2003. ISSN 0004-282X.

BUCKS, R. S. et al. Assessment of activities of daily living in dementia: development of the Bristol Activities of Daily Living Scale. Age and ageing, $v$. 25, n. 2, p. 113-120, 1996. ISSN 1468-2834. 
BURLÁ, C. et al. Panorama prospectivo das demências no Brasil: um enfoque demográfico. Ciência \& Saúde Coletiva, v. 18, n. 10, p. 2949-2956, 2013. ISSN 1413-8123.

BURTON, C. L. et al. Functional abilities in older adults with mild cognitive impairment. Gerontology, v. 55, n. 5, p. 570-581, 2009. ISSN 0304-324X.

BUSTAMANTE, S. E. Z. et al. Instrumentos combinados na avaliação de demência em idosos: resultados preliminares. Arq Neuropsiquiatr, v. 61, n. 3A, p. 601-6, 2003.

CANEDO, B. D. S. Mini-exame do estado mental como instrumento de avaliação cognitiva: uma revisão bibliográfica. 2014.

CANON, M. B. F.; DE ALEMIEDA, M. H. M.; NOVELLI, M. M. P. C. Escala de avaliação de incapacidade na demência-versão longa (DADL-BR)/Disability assessment scale for dementia-long version (DADL-BR). Cadernos de Terapia Ocupacional da UFSCar, v. 24, n. 2, 2016. ISSN 2238-2860.

CANON, M. B. F.; NOVELLI, M. M. P. C. Estudo dos instrumentos de avaliação funcional em demência comumente utilizados no Brasil. Journal of Occupational Therapy of University of São Paulo/Revista de Terapia Ocupacional da Universidade de São Paulo, v. 23, n. 3, 2012. ISSN 14159104.

CAPORICCI, S.; NETO, M. Estudo comparativo de idosos ativos e inativos através da avaliação das atividades da vida diária e medição da qualidade de vida. Motricidade, v. 7, n. 2, 2011. ISSN 1646-107X.

CARAMELLIA, P.; BARBOSA, M. T. Como diagnosticar as quatro causas mais freqüentes de demência? How to diagnose the four most frequent causes of dementia? Rev Bras Psiquiatr, v. 24, n. Supl I, p. 7-10, 2002.

CARTHERY-GOULART, M. T. et al. Cross-cultural adaptation of the Disability Assessment for Dementia (DAD). Arquivos de Neuro-psiquiatria, v. 65, n. 3B, p. 916-919, 2007. ISSN 0004-282X.

CARVALHO, J. A. M. D.; RODRíGUEZ-WONG, L. L. A transição da estrutura etária da população brasileira na primeira metade do século XXI. Cadernos de Saúde Pública, v. 24, p. 597-605, 2008. ISSN 0102-311X.

CECATO, J. F. et al. Poder preditivo do MoCa na avaliação neuropsicológica de pacientes com diagnóstico de demência. Revista Brasileira de Geriatria e Gerontologia, v. 17, n. 4, p. 707-719, 2014. ISSN 1809-9823. 
CESÁRIO, V. A. C. et al. Estresse e qualidade de vida do cuidador familiar de idoso portador da doença de Alzheimer. Saúde em Debate, v. 41, p. 171-182, 2017. ISSN 0103-1104.

CHAVES, M. L. et al. Doença de Alzheimer. Avaliação cognitiva, comportamental e funcional. Dementia \& Neuropsychologia, v. 5, n. 1, 2011. ISSN 1980-5764.

CORNELIS, E. et al. Early diagnosis of mild cognitive impairment and mild dementia through basic and instrumental activities of daily living: Development of a new evaluation tool. PLoS medicine, v. 14, n. 3, p. e1002250, 2017. ISSN 1549-1676.

COSTA, A. J. L. Metodologias e indicadores para avaliação da capacidade funcional: análise preliminar do Suplemento Saúde da Pesquisa Nacional por Amostra de Domicílios-PNAD, Brasil, 2003. Ciência \& Saúde Coletiva, v. 11, n. 4, p. 927-940, 2006. ISSN 1413-8123.

COSTA, E. C.; KYOSEN NAKATANI, A. Y.; BACHION, M. M. Capacidade de idosos da comunidade para desenvolver Atividades de Vida Diária e Atividades Instrumentais de Vida Diária. Acta paulista de enfermagem, v. 19, n. 1, 2006. ISSN 0103-2100.

CRUZ, M. D. N.; HAMDAN, A. C. O impacto da doença de Alzheimer no cuidador. Psicol. estud.[serie en Internet], 2008.

CRUZ V T, V. T. et al. Sintomas iniciais de demência de Alzheimer: a percepção dos familiares. Acta Med Port, v. 17, p. 435-444, 2004.

CUNHA, F. C. M. D. et al. Declínio funcional em idosos com comprometimento cognitivo leve. 2015.

CUNHA, J. A. Manual da versão em português das Escalas Beck. São Paulo: Casa do Psicólogo, p. 11-13, 2001.

CUSTODIO, N. et al. Dementia in latin america: epidemiological evidence and implications for public policy. Frontiers in aging neuroscience, v. 9, p. 221, 2017. ISSN 1663-4365.

DASH, T.; JOANETTE, Y.; . Neurocognitive Markers of Aging Encyclopedia of Geropsychology. SPRINGER 2016. 
DIAS, E. G. et al. As Atividades avançadas de vida diária como componente da avaliação funcional do idoso. Revista de Terapia Ocupacional da Universidade de São Paulo, v. 25, n. 3, p. 225-232, 2014. ISSN 2238-6149.

DUTRA, M. C. et al. Accuracy and reliability of the Pfeffer Questionnaire for the Brazilian elderly population. Dementia \& Neuropsychologia, v. 9, n. 2, p. 176183, 2015. ISSN 1980-5764.

FAGUNDES, T. A. et al. Incapacidade funcional de idosos com demência/Functional disability in elderly with dementia. Cadernos Brasileiros de Terapia Ocupacional, v. 25, n. 1, 2017. ISSN 2526-8910.

FARIAS, N.; BUCHALLA, C. M. A classificação internacional de funcionalidade, incapacidade e saúde da organização mundial da saúde: conceitos, usos e perspectivas. Revista brasileira de epidemiologia, v. 8, n. 2, p. 187-193, 2005. ISSN 1415-790X.

FAUL, F. et al. G* Power 3: A flexible statistical power analysis program for the social, behavioral, and biomedical sciences. Behavior research methods, v. 39 , n. 2, p. 175-191, 2007. ISSN 1554-351X.

FERREIRA, N. C. L. Q. - As dificuldades dos familiares que atuam no cuidado dos idosos portadores da doença de Alzheimer: uma revisão bibliográfica. REVISTA CIÊNCIA ET PRAXIS, v. 8, n. 15, p. 35-42, 2017. ISSN 1983-912X.

FJELL, A. M. et al. What is normal in normal aging? Effects of aging, amyloid and Alzheimer's disease on the cerebral cortex and the hippocampus. 2014. 20-40 ISBN 0301-0082.

FOLQUITTO, J. C. et al. The Bayer: Activities of Daily Living Scale (B-ADL) in the differentiation between mild to moderate dementia and normal aging. Revista Brasileira de Psiquiatria, v. 29, n. 4, p. 350-353, 2007. ISSN 15164446.

FOLSTEIN, M. F.; FOLSTEIN, S. E.; MCHUGH, P. R. "Mini-mental state": a practical method for grading the cognitive state of patients for the clinician. Journal of psychiatric research, v. 12, n. 3, p. 189-198, 1975. ISSN 00223956.

FUCHS, J. et al. Indicators for healthy ageing - a debate. International journal of environmental research and public health, v. 10 , n. 12, p. 6630-6644, 2013. 
GALLUCCI NETO, J.; JÚNIOR, M. S. C.; VON KRAKAUER HÜBNER, C. Escala de Depressão de Hamilton (HAM-D): revisão dos 40 anos de sua utilização. Revista da Faculdade de Ciências Médicas de Sorocaba. ISSN eletrônico 1984-4840, v. 3, n. 1, p. 10-14, 2001. ISSN 1984-4840.

GARRIDO, R.; MENEZES, P. R. Impacto em cuidadores de idosos com demência atendidos em um serviço psicogeriátrico. Revista de Saúde Pública, v. 38, n. 6 , p. 835-841, 2004. ISSN 1518-8787.

GAUTHIER L et al. Disability Assessment for Dementia (DAD) user's guide, 1994., 1994.

GOMES-OLIVEIRA, M. H. et al. Validation of the Brazilian Portuguese version of the Beck Depression Inventory-II in a community sample. Revista Brasileira de Psiquiatria, v. 34, n. 4, p. 389-394, 2012. ISSN 1516-4446.

GOMES, P. S.; PAMPLONA, J. B. ENVELHECIMENTO POPULACIONAL, MERCADO DE TRABALHO E POLÍTICA PÚBLICA DE EMPREGO NO BRASIL. Economia \& Gestão, v. 15, n. 41, p. 206-230, 2015. ISSN 19846606.

GRANGER, C. V. et al. Advances in functional assessment for medical rehabilitation. Topics in geriatric rehabilitation, v. 1, n. 3, p. 59-74, 1986. ISSN 0882-7524.

GUTIERREZ, L. L. P.; FERNANDES, N. R. M.; MASCARENHAS, M. Caracterização de cuidadores de idosos da região metropolitana de Porto Alegre (RS): perfil do cuidado. Saúde em Debate, v. 41, p. 885-898, 2017. ISSN 0103-1104.

HAMILTON, M. A rating scale for depression. Journal of neurology, neurosurgery, and psychiatry, v. 23, n. 1, p. 56, 1960.

HERRERA JR, E. et al. Epidemiologic survey of dementia in a communitydwelling Brazilian population. Alzheimer Disease \& Associated Disorders, v. 16, n. 2, p. 103-108, 2002. ISSN 0893-0341.

HINDMARCH, I. et al. The Bayer activities of daily living scale (B-ADL). Dementia and geriatric cognitive disorders, v. 9, n. Suppl. 2, p. 20-26, 1998. ISSN 1420-8008.

HOPKINS, R. O. et al. Instrumental Activities of Daily Living after Critical Illness: A Systematic Review. Annals of the American Thoracic Society, n. ja, 2017. ISSN 2329-6933. 
HUGHES, C. P. et al. A new clinical scale for the staging of dementia. The British journal of psychiatry, v. 140, n. 6, p. 566-572, 1982. ISSN 0007-1250. IBGE. (2014). "Brasil é reconhecido por políticas públicas em favor de idosos." Retrieved 08/2013, 2014, from http://ibege.gov.br

JACINTO, A. F. Alterações cognitivas em pacientes idosos atendidos em ambulatório geral de clínica médica. 2008. Universidade de São Paulo

JEFFERSON, A. L. et al. Characterization of activities of daily living in individuals with mild cognitive impairment. The American Journal of Geriatric Psychiatry, v. 16, n. 5, p. 375-383, 2008. ISSN 1064-7481.

JEKEL, K. et al. Mild cognitive impairment and deficits in instrumental activities of daily living: a systematic review. Alzheimer's research \& therapy, v. 7, n. 1, p. 17, 2015. ISSN 1758-9193.

JOHNSON, N. et al. The Activities of Daily Living Questionnaire: a validation study in patients with dementia. Alzheimer disease \& associated disorders, v. 18 , n. 4, p. 223-230, 2004. ISSN 0893-0341.

JORM, A.; JACOMB, P. The Informant Questionnaire on Cognitive Decline in the Elderly (IQCODE): socio-demographic correlates, reliability, validity and some norms. Psychological medicine, v. 19, n. 4, p. 1015-1022, 1989. ISSN 1469-8978.

KATZ, N. Cognition, Occupation, and Participation Across the Life Span. Bethesda: The American Occupational Therapy Association, 2011.

KATZ, S. et al. Studies of illness in the aged: the index of ADL: a standardized measure of biological and psychosocial function. Jama, v. 185, n. 12, p. 914919, 1963. ISSN 0098-7484.

KÜÇÜKGÜÇLÜ, Ö. et al. Examining Factors Affecting Caregiver Burden: A Comparison of Frontotemporal Dementia and Alzheimer's Disease. American Journal of Alzheimer's Disease \& Other Dementias ${ }^{\circledR}$, v. 32, n. 4, p. 200-206, 2017. ISSN 1533-3175.

LARA, J. et al. A proposed panel of biomarkers of healthy ageing. BMC medicine, v. 13, n. 1, p. 222, 2015. ISSN 1741-7015.

LAWTON, M. P.; BRODY, E. M. Assessment of older people: self-maintaining and instrumental activities of daily living. Nursing Research, v. 19, n. 3, p. 278, 1970. ISSN 0029-6562. 
LIMA-SILVA, T. B. et al. Direct and indirect assessments of activities of daily living in behavioral variant frontotemporal dementia and Alzheimer disease. Journal of geriatric psychiatry and neurology, v. 28, n. 1, p. 19-26, 2015. ISSN 0891-9887.

LIN, A. et al. Participant-Informant Relationships Affect Quality of Life Ratings in Incipient and Clinical Alzheimer Disease. The American Journal of Geriatric Psychiatry, v. 25, n. 3, p. 297-307, 2017. ISSN 1064-7481.

LINO, V. T. S. et al. Cross-cultural adaptation of the independence in activities of daily living index (Katz index). Cadernos de Saúde Pública, v. 24, n. 1, p. 103-112, 2008. ISSN 0102-311X.

LOEWENSTEIN, D. A. et al. A New Scale for the Assessment of Functional Status in Alzheimer's Disease and Related Disorders. Journal of Gerontology, v. 44, n. 4, p. P114-P121, 1989. ISSN 0022-1422. Disponível em: < http://dx.doi.org/10.1093/geronj/44.4.P114 >.

LOPES DOS SANTOS, R.; VIRTUOSO JÚNIOR, J. S. Confiabilidade da versão brasileira da escala de atividades instrumentais da vida diária. Revista Brasileira em Promoção da Saúde, v. 21, n. 4, 2008. ISSN 1806-1222.

MAHONEY, F. I.; BARTHEL, D. W. Functional evaluation: the Barthel Index: a simple index of independence useful in scoring improvement in the rehabilitation of the chronically ill. Maryland state medical journal, 1965. ISSN 0025-4363.

MAPI, R. I. Cultural Adaptation of the Bayer Activities of Daily Living Scale (B-ADL) into Brazilian Portuguese: Mapi Research Institute Lyon-France 1999.

MARIGLIANO, R. X. et al. Estratégias de autocuidado usadas por cuidadores de idosos: análise de produção científica. Mudanças-Psicologia da Saúde, v. 23, n. 2, p. 37-45, 2015. ISSN 2176-1019.

MARRA, T. A. et al. Avaliação das atividades de vida diária de idosos com diferentes níveis de demência. Revista Brasileira de Fisioterapia, v. 11, n. 4, 2007. ISSN 1413-3555.

MARSHALL, G. A. et al. Activities of daily living measured by the Harvard Automated Phone Task track with cognitive decline over time in non-demented elderly. The journal of prevention of Alzheimer's disease, v. 4, n. 2, p. 81, 2017. 
MCKHANN, G. et al. Clinical diagnosis of Alzheimer's disease Report of the NINCDS-ADRDA Work Group* under the auspices of Department of Health and Human Services Task Force on Alzheimer's Disease. Neurology, v. 34, n. 7, p. 939-939, 1984. ISSN 0028-3878.

MEDEIROS, M.; GUERRA, R. Translation, cultural adaptation and psychometric analysis of the Activities of Daily Living Questionnaire (ADLQ) for functional assessment of patients with Alzheimer's disease. Brazilian Journal of Physical Therapy, v. 13, n. 3, p. 257-266, 2009. ISSN 1413-3555.

MLINAC, M. E.; FENG, M. C. Assessment of activities of daily living, self-care, and independence. Archives of Clinical Neuropsychology, v. 31, n. 6, p. 506516, 2016. ISSN 0887-6177.

MONTAÑO, M. B. M. M.; RAMOS, L. R. Validity of the Portuguese version of clinical dementia rating. Revista de Saude Publica, v. 39, n. 6, p. 912-917, 2005. ISSN 1518-8787.

MOURA MINOSSO, J. S. et al. Validação, no Brasil, do Índice de Barthel em idosos atendidos em ambulatórios. Acta Paulista de Enfermagem, v. 23, n. 2, 2010. ISSN 0103-2100.

NAGARATNAM, N.; NAGARATNAM, K.; O'MARA, D. Bayer-activities of daily living scale in mild and moderate dementia of the Alzheimer type. American Journal of Alzheimer's Disease \& Other Dementias ${ }^{\circledR}$, v. 28, n. 8, p. 784-789, 2013. ISSN 1533-3175.

NASREDDINE, Z. S. et al. The Montreal Cognitive Assessment, MoCA: a brief screening tool for mild cognitive impairment. Journal of the American Geriatrics Society, v. 53, n. 4, p. 695-699, 2005. ISSN 1532-5415.

NEUBERN, P. C. B. Funcioalidade e funçoes executivas em idosos saudáveis e portadores de demências na doença de Alzheimer: um estudo de validação do Executive Functiona Performance Teste- BR. 2018. (Phd). faculdade de Medicidade Universidade de São Paulo, USP

NITRINI, R. et al. Prevalence of dementia in Latin America: a collaborative study of population-based cohorts. International Psychogeriatrics, v. 21, n. 4, p. 622-630, 2009. ISSN 1741-203X.

NITRINI, R. et al. Diagnóstico de doença de Alzheimer no Brasil: avaliação cognitiva e funcional. Arq neuropsiquiatr, v. 63, n. 3-A, p. 720-727, $2005 a$. 
Diagnóstico de doença de Alzheimer no Brasil: critérios diagnósticos e exames complementares. Arq Neuropsiquiatr, v. 63, n. 3-A, p. 713-719, 2005b.

NITRINI, R. et al. Incidence of dementia in a community-dwelling Brazilian population. Alzheimer Disease \& Associated Disorders, v. 18, n. 4, p. 241246, 2004. ISSN 0893-0341.

NOVAK, M.; GUEST, C. Application of a multidimensional caregiver burden inventory. The gerontologist, v. 29, n. 6, p. 798-803, 1989. ISSN 1758-5341.

NOVELLI, M. M. P. C.; NITRINI, R.; CARAMELLI, P. Cuidadores de idosos com demência: perfil sociodemográfico e impacto diário. Revista de terapia ocupacional da Universidade de São Paulo, v. 21, n. 2, p. 139-147, 2010. ISSN 2238-6149.

NYBERG, L. et al. Memory aging and brain maintenance. Trends in cognitive sciences, v. 16, n. 5, p. 292-305, 2012. ISSN 1364-6613.

PAIXÃO JR, C. M.; REICHENHEIM, M. E. Uma revisão sobre instrumentos de avaliação do estado funcional do idoso $A$ review of functional status evaluation instruments in the elderly. Cad. Saúde Pública, v. 21, n. 1, p. 7-19, 2005.

PARADELA, E. M. P.; DE SOUZA LOPES, C.; LOURENÇO, R. A. Adaptação para o português do Cambridge Cognitive Examination-Revised aplicado em um ambulatório público de geriatria Portuguese adaptation of the Cambridge Cognitive Examination-Revised in. Cad. Saúde Pública, v. 25, n. 12, p. 25622570, 2009.

PEREIRA, F. S. et al. Cross-cultural adaptation, reliability and validity of the DAFS-R in a sample of Brazilian older adults. Archives of Clinical Neuropsychology, v. 25, n. 4, p. 335-343, 2010. ISSN 1873-5843.

PEREIRA J K, J. K.; OLIVEIRA ARAÚJO FIRMO, J.; GIACOMIN, K. C. Maneiras de pensar e de agir de idosos frente às questões relativas à funcionalidade/incapacidade. Ciência \& Saúde Coletiva, v. 19, n. 8, 2014. ISSN 1413-8123.

PERROCO, T. R. et al. Short IQCODE as a screening tool for $\mathrm{MCl}$ and dementia: preliminary results. Dementia \& Neuropsychologia, v. 2, n. 4, p. 300-304, 2008. ISSN 1980-5764. 
PFEFFER, R. et al. Measurement of functional activities in older adults in the community. Journal of gerontology, v. 37, n. 3, p. 323-329, 1982. ISSN $0022-$ 1422.

PINTO, F. N. F. R.; BARHAM, E. J. Bem estar psicológico: Comparação entre cuidadores de idosos com e sem demência. Psicologia, Saúde \& Doenças, v. 15, n. 3, p. 635-655, 2014. ISSN 1645-0086.

QUINTÃO, S.; DELGADO, A. R.; PRIETO, G. Estudo de validade da versao portuguesa do Beck Anxiety Inventory mediante o modelo Rasch Rating Scale. Psicologia: Reflexao \& Critica, v. 26, n. 2, p. 305-311, 2013. ISSN 01027972.

RAMOS, L. R. Fatores determinantes do envelhecimento saudável em idosos residentes em centro urbano: Projeto Epidoso, São Paulo. Cadernos de Saúde Pública, 2003. ISSN 0102-311X.

RAZANI, J. et al. Predicting caregiver burden from daily functional abilities of patients with mild dementia. Journal of the American Geriatrics Society, v. 55 , n. 9, p. 1415-1420, 2007. ISSN 1532-5415.

RIBERTO, M. et al. Validação da versão brasileira da Medida de Independência Funcional. Acta fisiátrica, v. 11, n. 2, p. 72-76, 2016. ISSN 2317-0190.

ROTH, M. et al. CAMDEX. A standardised instrument for the diagnosis of mental disorder in the elderly with special reference to the early detection of dementia. The British journal of psychiatry, v. 149, n. 6, p. 698-709, 1986. ISSN 0007-1250.

ROWE, J. W.; KAHN, R. L. Human aging: usual and successful. Science, v. 237, n. 4811, p. 143-149, 1987. ISSN 0036-8075.

SANCHEZ, M. A. D. S.; CORREA, P. C. R.; LOURENÇO, R. A. Cross-cultural Adaptation of the" Functional Activities Questionnaire-FAQ" for use in Brazil. Dementia \& Neuropsychologia, v. 5, n. 4, p. 322-327, 2011. ISSN 19805764.

SANCHEZ, M. A. D. S.; LOURENÇO, R. A. Informant Questionnaire on Cognitive Decline in the Elderly (IQCODE): cross-cultural adaptation for use in Brazil. Cadernos de saude publica, v. 25, n. 7, p. 1455-1465, 2009. ISSN 0102-311X. 
SANTOS, M. D. D.; MELO BORGES, S. D. Percepção da funcionalidade nas fases leve e moderada da doença de Alzheimer: visão do paciente e seu cuidador. Revista Brasileira de Geriatria e Gerontologia, v. 18, n. 2, p. 339349, 2015. ISSN 1809-9823.

SARMENTO, A. L. R. Apresentação e aplicabilidade da versão brasileira da MoCA (Montreal Cognitive Assessment) para rastreio de comprometimento cognitivo leve. 2009.

SAÚDE, O. M. D. CIF: classificação internacional de funcionalidade, incapacidade e saúde: Edusp São Paulo 2004.

SCAZUFCA, M. Brazilian version of the Burden Interview scale for the assessment of burden of care in carers of people with mental illnesses. Revista brasileira de psiquiatria, v. 24, n. 1, p. 12-17, 2002. ISSN 1516-4446.

SILVA FALCÃO, D. V.; NOBRE FERRO BUCHER-MALUSCHKE, J. S. Cuidar de familiares idosos com a doença de alzheimer: uma reflexão sobre aspectos psicossociais. Psicologia em Estudo, v. 14, n. 4, 2009. ISSN 1413-7372.

SILVA TALMELLI, L. F. D. et al. Nível de independência funcional e déficit cognitivo em idosos com doença de Alzheimer. Revista da Escola de Enfermagem da USP, v. 44, n. 4, 2010. ISSN 0080-6234.

SOUZA MENDES, R.; NOVELLI, C.; PIRES, M. M. Perfil cognitivo e funcional de idosos moradores de uma instituição de longa permanência para idosos. Cadernos de Terapia Ocupacional da UFSCar, v. 23, n. 4, 2015. ISSN 01044931.

SOUZA, S. et al. O planejamento do autocuidado para o cuidador de idosos: revisão integrativa. Revista de enfermagem UFPE on line-ISSN: 1981-8963, v. 10 , n. 5 , p. 1866-1872, 2016. ISSN 1981-8963.

SPOSITO, G.; NERI, A. L.; YASSUDA, M. S. Atividades avançadas de vida diária (AAVDs) e o desempenho cognitivo em idosos residentes na comunidade: Dados do Estudo FIBRA Polo UNICAMP. Revista Brasileira de Geriatria e Gerontologia, v. 19, n. 1, p. 7-20, 2016. ISSN 1809-9823.

TRINDADE, A. P. N. T. D. et al. Repercussão do declínio cognitivo na capacidade funcional em idosos institucionalizados e não institucionalizados. Fisioterapia em Movimento, v. 26, n. 2, 2017. ISSN 1980-5918.

VALER, D. Adaptação do instrumento Caregiver Burden Inventory para uso com cuidadores de pessoas idosas no Brasil [dissertação]. Porto Alegre (RS): 
Escola de Enfermagem, Universidade Federal do Rio Grande do Sul, 2012.

VALER, D. B. et al. Adaptação do instrumento Caregiver Burden Inventory para uso com cuidadores de pessoas

idosas no Brasil" Rev. Latino-Am. Enfermagem

v. 23 , p. $130-8,2015$.

VALLEJO, V. et al. Evaluation of a novel Serious Game based assessment tool for patients with Alzheimer's disease. PloS one, v. 12, n. 5, p. e0175999, 2017. ISSN 1932-6203.

VIÑAS-DIEZ, V. et al. Kinship and cohabitation in relation to caregiver burden in the context of Alzheimer's disease: a 24-month longitudinal study. International journal of geriatric psychiatry, 2017. ISSN 1099-1166.

WHO, W. H. O. Relatório Mundial de Envelhecimento e Saúde: Luxemburg: WHO/FWC/ALC 2015.

WOLFF, J. L. et al. Family Caregivers of Older Adults, 1999-2015: Trends in Characteristics, Circumstances, and Role-Related Appraisal. The Gerontologist, p. gnx093-gnx093, 2017. ISSN 0016-9013. Disponível em: < http://dx.doi.org/10.1093/geront/gnx093 >.

$\mathrm{YU}, \mathrm{H}$. et al. Measuring the caregiver burden of caring for community-residing people with Alzheimer's disease. PloS one, v. 10, n. 7, p. e0132168, 2015. ISSN 1932-6203.

ZANETTI, O. et al. Contrasting results between caregiver's report and direct assessment of activities of daily living in patients affected by mild and very mild dementia: the contribution of the caregiver's personal characteristics. Journal of the American Geriatrics Society, v. 47, n. 2, p. 196-202, 1999. ISSN 15325415.

ZARIT, S.; ZARIT, J. The memory and behavior problems checklist and the burden interview-Penn State Gerontology Center. University Park, 1983. 


\section{ANEXOS}

Anexo A - Termo de Consentimento Livre e Esclarecido - Casos e Controles

\section{HOSPITAL DAS CLÍNICAS}

DA

FACULDADE DE MEDICINA DA UNIVERSIDADE DE SÃO PAULO

TERMO DE CONSENTIMENTO PÓS-INFORMAÇÃO

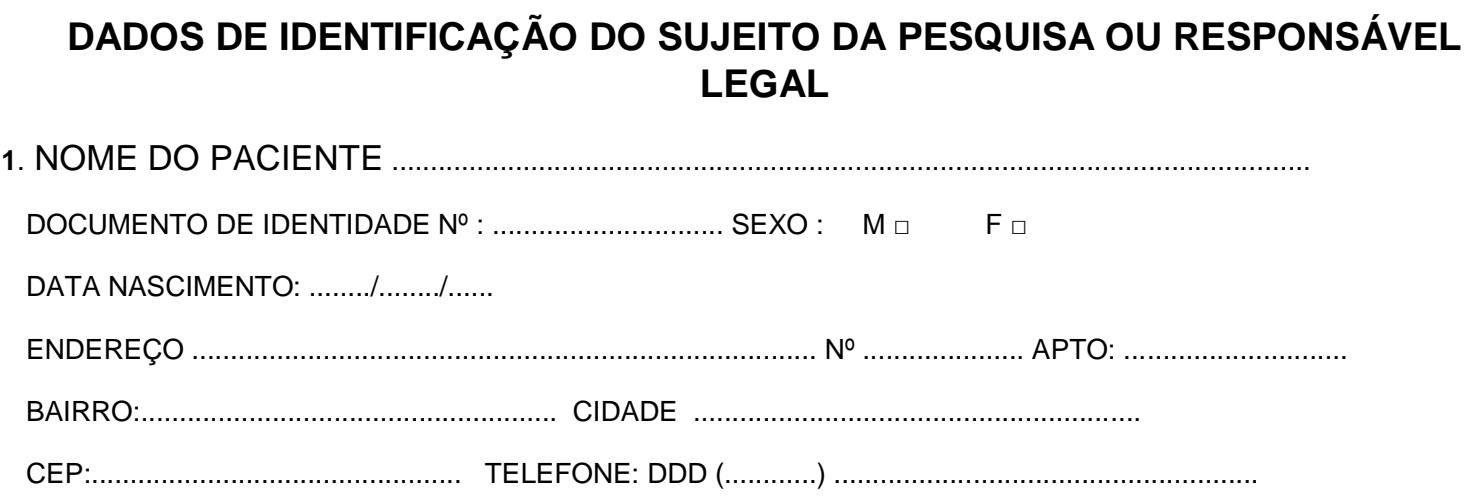

2.RESPONSÁVEL LEGAL

NATUREZA (grau de parentesco, tutor, curador etc.)

DOCUMENTO DE IDENTIDADE :.

SEXO: $\quad M \square \quad F \square$

DATA NASCIMENTO.

ENDEREÇO

№

APTO:

BAIRRO

CIDADE

CEP:

TELEFONE: DDD

\section{DADOS SOBRE A PESQUISA}

1. TítULO DO PROTOCOLO DE PESQUISA."Funcionalidade e Qualidade de Vida na Doença de Alzheimer".

PESQUISADOR: Profa. Dr. Tânia Correa de Toledo Ferraz Alves

CARGO/FUNÇÃO: Médico assistente INSCRIÇÃO CONSELHO REGIONAL № 85182

UNIDADE DO HC-FMUSP: Instituto de Psiquiatria do HC-FMUSP

2. AVALIAÇÃO DO RISCO DA PESQUISA:

$\begin{array}{llll}\text { SEM RISCO } & x & \text { RISCO MÍNIMO } \\ \text { RISCO BAIXO } & \square & \text { RISCO MAIOR } \square & \text { RISCO MÉDIO } \square\end{array}$

3. DURAÇÃO DA PESQUISA : 48 meses 
1- Desenho do estudo e objetivo (s) O Senhor (a) esta sendo convidado á participar voluntariamente de uma pesquisa que pretende avaliar como esta a sua qualidade de vida e como você realiza atividades do dia a dia. O nosso objetivo é identificar como as pessoas que tem esta doença fazem as coisas do dia a dia e se estão vivendo com qualidade. Também queremos verificar como está a pessoa que cuida diariamente de quem tem a doença.

2- $\quad$ Procedimentos do estudo: Esse termo fornecerá a você informações sobre sua participação no estudo. Por exemplo, quanto tempo ira durar a visita e os testes. Será solicitado que você leia e assine um termo de consentimento.

3- $\quad$ Relação dos procedimentos rotineiros e como são realizados O senhor (a) irá responder diversas perguntas e realizar algumas tarefas muito parecidas com coisas do dia a dia (por exemplo fazer café, contar dinheiro, entre outras), com perguntas de como o senhor se sente ou com exercícios com lápis e papel como por exemplo desenhar um cubo.

4- Descrição dos desconfortos e riscos esperados Estes testes irão demorar algumas horas iremos fazer intervalo para que o senhor não se sinta cansado. Não existe risco esperado pois respondera apenas a perguntas e realizara atividades de dia a dia.

5. Benefícios para o participante Com os resultados dos testes poderemos conhecer melhor como a doença interfere no dia a dia de vocês e estas informações podem ser usadas por quem trata do senhor .

6. Relação de procedimentos alternativos que possam ver vantajosos, pelos quais o paciente pode optar; Você pode recusar participar do estudo ou pode interromper sua participação a qualquer momento, sem penalidade ou perda de benefícios aos quais você tem direito de outro modo.

7. Garantia de acesso: em qualquer etapa do estudo, você terá acesso aos profissionais responsáveis pela pesquisa para esclarecimento de eventuais dúvidas. $\mathrm{O}$ principal investigador é a Dra Tania Correa de Toledo Ferraz Alves que pode ser encontrado no endereço Rua Dr. Ovídio Pires de Campos, 785 - 3 andar - PROTER Instituto de Psiquiatria do HCFMUSP, Telefones (11) 2661-6973 e email:

proter.ipq@hc.fm.usp.br. Se você tiver alguma consideração ou dúvida sobre a ética da pesquisa, entre em contato com o Comitê de Ética em Pesquisa (CEP) - Rua Dr. Ovídio Pires de Campos, 225 - 5o andar - Tel: 11-2661-6442 ramais 16, 17, 18 e email:

cappesq@hc.fm.usp.br.

8. E garantia a liberdade da retirada de consentimento a qualquer momento $e$ deixar de participar do estudo, sem qualquer prejuízo à continuidade de seu tratamento na Instituição.

Sua participação neste estudo é completamente voluntária. Você pode recusar participar do estudo ou pode interromper sua participação a qualquer momento, sem penalidade ou perda de benefícios aos quais você tem direito de outro modo.

9. Direito de confidencialidade- As informações obtidas serão analisadas em conjunto com outros pacientes, não sendo divulgado a identificação de nenhum paciente. O médico do estudo e a equipe irão tratar as informações que identificam você de uma forma confidencial. As normas brasileiras que protegem os seus direitos em acessar suas informações pessoais serão seguidas. Se os dados do estudo forem publicados ou divididos com terceiros, como parte de discussões científicas, sua identidade permanecerá confidencial.

Você pode cancelar sua autorização a qualquer momento. Se você cancelar sua autorização, o médico do estudo e sua equipe não usarão ou divulgarão mais suas informações médicas 
10. Despesas e compensações: Não há despesas pessoais para o participante. Também não há compensação financeira relacionada à sua participação.

Acredito ter sido suficiente informado a respeito das informações que li ou que foram lidas para mim, descrevendo o estudo "Funcionalidade e Qualidade de Vida na Doença de Alzheimer I'".

Eu discuti com o a Dra Tania Correa de Toledo Ferraz Alves sobre a minha decisão em participar neste estudo. Ficaram claros para mim quais são os propósitos do estudo, os procedimentos a serem realizados, seus desconfortos e riscos, as garantias de confidencialidade e de esclarecimentos permanentes. Ficou claro também que minha participação é isenta de despesas e que tenho garantia do acesso a tratamento hospitalar quando necessário.

Concordo voluntariamente em participar deste estudo e poderei retirar o meu consentimento a qualquer momento, antes ou durante o mesmo, sem penalidades prejuízo ou perda de qualquer benefício que eu possa ter adquirido, ou meu atendimento neste serviço.

Assinatura do paciente

Assinatura do representante legal

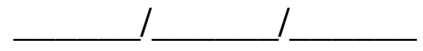

Data

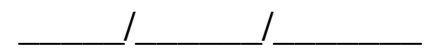

Data

Para casos de pacientes analfabetos, semi-analfabetos ou portadores de deficiência auditiva ou visual.

Declaro que obtive de forma apropriada e voluntária o Consentimento Livre e Esclarecido deste paciente ou representante legal a participação neste estudo. 
Anexo B - Termo de Consentimento Livre Esclarecido -

Cuidador HOSPITAL DAS CLÍNICAS

DA

FACULDADE DE MEDICINA DA UNIVERSIDADE DE SÃO PAULO

TERMO DE CONSENTIMENTO PÓS-INFORMAÇÃO

\section{DADOS DE IDENTIFICAÇÃO DO SUJEITO DA PESQUISA OU RESPONSÁVEL LEGAL}

1. NOME DO PACIENTE

DOCUMENTO DE IDENTIDADE № : SEXO : $\quad M \square \quad F \square$

DATA NASCIMENTO: № APTO:

ENDEREÇO CIDADE

BAIRRO: TELEFONE: DDD (............)

CEP

2.RESPONSÁVEL LEGAL

NATUREZA (grau de parentesco, tutor, curador etc.)

DOCUMENTO DE IDENTIDADE :

SEXO: $\quad M \square \quad F \square$

DATA NASCIMENTO.:

ENDEREÇO № APTO:

BAIRRO: CIDADE

CEP TELEFONE: DDD (

\section{DADOS SOBRE A PESQUISA}

4. TíTULO DO PROTOCOLO DE PESQUISA."Funcionalidade e Qualidade de Vida na Doença de Alzheimer".

PESQUISADOR: Profa. Dr. Tânia Correa de Toledo Ferraz Alves

CARGO/FUNÇÃO: Médico assistente IINSCRIÇÃO CONSELHO REGIONAL № 85182 UNIDADE DO HC-FMUSP: Instituto de Psiquiatria do HC-FMUSP

5. AVALIAÇÃO DO RISCO DA PESQUISA:

$\begin{array}{llll}\text { SEM RISCO } & x & \text { RISCO MÍNIMO } & \text { RISCO MÉDIO } \\ \text { RISCO BAIXO } & \square & \text { RISCO MAIOR } & \square\end{array}$


5- Desenho do estudo e objetivo (s) O Senhor (a) esta sendo convidado á participar voluntariamente de uma pesquisa que pretende avaliar como esta a sua qualidade de vida e como você realiza atividades do dia a dia. O nosso objetivo é identificar como as pessoas que tem esta doença fazem as coisas do dia a dia e se estão vivendo com qualidade. Também queremos verificar como está a pessoa que cuida diariamente de quem tem a doença.

6- $\quad$ Procedimentos do estudo: Esse termo fornecerá a você informações sobre sua participção no estudo. Por exemplo, quanto tempo ira durar a visita e os testes. Será solicitado que você leia e assine um termo de consentimento.

7- $\quad$ Relação dos procedimentos rotineiros e como são realizados $O$ senhor (a) irá responder diversas perguntas e realizar algumas tarefas muito parecidas com coisas do dia a dia (por exemplo fazer café, contar dinheiro, entre outras), com perguntas de como o senhor se sente ou com exercícios com lápis e papel como por exemplo desenhar um cubo.

8- Descrição dos desconfortos e riscos esperados Estes testes irão demorar algumas horas iremos fazer intervalo para que o senhor não se sinta cansado. Não existe risco esperado pois respondera apenas a perguntas e realizara atividades de dia a dia.

11. Beneficios para o participante Com os resultados dos testes poderemos conhecer melhor como a doença interfere no dia a dia de vocês e estas informações podem ser usadas por quem trata do senhor .

12. Relação de procedimentos alternativos que possam ver vantajosos, pelos quais o paciente pode optar; Você pode recusar participar do estudo ou pode interromper sua participação a qualquer momento, sem penalidade ou perda de benefícios aos quais você tem direito de outro modo.

13. Garantia de acesso: em qualquer etapa do estudo, você terá acesso aos profissionais responsáveis pela pesquisa para esclarecimento de eventuais dúvidas. $\mathrm{O}$ principal investigador é a Dra Tania Correa de Toledo Ferraz Alves que pode ser encontrado no endereço Rua Dr. Ovídio Pires de Campos, 785 - 3 andar - PROTER Instituto de Psiquiatria do HCFMUSP, Telefones (11) 2661-6973 e email:

proter.ipq@hc.fm.usp.br. Se você tiver alguma consideração ou dúvida sobre a ética da pesquisa, entre em contato com o Comitê de Ética em Pesquisa (CEP) - Rua Dr. Ovídio Pires de Campos, 225 - 5o andar - Tel: 11-2661-6442 ramais 16, 17, 18 e email: cappesg@hc.fm.usp.br.

14. E garantia a liberdade da retirada de consentimento a qualquer momento e deixar de participar do estudo, sem qualquer prejuízo à continuidade de seu tratamento na Instituição.

Sua participação neste estudo é completamente voluntária. Você pode recusar participar do estudo ou pode interromper sua participaçãoa qualquer momento, sem penalidade ou perda de benefícios aos quais você tem direito de outro modo.

15. Direito de confidencialidade- As informações obtidas serão analisadas em conjunto com outros pacientes, não sendo divulgado a identificação de nenhum paciente. O médico do estudo e a equipe irão tratar as informações que identificam você de uma forma confidencial. As normas brasileiras que protegem os seus direitos em acessar suas informações pessoais serãoseguidas. Se os dados do estudo forem publicados ou divididos com terceiros, como parte de discussões científicas, sua identidade permanecerá confidencial.

Você pode cancelar sua autorização a qualquer momento. Se você cancelar sua autorização, o médico do estudo e sua equipe não usarão ou divulgarão mais suas informações médicas

16. Despesas e compensações: Não há despesas pessoais para o participante. Também não há compensação financeira relacionada à sua participação. 
Acredito ter sido suficiente informado a respeito das informações que li ou que foram lidas para mim, descrevendo o estudo "Funcionalidade e Qualidade de Vida na Doença de Alzheimer l'".

Eu discuti com o a Dra Tania Correa de Toledo Ferraz Alves sobre a minha decisão em participar neste estudo. Ficaram claros para mim quais são os propósitos do estudo, os procedimentos a serem realizados, seus desconfortos e riscos, as garantias de confidencialidade e de esclarecimentos permanentes. Ficou claro também que minha participação é isenta de despesas e que tenho garantia do acesso a tratamento hospitalar quando necessário.

Concordo voluntariamente em participar deste estudo e poderei retirar o meu consentimento a qualquer momento, antes ou durante o mesmo, sem penalidades prejuízo ou perda de qualquer benefício que eu possa ter adquirido, ou meu atendimento neste serviço.

Assinatura do paciente

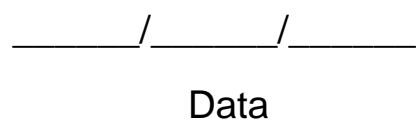

Assinatura do representante legal

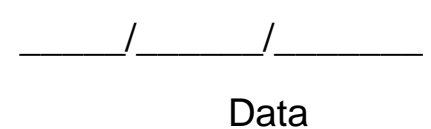

Para casos de pacientes analfabetos, semi-analfabetos ou portadores de deficiência auditiva ou visual.

Declaro que obtive de forma apropriada e voluntária o Consentimento Livre e Esclarecido deste paciente ou representante legal a participação neste estudo.

Pesquisador Principal

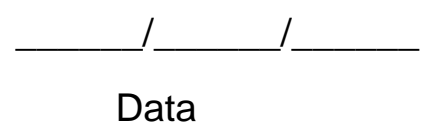




\section{Anexo C - APROVAÇÃO DA COMISSÃO DE ÉTICA}

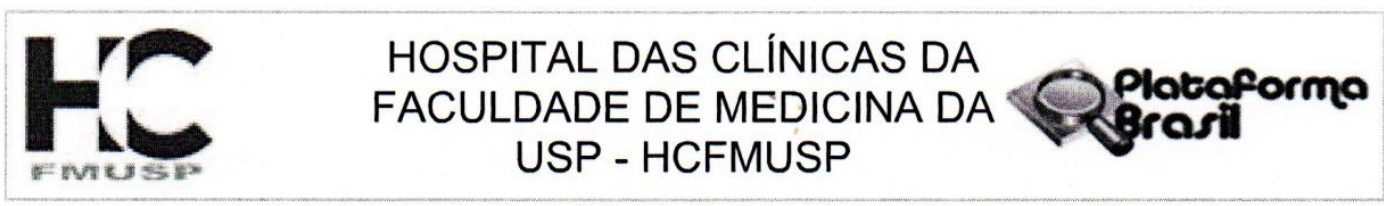

\section{PARECER CONSUBSTANCIADO DO CEP}

\section{DADOS DO PROJETO DE PESQUISA}

Título da Pesquisa: FUNCIONALIDADE E QUALIDADE DE VIDA NA DOENÇA DE ALZHEIMER

Pesquisador: Tania Correa de Toledo Ferraz Alves

Área Temática:

Versão: 2

CAAE: 25866714.3 .0000 .0068

Instituição Proponente: HOSPITAL DAS CLINICAS DA FACULDADE DE MEDICINA DA U S P

Patrocinador Principal: Financiamento Próprio

\section{DADOS DO PARECER}

Número do Parecer: 835.739

Data da Relatoria: 15/10/2014

\section{Apresentação do Projeto:}

Trata-se de projeto de pesquisa para tese de Doutorado de Patricia Cardoso Buchain Neubern sob orientação da Prof.(a). Dra. Tânia Corrêa de Toledo Ferraz Alves que tem como objetivo relacionar o desempenho funcional do indivíduo com as alterações cognitivas. $E$ de que forma estes fatores irão impactar na qualidade de vida do sujeito. Esse e um estudo controlado, que pretende comparar sujeitos portadores de DA e controles emparelhados para faixa etária e escolaridade do ponto de vista cognitivo e funcional. Após caracterização diagnóstica serão realizadas as avaliações neuropsicológica, funcional e de qualidade de vida. Pretende se também realizar dentro deste projeto a avaliação da validade e confiabilidade do Executive Function Performance Test (EFPT-Br) na amostra de idosos com DA. Este estudo foi aprovado em 05/02/2014 com PARECER CONSUBSTANCIADO DO CEP. Retorna com emenda para inclusão das escalas: Cumulative IIIness Rating Scale (CIRS), Escala de Atividades Instrumentais da Vida Diária de Lawton e Brody, Questionário de Atividades Funcionais de Pfeffer, Inventários de depressão e ansiedade de Beck, e Inventário de Sobrecarga do Cuidador (detalhados em anexo). A inclusão destas escalas permitirá maior detalhamento dos aspectos cognitivos e funcionais da amostra a ser coletada, e o tempo de aplicação será aumentado em vinte minutos. A inclusão destas escalas não modificará os parâmetros de risco, e não haverá necessidade de

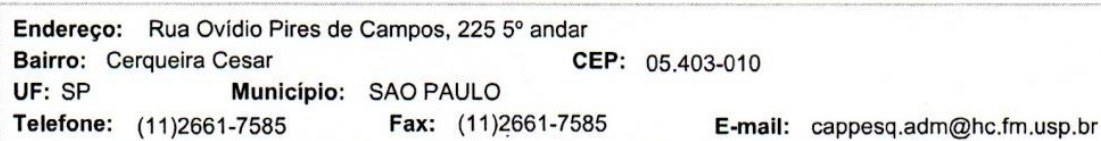




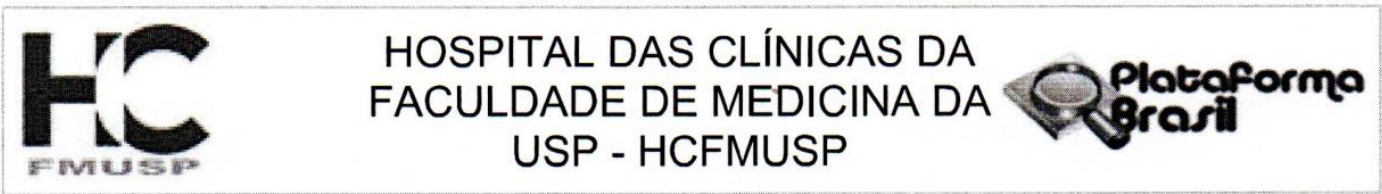

Continuação do Parecer: 835.739

\section{modificação no TCLE. CIRS}

(comorbidade clinica) (Miller, Paradis et al. 1992) Avalia a presença e a gravidade de comorbidades médicas em pacientes geriátricos. O médico utiliza o critério clínico para dar a cada sistema do corpo (renal, respiratório, vascular etc.) uma nota de gravidade de 0 a 4 pontos. Seu escore é a soma de todas as notas obtidas em cada sistema, sendo que, quanto maior for a nota, pior a condição de saúde. $O$ instrumento permite também quantificar o número de sistemas afetados. Escala De Atividades Instrumentais Da Vida Diária (Lawton e Brody, 1969). A escala tem como objetivo mensurar a incapacidade do idoso em relação as atividades independente de vida diária. O instrumento é composto por oito tarefas tais como: como usar telefone, fazer compras, preparação da alimentação, Arrumação da casa, lavagem da roupa, uso de transportes, preparar medicação e gerir o dinheiro. A pontuação máxima é de 16 pontos, sendo o maior numero representante de independência ou sutil dependência. Questionário de Atividades funcionais de Pfeffer (ÍNDICE DE PFEFFER) (Pfeffer et al. 1982) Esta escala é constituída por dez itens e evidencia a funcionalidade por meio do grau de independência para realização das atividades. $O$ escore mínimo é 0 e o máximo é 30 . Quanto maior a pontuação, maior é a dependência do paciente, sendo considerada a presença de prejuizo funcional a partir de um escore de 5 pontos. Inventário de Sobrecarga do Cuidador (Novak et al, 1989)- o instrumento é composto por 24 questões fechadas que medem o impacto da sobrecarga dos cuidadores, estando elas divididas em cinco domínios: tempo dependente, vida pessoal, físico, emocional e social. Cada domínio possui 5 questões com exceção do domínio de sobrecarga física ( 4 questões) e cada questão recebe uma pontuação de 0 ( discordo totalmente) a 4 (concordo totalmente) sendo que quanto maior o escore maior a sobrecarga do cuidador. Inventário de Depressão de Beck (BDI) (Beck et. al., 1961) trata-se de uma escala de auto-aplicativa com 21 questões de múltipla escolha que abrange componentes cognitivos, afetivos, comportamentais e somáticos da depressão. $O$ escore final é obtido pela somatória de todos os itens que compõe a escala. Inventório de Ansiedade de Beck (BAI),(Beck et al., 1961) trata-se de uma escala auto-aplicativa com 21 questões de múltipla escolha, utilizada para medir a gravidade os sintomas de ansiedade num período de tempo determinado (ultima semana), expressas em sintomas comuns de ansiedade (como sudorese e sentimentos de angustia.

\section{Objetivo da Pesquisa:}

1. Investigar a relação entre comprometimento das funções executivas, desempenho funcional e o impacto na qualidade de vida dos pacientes com DA. 2. Correlacionar rastreio cognitivo geral e

Endereço: Rua Ovídio Pires de Campos, $2255^{\circ}$ andar

Bairro: Cerqueira Cesar CEP: $05.403-010$

UF: SP Município: SAOPAULO

Telefone: (11)2661-7585 Fax: (11)2661-7585 E-mail: cappesq.adm@hc.fm.usp.br 


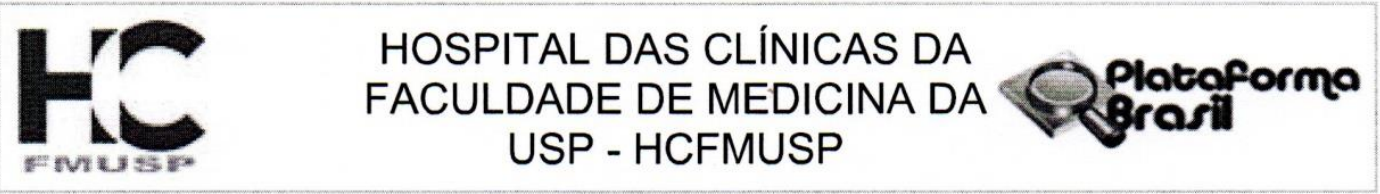

Continuação do Parecer: 835.739

especifico de função executiva com o status funcional de idosos com DA. 3. Correlacionar o status funcional com medidas de qualidade de vida de idosos com DA. 4. Caracterizar o perfil de funcionalidade de idosos com DA.

Avaliação dos Riscos e Benefícios:

já relatado

Comentários e Considerações sobre a Pesquisa:

já relatado

Considerações sobre os Termos de apresentação obrigatória:

ja relatado

Recomendações:

já relatado

Conclusões ou Pendências e Lista de Inadequações:

A emenda solicitada está adequadamente formulada e fundamentada, não apresentando pendencias ética, portanto sugiro aprovação.

Situação do Parecer:

Aprovado

Necessita Apreciação da CONEP:

Não

Considerações Finais a critério do CEP:

SAO PAULO, 17 de Outubro de 2014

Assinado por:

ALFREDO JOSE MANSUR

(Coordenador)

Endereço: Rua Ovídio Pires de Campos, $2255^{\circ}$ andar

Bairro: Cerqueira Cesar

CEP: $\quad 05.403-010$

UF: SP Município: SAO PAULO

Telefone: (11)2661-7585 Fax: (11)2661-7585

E-mail: cappesq.adm@hc.fm.usp.br 


\section{Hospital das Clínicas da FMUSP}

Comissão de Ética para Análise de Projetos de Pesquisa - CAPPesq

\section{PROJETO DE PESQUISA}

Título: FUNCIONALIDADE E QUALIDADE DE VIDA NA DOENÇA DE ALZHEIMER

Pesquisador Responsável: Tania Corrêa de Toledo Ferraz Versão: 1

Alves

Pesquisador Executante: Patricia Cardoso Buchain Neubern CAAE: 25866714.3.0000.0068

Co-autores:

Finalidade Acadêmica Doutorado

Orientador: Tania Corrêa de Toledo Ferraz Alves

Instituição: HCFMUSP

Departamento: PSIQUIATRIA

\section{PARECER CONSUBSTANCIADO DO CEP}

Registro on-line: 11756

Número do Parecer: 1.214 .387

Data da Relatoria: 02/09/2015

Apresentação do Projeto: Justificativa da Emenda: Solicitação de análise a aprovação de um Subprojeto intitulado "A percepção do informante frente a funcionalidade do idoso com Doença de Alzheimer em fase inicial" para dissertação de mestrado de Janaina Harder sob orientação da Prof.(a). Dra. Tânia Corrêa de Toledo Ferraz Alves.

Objetivo da Pesquisa: Inclusão de Sub projeto "A percepção do informante frente a funcionalidade do idoso com Doença de Alzheimer em fase inicial" Este estudo tem como objetivo comparar a avaliação da funcionalidade objetiva realizada com o idoso com a avaliação da funcionalidade subjetiva realizada com o informante, além de investigar as características do informante que podem interferir na capacidade de avaliação do idoso $A$ importância de novas pesquisas que aprofundem no esclarecimento da possível distorção desta percepção dos informantes pode ser útil para a compreensão dos melhores instrumentos a serem utilizados com o objetivo de um diagnóstico mais precoce e fidedigno assim como nas elaborações de orientações e esclarecimentos a estes informantes a cerca dos conhecimentos e tratamentos da Doença de Alzheimer em fase inicial.

Avaliação dos Riscos e Benefícios: Por se tratar de um estudo observacional, e não envolver nenhum procedimento invasivo ou exame complementar, não haverá risco significativo de natureza psíquica ou física para os participantes.

Comentários e Considerações sobre a Pesquisa: Sem comentários.

Considerações sobre os Termos de apresentação obrigatória: Adequados.

Recomendações: Sem recomendações.

Conclusões ou Pendências e Lista de Inadequações: Sugiro aprovação da emenda.

Situação do Parecer: Aprovado.

Necessita Apreciação da CONEP: Não.

São Paulo, 02 de Setembro de 2015

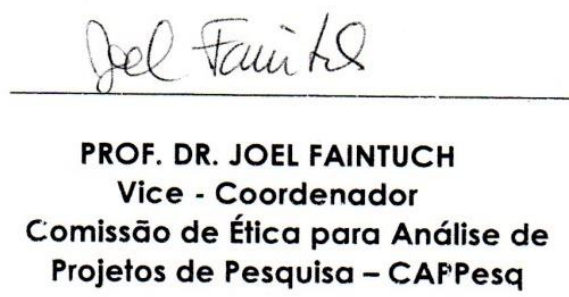

Rua Dr. Ovídio Pires de Campos, 225 - Prédio da Administração - 5o andar CEP 05403-010 - São Paulo - SP.

5511 2661-7585 - 5511 2661-6442 ramais: 16, 17, 18 | cappesq.adm@hc.fm.usp.br 


\section{Anexo D- DAFS-BR - Direct Assessment of Functional Status-Revised}

Data: Examinador:

Uso de cheque: $\quad$ ( ) Sim ( ) Não

Instruções: "Eu vou lhe pedir para fazer algumas coisas com as quais você já deve estar familiarizado. Você pode achar algumas tarefas mais difíceis que outras. mas tudo bem. Tente fazer o melhor que puder".

\section{ORIENTAÇÃO TEMPORAL (16 pontos)}

A. Dizer a hora (8 pontos): (Utilize um modelo de relógio com mostrador grande).

Instruções: "Me diga que horas são". O examinador não pode dizer ao paciente se ele está certo. deve continuar e apresentar o próximo horário.

$\begin{array}{cc}\text { Correto } & \text { Incorreto } \\ \text { (2 pontos) } & \text { (0 ponto) }\end{array}$

3:00

8:00

10:30

12:15

B. Orientacão para a data (8 pontos):

Instruções: As perguntas devem ser feitas ao paciente na ordem:

$$
\begin{array}{cc}
\text { Correto } & \text { Incorreto } \\
\text { ( } 2 \text { pontos }) & \text { (0 ponto })
\end{array}
$$

Qual é o dia do mês?

Qual dia da semana é hoje?

Em que mês estamos?

Em que ano estamos?

\section{COMUNICAÇÃO (15 pontos)}

(Utilize um telefone de teclas) (Se durante a tarefa. o paciente disca. atende ou desliga 0 telefone. é dado crédito pelos itens conforme descrito abaixo) .Instruções: " Mostre como você ligaria para sua casa".
A. Usar o telefone (9 pontos): 


$$
\begin{array}{cc}
\text { Correto } & \text { Incorreto } \\
\text { (1 ponto) } & \text { (0 pontos) }
\end{array}
$$

Ligar para a própria residência

Instruções: Se o paciente começa discar sem tirar o telefone do gancho. o examinador deve reorientar o paciente informando. "Quero que você faça tudo o que é necessário para ligar para sua própria casa".

Instruções:“ Quero que disque para o número de João Faria.” (Escrito na agenda).

" Gostaria que você discasse para o número 596-6996." (Apresentação oral) “ Por favor. disque este número para mim." (Estímulo escrito).

$\begin{array}{cc}\text { Correto } & \text { Incorreto } \\ \text { (1 ponto) } & \text { (0 ponto) }\end{array}$

Discar um número da agenda telefônica

(João Faria/324-5612)

Discar o número apresentado oralmente (596-6996)

Discar o número escrito (235-2762)

Procurar um número de telefone na agenda

Pegar o fone do gancho

Habilidade para discar

Desligar o telefone

Sequência correta das provas anteriores

\section{B. Preparar uma carta para postar (6 pontos):}

Instruções: "Agora nós vamos testar sua habilidade para enviar uma carta". Neste momento o examinador apresenta uma folha de papel de carta 8.5" X 11" e diz: "Imagine que esta folha de papel é uma carta e você vai enviá-la para Jorge Silveira". "Eu quero que você faça tudo que é necessário para preparar esta carta para que possamos colocá-la no correio". Cada uma das tarefas seguintes é pontuada individualmente ( 1 quando correto e 0 quando incorreto.)

$$
\begin{array}{cc}
\text { Correto } & \text { Incorreto } \\
\text { (1 ponto) } & \text { (0 ponto) }
\end{array}
$$

Dobrar ao meio ou em 3 partes

Colocar em um envelope

Colar o envelope

Colar o selo no envelope

Escrever o endereço com CEP* 
Escrever o endereço do remetente

*(deve ser idêntico ao endereço apresentado pelo examinador)

Instruções: Se o paciente pára no meio da tarefa. lembre-o: "Existe mais alguma coisa que você deve fazer antes de colocar esta carta no correio?" Se o paciente completa com sucesso todos componentes da tarefa. mas não coloca a carta no envelope. ou não a fecha. 0 examinador deve mais uma vez lembrar: "Existe mais alguma coisa que você deve fazer para colocar esta carta no correio?"

*** Neste momento o examinador deve dizer ao paciente que ele/ela irá a um supermercado em 10 minutos e que ele deverá apanhar 6 produtos que ele/ela tenha memorizado previamente de uma lista. Cada um desses itens é dito ao paciente. em intervalos de 3 segundos. Cada produto desta lista é repetido pelo paciente e após 3 segundos é dito o item seguinte. Os itens são os seguintes: 1) Café 2) Gelatina 3) Fermento 4) Atum 5) Chocolate 6) Suco de laranja.

Então deve ser dito ao paciente "Por favor. memorize estes itens para que você possa lembrar deles mais tarde". O examinador deve se preparar para retomar a tarefa em 10 minutos.

\section{HABILIDADE PARA LIDAR COM DINHEIRO (32 pontos)}

Instruções: Apresente da sua direita para a esquerda. uma nota de dez reais. três notas de um real. uma nota de cinco reais. 3 moedas de 25 centavos. duas moedas de 10 centavos. uma moeda de 5 centavos e três moedas de um centavo.Avalia-se a habilidade de calcular troco referente à compra dos itens de supermercado. Deve ser dito ao paciente: "Mostre-me uma moeda de 1 centavo. uma de 5 centavos. uma de 10 centavos. uma nota de 1 real. uma nota de 5 reais e uma nota de 10 reais". Se correto pontue 1 ; incorreto $=0$.

\section{A. Identificar a moeda corrente (7 pontos)}

$\begin{array}{cc}\text { Correto } & \text { Incorreto } \\ \text { (1 ponto) } & \text { (0 ponto) }\end{array}$

Identificar moeda de 1 centavo

Identificar moeda de 5 centavos

Identificar moeda de 10 centavos

Identificar moeda de 25 centavos

Identificar cédula de 1 real

Identificar cédula de 5 reais

Identificar cédula de 10 reais

\section{B. Contar moeda corrente (4 pontos)}

Instruções: "Mostre

em moedas"

Pontua-se 1 se correto e 0 se incorreto.

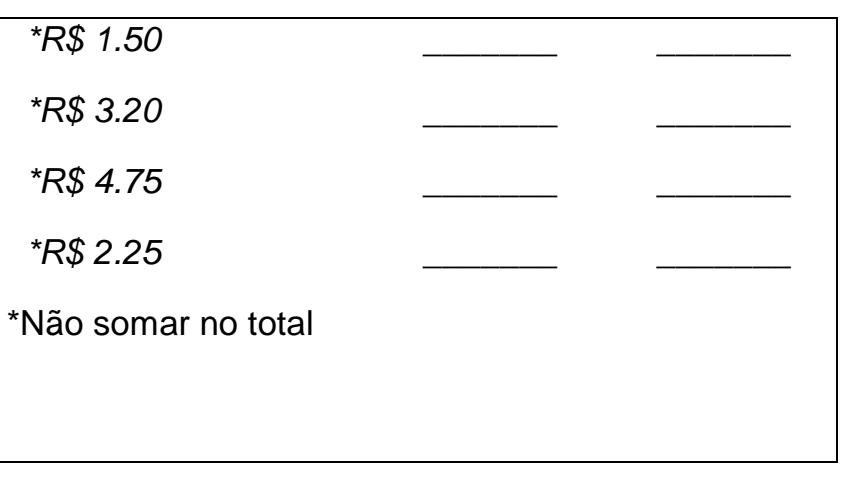




\section{Correto Incorreto \\ (1 ponto) (Oponto)}

6 centavos

$\mathrm{R} \$ 1.02$

$\mathrm{R} \$ 6.73$

$\mathrm{R} \$ 12.17$

C. Troco Correto (8 pontos) Somente o primeiro item contribui para a pontuação total das habilidades de contar dinheiro; entretanto. uma pontuação opcional pode ser calculada usando 4 itens.

Instruções: "Imagine que você vai pagar um produto no supermercado e o caixa diz que a conta é $\boldsymbol{R} \$ \mathbf{2 . 4 9}$. (Você pagou com uma nota de 5 reais). Calcule e mostre quanto é $o$ troco".Repita as instruções para os outros 3 valores.

$\begin{array}{cc}\text { Correto } & \text { Incorreto } \\ \text { (2 pontos) } & \text { (0 ponto) }\end{array}$

$\mathrm{R} \$ 2.49(\mathrm{R} \$ 2.51)$

$\mathrm{R} \$ 1.68(\mathrm{R} \$ 3.32)$

$\mathrm{R} \$ 3.22(\mathrm{R} \$ 1.78)$

$\mathrm{R} \$ 3.83(\mathrm{R} \$ 1.17)$

D. Preencher um cheque (5 pontos):

Instruções: $O$ examinador dá ao paciente um cheque em branco e solicita "Eu gostaria que você preenchesse um cheque nominal a você mesmo no valor de $R \$ 400.00$ ". Pede-se ao paciente que assine o cheque. escreva o valor por extenso. o valor numérico. que seja nominal a ele mesmo e a data. A data não precisa estar correta pois esse quesito já foi avaliado na escala orientação. Entretanto. a data deve ser colocada no local correto para ser pontuada. Cada item abaixo é pontuado separadamente.

$$
\begin{array}{cc}
\text { Correto } & \text { Incorreto } \\
\text { (1 pontos) } & \text { (0 ponto) }
\end{array}
$$

Assinatura

Pagar em ordem à

Escrever o valor por extenso

Escrever o valor numérico

\section{E. Calcular o saldo da conta (8 pontos)}

Instruções: $O$ examinador dá ao paciente o canhoto de um cheque. Então pede que 0 paciente calcule o saldo dos gastos em diferentes níveis de dificuldade. É dito ao paciente: "Você vai calcular o saldo dos gastos no canhoto do talão de cheques" "Você pode fazer as contas em um rascunho.mas os valores corretos devem ser preenchidos nos locais apropriados do canhoto". O examinador deve dobrar o papel e mostrar um problema de cada vez. Pontua-se 2 se correto e 0 se incorreto. Correções feitas pelo próprio paciente são permitidas. Anote no protocolo a reposta final. 


$\begin{array}{llll} & \begin{array}{c}\text { Correto } \\ (2 \text { pontos })\end{array} & \begin{array}{l}\text { Incorreto } \\ \text { (0 ponto) }\end{array} \\ \text { Valor } A(R \$ 500.00-R \$ 350.00) & \text { Correto }=R \$ 150.00 & - & - \\ \text { Valor } B(R \$ 323.00-R \$ 23.50) & \text { Correto }=R \$ 299.50 & - & - \\ \text { Valor } \mathbf{C}(R \$ 21.75-R \$ 3.92) & \text { Correto }=R \$ 17.83 & - & - \\ \text { Valor } D(R \$ 673.16-R \$ 79.23) & \text { Correto }=R \$ 593.93 & -\end{array}$

IV. HABILIDADE PARA FAZER COMPRAS (20 pontos):

Instruções: É solicitado ao paciente que lembre dos 6 itens que ele/ela repetiu antes do teste "habilidades para usar dinheiro". Pontua-se 2 correto se correto e 0 se incorreto.

Permitir 60 segundos para evocação.

A. Memória para 6 itens de supermercado (12 pontos)

B. Selecionar itens de supermercado de uma lista escrita (8 pontos):

Instruções: Cada item é selecionado do supermercado entre 21 produtos. Cada produto selecionado corretamente é marcado 2 pontos.

$\begin{array}{cc}\text { Correto } & \text { Incorreto } \\ \text { (2 pontos) } & \text { (0 ponto) }\end{array}$

Leite

Ovos

Detergente

Bolacha

V. VESTIR-SE/HIGIENE PESSOAL (13 pontos):

\section{A. Escovar os dentes}

Identificar e pegar a escova de dente

Tirar a tampa do tubo da pasta de dente

Colocar pasta de dente na escova

Demonstrar como escova os dentes

$\begin{array}{ccc}\text { Espontâneo } & \begin{array}{c}\text { Reconhe } \\ \text { cimento }\end{array} & \text { Total } \\ \text { (1 ponto }) & \text { (1 ponto) }\end{array}$

Café

Gelatina

Fermento

Atum

Chocolate

Suco de laranja $\begin{array}{cc}\text { Correto } & \text { Incorreto } \\ \text { (1 pontos) } & \text { (0 ponto) }\end{array}$

(1 pontos) (n ponto)

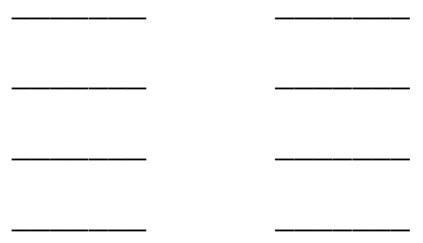


B. Lavar as mãos

Correto Incorreto

(1 pontos) (0 ponto)

Abrir a torneira

Usar o sabonete

Lavar as mãos

Fechar a torneira

C. Vestir-se

Correto Incorreto

(1 pontos) (0 ponto)

Vestir o casaco

Abotoar o casaco

Fechar o zíper

Amarrar os sapatos

Escovar o cabelo

VI. ALIMENTAR-SE (10 pontos)

Instruções: Colocar os utensílios de cozinha em frente ao paciente e pedir para que sente à mesa.

$\begin{array}{cc}\text { Correto } & \text { Incorreto } \\ \text { (2 pontos) } & \text { (0 ponto) }\end{array}$

Usar o garfo

Usar a faca

Usar a colher

Servir água

Beber água no copo

\section{RESULTADOS}

\begin{tabular}{|l|l|}
\hline I -Orientação Temporal & \\
\hline II- Comunicação & \\
\hline III- Habilidade para lidar com dinheiro & \\
\hline IV- Habilidade para fazer compras & \\
\hline V-Vestir-se / Higiene Pessoal & \\
\hline VI- Alimentar-se & \\
\hline ESCORE TOTAL & \\
\hline
\end{tabular}




\section{Anexo E- Escala de Lawton e Brody}

Esta entrevista tem como propósito identificar o nível de condição funcional da Sr./Sra.. por intermédio das possíveis dificuldades do seu dia-a-dia Procure recordar em cada atividade a ser questionada. se a Sr./Sra. faz sem ajuda, com algum auxílio ou não realiza de forma alguma.

a) Em relação ao Telefone:

()$^{3}$ Recebe e faz ligações sem assistência

()$^{2}$ Necessita de assistência para realizar ligações telefônicas

( ) Não tem hábito ou é incapaz de usar telefone

b) Em relação as viagens:

()$^{3}$ Realiza viagens sozinha

()$^{2}$ Somente viaja quando tem companhia

( ) Não tem o hábito ou é incapaz de viajar

c) Em relação a realização de compras:

()$^{3}$ Realiza compras. quando é fornecido o transporte

()$^{2}$ Somente faz compras quando tem companhia

( ) Não tem o hábito ou é incapaz de realizar compras

d) Em relação ao preparo de refeições:

( ( ) Planeja e cozinha as refeições completas

()$^{2}$ Prepara somente refeições pequenas ou quando recebe ajuda

( )' Não tem o hábito ou é incapaz de preparar refeições

e) Em relação ao trabalho doméstico:

()$^{3}$ Realiza tarefas pesadas

()$^{2}$ Realiza tarefa leves. necessitando de ajuda nas pesadas

( ) Não tem o hábito ou é incapaz de realizar trabalhos domésticos

f) Em relação ao uso de medicamentos:

( ) $)^{3}$ Faz uso de medicamentos sem assistência

()$^{2}$ Necessita de lembretes ou assistência

( ) ${ }^{1}$ É incapaz de controlar sozinho o uso de medicamentos

g) Em relação ao manuseio do dinheiro:

()$^{3}$ Preenche cheque e paga contas sem auxílio 
()$^{2}$ Necessita de assistência para o uso de cheques e contas

( ) ${ }^{1}$ Não tem o hábito de lidar com o dinheiro ou é incapaz de manusear dinheiro. contas...

Classificação:

( ) Dependência total $=<5$ (P25)

() Dependência parcial $=>5<21(>\mathrm{P} 25<\mathrm{P} 100)$

( ) Independência $=21$ (P100)

Ass:

Data:___ _ 


\section{Anexo F- Escala de Pfeffer (FAQ)}

\section{Questionário de Atividades Funcionais de Pfeffer ( FAQ )}

1) Ele (a) manuseia seu próprio dinheiro?

$0=$ Normal. ou nunca fez mas poderia fazê-lo agora

1 = Faz com dificuldades, ou nunca o fez e agora teria dificuldades

2 = Necessita de ajuda

3 = Não é capaz

2) Ele (a) é capaz de comprar comidas. roupas. coisas para casa sozinho(a) ?

$0=$ Normal. ou nunca fez mas poderia fazê-lo agora

1 = Faz com dificuldades, ou nunca o fez e agora teria dificuldades

2 = Necessita de ajuda

3 = Não é capaz

3) Ele (a) é capaz de esquentar a água para o café e apagar o fogo?

$0=$ Normal. ou nunca fez mas poderia fazê-lo agora

1 = Faz com dificuldades, ou nunca o fez e agora teria dificuldades

2 = Necessita de ajuda

3 = Não é capaz

4) Ele (a) é capaz de preparar uma comida?

$0=$ Normal. ou nunca fez mas poderia fazê-lo agora

1 = Faz com dificuldades, ou nunca o fez e agora teria dificuldades

2 = Necessita de ajuda

3 = Não é capaz

5) Ele (a) é capaz de manter-se em dia com as atualidades. com os acontecimentos. da comunidade?

$0=$ Normal. ou nunca fez mas poderia fazê-lo agora

1 = Faz com dificuldades, ou nunca o fez e agora teria dificuldades

2 = Necessita de ajuda

$3=$ Não é capaz

6) Ele (a) é capaz de prestar atenção. entender e discutir um programa de rádio. jornal ou televisão?

$0=$ Normal. ou nunca fez mas poderia fazê-lo agora

$1=$ Faz com dificuldades, ou nunca o fez e agora teria dificuldades

2 = Necessita de ajuda

3 = Não é capaz

7) Ele (a) é capaz de lembrar-se de compromissos. acontecimentos familiares. feriados?

$0=$ Normal. ou nunca fez mas poderia fazê-lo agora

1 = Faz com dificuldades, ou nunca o fez e agora teria dificuldades

2 = Necessita de ajuda

3 = Não é capaz 
8) Ele (a) é capaz de manusear seus próprios remédios?

$0=$ Normal. ou nunca fez mas poderia fazê-lo agora

1 = Faz com dificuldades, ou nunca o fez e agora teria dificuldades

2 = Necessita de ajuda

3 = Não é capaz

9) Ele (a) é capaz de passear pela vizinhança e encontrar o caminho de volta para casa? $0=$ Normal. ou nunca fez mas poderia fazê-lo agora

1 = Faz com dificuldades, ou nunca o fez e agora teria dificuldades

2 = Necessita de ajuda

3 = Não é capaz

10) Ele (a) pode ser deixado (a) em casa sozinho (a) de forma segura?

$0=$ Normal. ou nunca fez mas poderia fazê-lo agora

$1=$ Sim, mas com preocupações. ou nunca ficou e agora teria dificuldades

$2=\operatorname{Sim}$, por períodos curtos

$3=$ Não poderia 


\section{Anexo G- Escala de B-ADL}

\section{Bayer Activitiesof Daily Living Scale (B-ADL)}

Data:

Examinador:

As perguntas seguintes abordam atividades diárias que a pessoa poderia ter dificuldade. Estas perguntas devem ser respondidas por familiar/informante que conheça bem o sujeito. Por favor. indique o quão frequentemente estas dificuldades ocorrem. marcando os números apropriados. Quanto maior o número. mais dificuldade a pessoa tem para fazer a atividade em questão. Se a dificuldade nunca ocorre marque 1. Se ocorre sempre. marque 10.

\begin{tabular}{|c|c|c|c|c|}
\hline A pessoa tem dificuldade & Pontuação & Não se & Não & Escore \\
\hline $\begin{array}{l}\text { 1.fazer suas atividades } \\
\text { diárias }\end{array}$ & $\begin{array}{lllllllllll}\begin{array}{l}\text { Nunca } \\
\text { sempre }\end{array} & 1 & 2 & 3 & 4 & 5 & 6 & 7 & 8 & 9 & 10 \\
\end{array}$ & & & \\
\hline 2. cuidar de si próprio & $\begin{array}{lllllllllll}\begin{array}{l}\text { Nunca } \\
\text { sempre }\end{array} & 1 & 2 & 3 & 4 & 5 & 6 & 7 & 8 & 9 & 10 \\
\end{array}$ & & & \\
\hline $\begin{array}{l}\text { 3. tomar remédio sem } \\
\text { supervisão }\end{array}$ & $\begin{array}{lllllllllll}\begin{array}{l}\text { Nunca } \\
\text { sempre }\end{array} & 1 & 2 & 3 & 4 & 5 & 6 & 7 & 8 & 9 & 10 \\
\end{array}$ & & & \\
\hline $\begin{array}{l}\text { 4. cuidar de sua higiene } \\
\text { pessoal }\end{array}$ & $\begin{array}{lllllllllll}\begin{array}{l}\text { Nunca } \\
\text { sempre }\end{array} & 1 & 2 & 3 & 4 & 5 & 6 & 7 & 8 & 9 & 10 \\
\end{array}$ & & & \\
\hline $\begin{array}{l}\text { 5. lembrar de datas } \\
\text { acontecimentos } \\
\text { e compromissos } \\
\text { importantes }\end{array}$ & $\begin{array}{lllllllllll}\begin{array}{l}\text { Nunca } \\
\text { sempre }\end{array} & 1 & 2 & 3 & 4 & 5 & 6 & 7 & 8 & 9 & 10 \\
\end{array}$ & & & \\
\hline 6. concentra-se na leitura & $\begin{array}{lllllllllll}\begin{array}{l}\text { Nunca } \\
\text { sempre }\end{array} & 1 & 2 & 3 & 4 & 5 & 6 & 7 & 8 & 9 & 10 \\
\end{array}$ & & & \\
\hline $\begin{array}{l}\text { 7. descrever o que ela } \\
\text { acabou de ver ou ouvir }\end{array}$ & $\begin{array}{lllllllllll}\begin{array}{l}\text { Nunca } \\
\text { sempre }\end{array} & 1 & 2 & 3 & 4 & 5 & 6 & 7 & 8 & 9 & 10 \\
\end{array}$ & & & \\
\hline $\begin{array}{l}\text { 8. participar de uma } \\
\text { conversa }\end{array}$ & $\begin{array}{lllllllllll}\begin{array}{l}\text { Nunca } \\
\text { sempre }\end{array} & 1 & 2 & 3 & 4 & 5 & 6 & 7 & 8 & 9 & 10 \\
\end{array}$ & & & \\
\hline 9. usar o telefone & $\begin{array}{lllllllllll}\begin{array}{l}\text { Nunca } \\
\text { sempre }\end{array} & 1 & 2 & 3 & 4 & 5 & 6 & 7 & 8 & 9 & 10 \\
\end{array}$ & & & \\
\hline $\begin{array}{l}\text { 10. dar um recado a outra } \\
\text { pessoa }\end{array}$ & $\begin{array}{lllllllllll}\begin{array}{l}\text { Nunca } \\
\text { sempre }\end{array} & 1 & 2 & 3 & 4 & 5 & 6 & 7 & 8 & 9 & 10 \\
\end{array}$ & & & \\
\hline $\begin{array}{l}\text { 11. sair para uma caminhada } \\
\text { sem se perder }\end{array}$ & $\begin{array}{lllllllllll}\begin{array}{l}\text { Nunca } \\
\text { sempre }\end{array} & 1 & 2 & 3 & 4 & 5 & 6 & 7 & 8 & 9 & 10 \\
\end{array}$ & & & \\
\hline 12. fazer compras & $\begin{array}{lllllllllll}\begin{array}{l}\text { Nunca } \\
\text { sempre }\end{array} & 1 & 2 & 3 & 4 & 5 & 6 & 7 & 8 & 9 & 10 \\
\end{array}$ & & & \\
\hline 13. preparar comida & $\begin{array}{lllllllllll}\begin{array}{l}\text { Nunca } \\
\text { sempre }\end{array} & 1 & 2 & 3 & 4 & 5 & 6 & 7 & 8 & 9 & 10 \\
\end{array}$ & & & \\
\hline
\end{tabular}




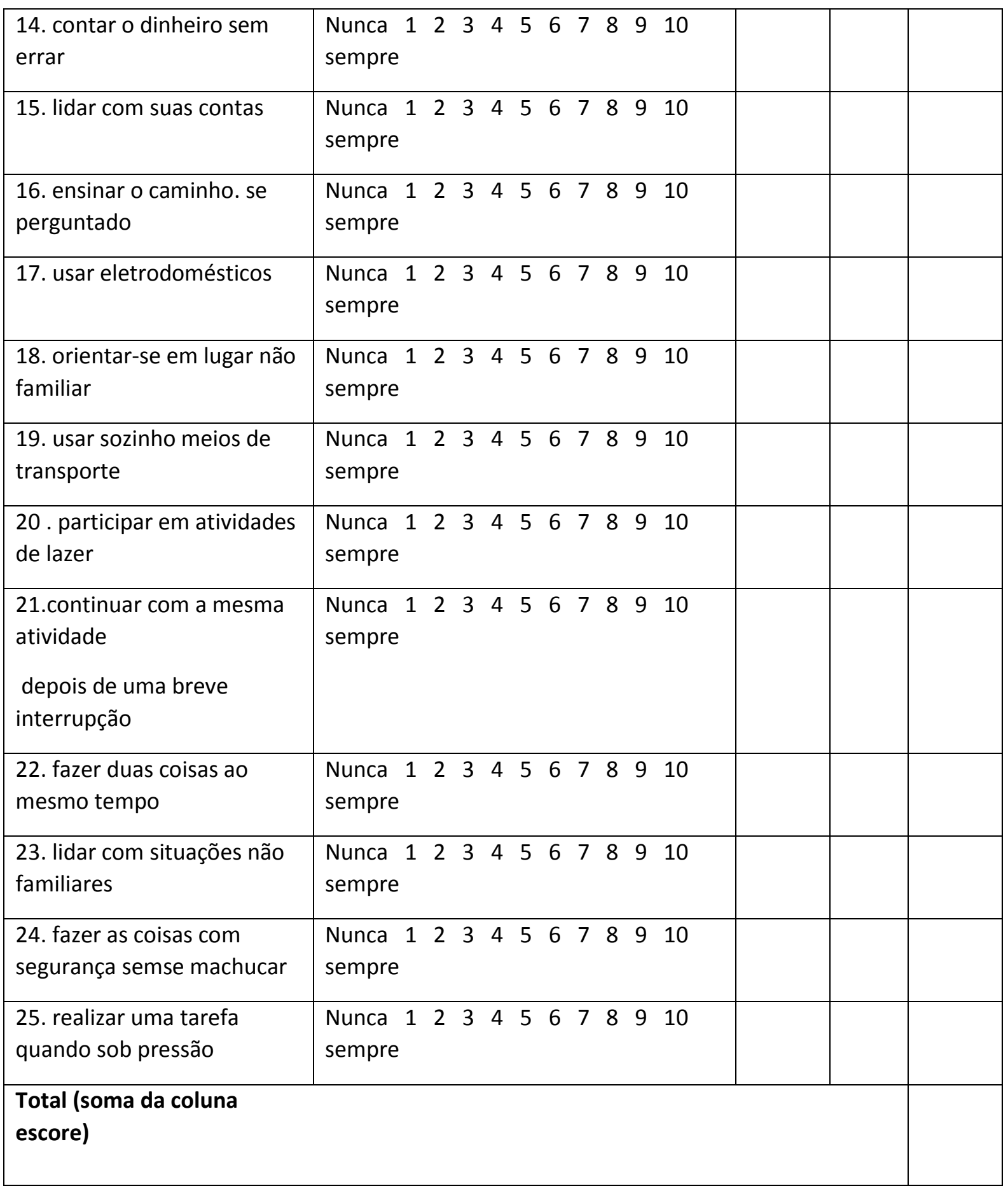

Escore ADL-IS =

$\underline{\text { Total }}$

Número de itens respondidos: 


\section{Anexo H - Escala de IQCODE}

\section{Informant Questionnaire on Cognitive Decline in the Elderly- IQCODE}

Data:

Examinador:

Nós queremos que você se lembre como o seu familiar estava há 10 anos atrás. e compare com o estado em que ele(a) está agora. As questões abaixo são situações nas quais esta pessoa usa sua memória. ou inteligência e nós queremos que você indique se estas situações melhoraram. pioraram ou se permaneceram do mesmo jeito. nos últimos dez anos. Por exemplo. se há 10 anos atrás esta pessoa sempre se esquecia onde guardava suas coisas. e ainda se esquece. isto seria considerado como "não muito alterado".

Marque com um " $x$ " na resposta apropriada. Se a pessoa nunca fez determinada função ou tarefa. marque "não se aplica". Se o familiar não tem certeza ou desconhece alguma informação. marque "não sabe".

\begin{tabular}{|c|c|c|c|c|c|c|c|}
\hline $\begin{array}{l}\text { Comparada há } 10 \text { anos } \\
\text { atrás. como essa pessoa } \\
\text { está em: }\end{array}$ & $\begin{array}{l}\text { Muito } \\
\text { melhor }\end{array}$ & Melhor & $\begin{array}{c}\text { Não } \\
\text { muito } \\
\text { alterado }\end{array}$ & Pior & $\begin{array}{l}\text { Muito } \\
\text { pior }\end{array}$ & $\begin{array}{l}\text { Não } \\
\text { se } \\
\text { aplica }\end{array}$ & $\begin{array}{l}\text { Não } \\
\text { sabe }\end{array}$ \\
\hline 1. Reconhecer familiares e amigo & & & & & & & \\
\hline 2. Lembrar-se do nome dos famili & & & & & & & \\
\hline $\begin{array}{l}\text { 3. Lembrar-se de coisas sobre os } \\
\text { Familiares }\end{array}$ & & & & & & & \\
\hline $\begin{array}{l}\text { 4. Lembrar-se de coisas que } \\
\text { aconteceram há pouco tempo }\end{array}$ & & & & & & & \\
\hline $\begin{array}{l}\text { 5. Lembrar-se de conversas dos } \\
\text { últimos dias }\end{array}$ & & & & & & & \\
\hline $\begin{array}{l}\text { 6. Esquecer o que ele(a) queria di } \\
\text { no meio da conversa }\end{array}$ & & & & & & & \\
\hline $\begin{array}{l}\text { 7. Lembrar-se do seu endereço e } \\
\text { Telefone }\end{array}$ & & & & & & & \\
\hline $\begin{array}{l}\text { 8. Lembrar-se em que dia e mês } \\
\text { Estamos }\end{array}$ & & & & & & & \\
\hline $\begin{array}{l}\text { 9. Lembrar onde as coisas são } \\
\text { guardadas usualmente (ex. rou } \\
\text { talheres. etc) }\end{array}$ & & & & & & & \\
\hline $\begin{array}{l}\text { 10. Lembrar onde achar coisas qu } \\
\text { foram guardadas em lugar difer } \\
\text { do de que de costume (ex. ócu } \\
\text { dinheiro. chaves) }\end{array}$ & & & & & & & \\
\hline $\begin{array}{l}\text { 11. Adaptar-se a mudanças em su } \\
\text { rotina diária }\end{array}$ & & & & & & & \\
\hline $\begin{array}{l}\text { 12.Saber usar aparelhos doméstic } \\
\text { que já conhece }\end{array}$ & & & & & & & \\
\hline $\begin{array}{l}\text { 13. Aprender a usar um aparelho } \\
\text { doméstico novo }\end{array}$ & & & & & & & \\
\hline
\end{tabular}




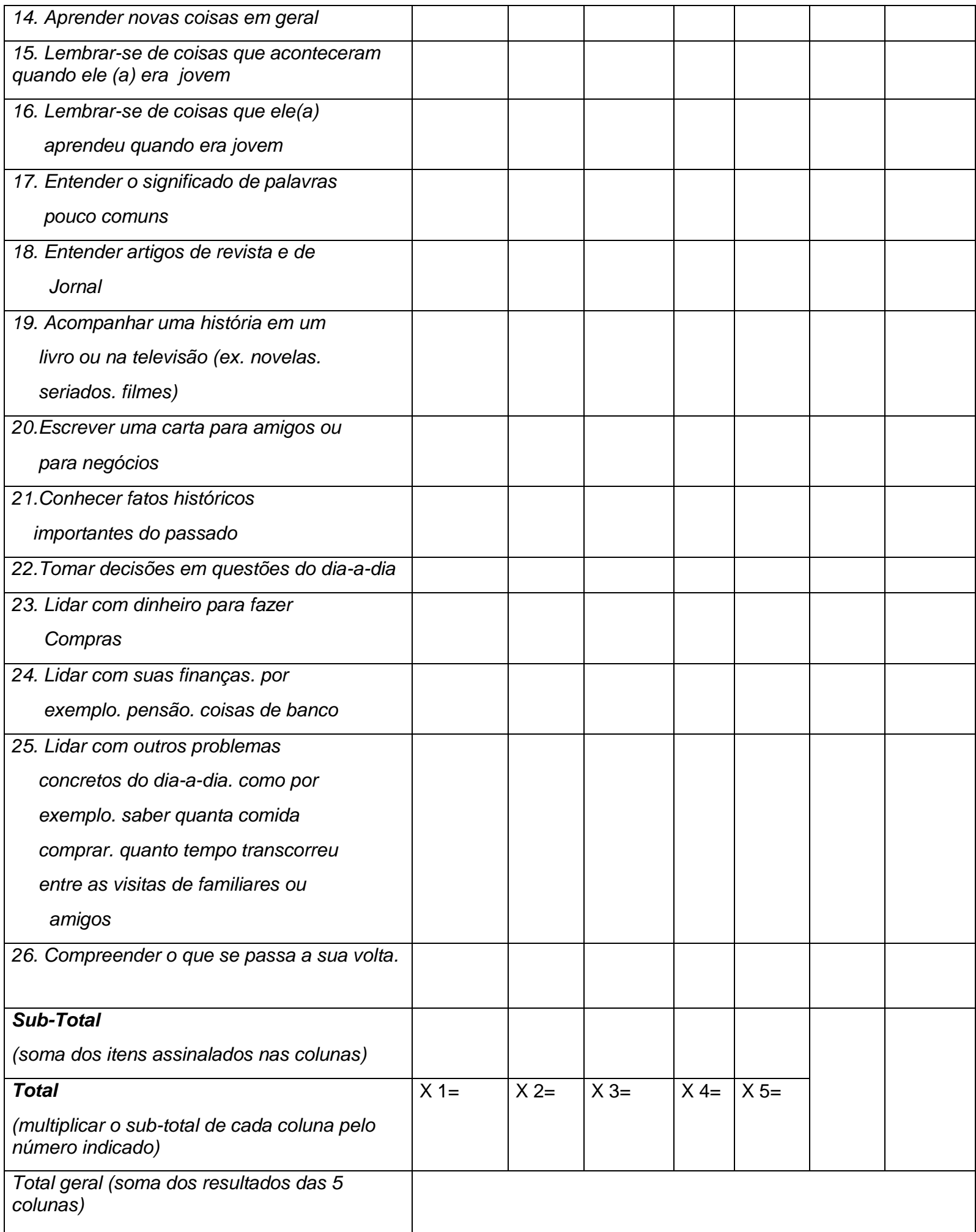

OBS: Nas colunas Não se aplica ou Não sabe. o sub-total não deve ser multiplicado por nenhum valor e. portanto. é igual ao total. Faça os cálculos com calma. depois de ter terminado a entrevista.

O cálculo do Escore final do IQCODE deve ser feito dividindo o total geral pelo número de perguntas respondidas (excluindo-se as questões assinaladas como Não se aplica ou Não sabe):

\section{Escore IQCODE $=\quad$ Total geral ESCORE FINAL IQCODE}

Número de itens respondidos 
Anexo I - ARTIGO SUBMETIDO - Influence of emotional aspects in informant's perception of the functionality of the elderly individual with Alzheimer's Disease

Running title: Informant perception of functionality in AD Janaina Harder ${ }^{1}$; Patricia Neubern Buchain ${ }^{1,2}$; Adriana Dias Barbosa Vizzotto ${ }^{2}$, MsC; Patricia Cotting Homem de Melo ${ }^{1,2}$; Alexandra Martini de Oliveira ${ }^{2}, \mathrm{MsC}$; Tania Correa de Toledo Ferraz Alves ${ }^{1}, \mathrm{MD}, \mathrm{PhD}$

${ }^{1}$ Old Age Research ( Proter) Departament and Institute of Psychiatry, Faculty of Medici, University of São Paulo, São Paulo, Brazil

${ }^{2}$ Occupacional Therapy Service, Institute of Psychiatry, Faculty of Medici, University of São Paulo, 05403-010 São Paulo, Brazil

Corresponding author: Tania Correa de Toledo Ferraz Alves

Address: R. Dr Ovidio Pires de Campos 785, $3^{\text {rd }}$ floor

Tel (+5511) 26616973

Email Tania.ctfalves@hc.fm.usp.br 


\section{Abstract}

Functional impairment is an important aspect for early diagnosis of dementia, but it might be compromised by emotional factors of the informant. Objective: We aimed to compare the direct functional assessment with the indirect evaluation and to investigate whether caregiver/informant burden, anxiety and depression might interfere in this process. Method: This is a crosssectional study of activities of daily living of 40 Alzheimer's disease (AD) patients compared to a matched 41 elderly controls. We assessed functionality by both, direct evaluations by a health professional and indirect instruments that were answered by the informant. We investigated the presence of depressive, anxiety and burden symptoms in the informant. Statistical analysis was performed based on single-factor analysis of variance (ANOVA) with multiple comparisons (Bonferroni test). For correlational analysis we used Pearson's correlation coefficient. Results: we observed between-groups significant differences in relation to the caregiver's burden $(p<0.001)$, however no other finding was observed related to depression, anxiety and cognition. In the analysis of correlations between emotional aspects and functionality evaluations we observed that in both controls and mild AD groups, IQCODE was the indirect assessment that most closely approximated to the direct evaluation and was less influenced by emotional symptoms. Conclusion: The presence of emotional symptoms influences the indirect evaluation of mild conditions of cognitive decline, in which case direct evaluation is preferable. In moderate cases, indirect evaluation is less influenced by caregiver burden because the impairment is more evident.

Key words: Alzheimer disease, functionality, occupational therapy, instrumental activities of daily living, burden, caregiver, diagnostic, dementia 


\section{Introduction}

For many elderly individuals, the maintenance of functional abilities is as important as the absence of disease itself (Who, 2015). Functionality exhibits impairment in mild cognitive decline and is accentuated in dementia. The impairment first affects the advanced activities of daily living (AADL) progresses to the instrumental activities of daily living (IADL) and finally affects the basic activities of daily living (BADL).(Cornelis et al., 2017). Cognitive rehabilitation is based on identifying the points of impairment and ability training involving different activities of daily living (ADL).

Recently international criteria such as National Institute of Neurological and Communicative Disorders and Stroke-Alzheimer's Disease and Related Disorders Association (NINCDS-ADRDA) (Mckhann et al., 1984)and Diagnostic and Statistical Manual of Mental Disorders 5th Edition (DSM-5)(Association, 2014) included functional assessment for $A D$ diagnosis. Usually this evaluation is performed indirectly with the informant (a family member in the household) using scales or questionnaires (Bravell et al., 2011; Lima-Silva et al., 2015; Mlinac e Feng, 2016). Also, ADL can be assessed directly by a mental health professional by observing the examinee in a therapeutic environment that closely resembles the elderly individual's daily life environment (Lawton e Brody, 1970; Pfeffer et al., 1982; Jorm e Jacomb, 1989; Pereira et al., 2010; Nagaratnam et al., 2013).

However, there is no consensus on whether indirect assessments, which rely on an informant's observation of impairments, can identify early impairment that usually is subtle (Burton et al. (2009). In addition, there may be distortions in the informant's interpretation of what is observed in the household. As indirect assessment is based on informant perceptions, factor such as uncertainty, anxiety, depression, intra-family conflicts, financial difficulties and other factors, can result in interpretation errors and may impact on the report of the functional performance of the elderly(Zanetti et al., 1999; Argüelles et al., 2001; Bressan et al., 2007). Nevertheless, direct evaluation is also problematic because it is time-consuming and requires a trained professional and can not be performed as a screening tool. Additionally, it also may be influenced by 
transient and occasional variables of the elderly at the time of assessment. Jefferson et al. (2008) note that although several studies recognize the existence of functional impairment, few studies have proposed an optimal method to identify early deficits in IADL. Thus, a better understanding of functionality and its evaluation can aid in early diagnosis and cognitivefunctional rehabilitation. This study aims to compare direct evaluation of functionality in the elderly with the indirect evaluation of functionality performed by the informant. In addition, we investigate whether emotional factors such as burden, anxiety and depression in the caregiver/informant can interfere in the ability to evaluate the elderly individual's functionality.

\section{Method}

We adopt a controlled cross-sectional approach to compare informants/caregivers of subjects with $A D$ and controls matched for age and functional perspective to investigate factors that might influence the evaluation of the elderly. This study was approved by the relevant research ethics committee. All subjects signed a free and informed consent form and voluntarily agreed to participate.

A total of 81 subjects and their respective caregivers/informants were evaluated. Of the 81 subjects, 40 had $A D$ (26 with mild $A D$ and 14 with moderate $A D$ ), and 41 were control subjects. All AD subjects were followed-up on by geriatric psychiatry services. The control subjects were healthy elderly individuals in the community or relatives or caregivers of the patients. The data were collected at the Institute of Psychiatry at the Clinics Hospital of the School of Medicine of São Paulo. 
As inclusion criteria, we selected elderly individuals over 60 years old with a diagnosis of mild or moderate $A D$ (for $A D$ groups) and the absence of dementia for the control group. The subjects of both groups had more than four years of schooling; absence of uncorrected and dysfunctional hearing or visual impairment; no history or clinical evidence of other neurological diseases (i.e., Parkinson's disease, epilepsy), stroke and/or serious systemic or cerebral diseases (infections, neoplasms, liver, kidney or metabolic diseases); and no history or clinical evidence of another psychiatric illness other than AD-comorbid depression (i.e., alcohol or drug dependence, schizophrenia, bipolar affective disorder).

The subjects were evaluated by a multi-professional team that included a psychiatrist and an occupational therapist and whose objective was the diagnostic confirmation of $A D$ and the direct and indirect evaluation of functionality. All evaluations were performed within a maximum of one week to avoid possible changes in the behavior and functionality of the elderly subjects. All clinical professionals involved in the survey received previous training in the application of the full protocol. The demographic evaluation was performed using data collected through an identification form developed for this study. The cognitive and functional evaluation of the elderly subjects involved the application of the Cambridge Cognition Test (CAMCOG), the Mini-Mental State Examination (MMSE), the Clinical Dementia Rating (CDR), the Direct Assessment of Functional State (DAFS-BR), the Pfeffer Functional Activity Questionnaire (FAQ), the Informant Questionnaire on Cognitive Decline (IQCODE), the Lawton and Brody Instrumental Activities of Daily Living Scale and the Bayer Activities of Daily Living Scale (B-ADL)(Lawton e Brody, 1970; Folstein et al., 1975; Hughes et al., 1982; Pfeffer et al., 1982; Roth et al., 1986; Jorm e Jacomb, 1989; Hindmarch et al., 1998; Pereira et al., 2010). The investigation of psychiatric comorbidities was performed using the MiniInternational Neuropsychiatric Interview (MINI) (Amorim, 2000) and the Hamilton Depression Rating Scale (HAMD) (Gallucci Neto et al., 2001). The following measures were applied to the caregivers: an identification form developed for this study, cognitive screening with the Montreal Cognitive Assessment (MoCA), evaluation of depressive symptoms with the Beck Depression Inventory (BDI), evaluation of anxiety symptoms with the Beck 
Anxiety Inventory (BAI) and the evaluation of burden and stress related to the care function with the Caregiver Burden Inventory (CBI) and the Zarit Burden Interview (Zarit)(Beck et al., 1961; Zarit e Zarit, 1983; Beck et al., 1988; Nasreddine et al., 2005; Valer et al., 2015).

\section{Statistical analysis}

Data were analyzed using the Statistical Package for Social Sciences (SPSS), version 22 for Windows. Initially, a demographic characterization of the subjects included in the study was performed. Continuous variables are described through means and standard deviations. Categorical variables are described by absolute frequencies and percentages. The groups were divided according to final CDR scores: controls (CDR 0) mild AD (CDR 1) and moderate $A D$ (CDR 2). The normal distribution of the sample was assessed using the Kolmogorov-Smirnov test. In the case of normal distribution of the quantitative variables, parametric tests for means of comparison (single-factor analysis of variance (ANOVA) with multiple comparisons by the Bonferroni test were used. Otherwise, non-parametric tests Kruskal-Wallis test with multiple comparisons of the Dunn test were used. For the qualitative variables, the chi-square test or Fisher's exact test was used. The correlation evaluation was performed using Pearson's correlation coefficient. For all analyses, the level of statistical significance was $5 \%$.

\section{Results}

The study sample consisted of 81 subjects divided into control $(n=41)$, mild $A D(n=26)$ and moderate $A D(n=14)$ groups. Table 1 shows the demographic and clinical characterization of the studied sample. Regarding schooling, the difference was presented in the analysis of the three groups. In the comparison of mild and moderate $A D$, there was no significant difference (Bonferroni test, $p=0.500$ ). As expected, the three groups presented statically difference in all cognitive and functional assessment's. 
Regarding to the functionality evaluated by indirect interviews, we observed that although all correlations were significant with DAFS, the Lawton and Brody Instrumental Activities of Daily Living Scale $(r=0.85$ and $p<0.001)$, $B-A D L(r=-0.77$ and $p<0.001)$ and $F A Q(r=-0.83$ and $p<0.001)$ had a strong correlation with DAFS-BR and the IQCODE $(r=-0.44$ and $p<0.001)$ correlation was moderate. To further study the perception of functionality, indirect scales were separated by individual items and correlated with DAFS-BR domains ( .

Related to the correlations between the DAFS-BR domains and separate items of each indirect scales we observed that most items presented significant correlation $(\mathrm{p}<0.05)$, with exception of Dealing with Finance and B-ADL $(r=0.069 p=0.545)$. We also observed that none of the indirect scales applied in this study contemplated all domains assessed by DAFS-BR. In the other direction all indirect scales investigated Dealing with Finance domain, respectively IQCODE $(r=-0.56 p<0.001)$, Lawton $(r=0.65 p<0.001)$, FAQ $(r=-$ $0.67 p<0.001) B-A D L(r=-0.06, p=0.54$ and $r=-0.30, p<0.001)$. Time Orientation was only assessed by IQCODE $(r=-0.701, p<0.001)$. Communication skills was investigated by IQCODE ( $r=-0.45, p<0.001)$, Lawton ( $r=0.56 p<0.001)$, B-ADL ( $r=-0.45, p<0.001)$. Shopping skills was assessed by FAQ $(r=-0.77, p<0.001)$ Lawton $(r=0.71, p<0.001)$ and B-ADL $(r=-0.74, p<0.001)$ and Grooming and Eating skills was only investigated by two question in B-ADL scale $(r=-0.35$, $p=0.001$ and $r=-0.36, p=0.001$ )

The caregivers/informants of the subjects of the control, mild $A D$ and moderate $A D$ groups were matched for all demographic characteristic but leaving with the elderly whereas $15(36.6 \%)$ in the control, $12(46.2 \%)$ in mild $A D$ and $11(78.6 \%)$ in moderate $A D$ lived with the elderly (chi-square test; $p=$ $0.025)$. By the chi-square partition, we observed that the control and mild $A D$ groups did not present significant differences $(p=0.444)$ and presented a significantly lower percentage of cases than the moderate $A D$ group $(p=$ 0.009). The mean age of the caregivers/informants was between 22 and 80 years (mean: 57.60 years; SD: 13.21 years; median: 59.00 years). Sixty-three (77.8\%) caregivers/informants were female. There was no significant difference between controls, mild $A D$ and moderate $A D$ in terms of age (58.05 \pm 14.52 , $57.58 \pm 11.89,56.36 \pm 12.31$, respectively, $p=0.92$ ), female gender ( 30 
[73.2\%], 21[80.8\%], 12[85.7\%], respectively) , living with partner marital status ( $19=46.3 \%, 17=65.4 \%, 8=57.1 \%$, respectively $p=0.30$ ), college and post graduation level of education (33 [80.5\%], 16 [57.7\%], 8 [57.1\%], respectively), currently working (19 [46.3\%],15 [57.7\%] 9 [64.3\%], respectively) and retired (19 [46.3\%], 8[30.8\%], 4[28.6\%], respectively) and years of retirement (10.70 \pm $8,72,15.40 \pm 15.53,11.00 \pm 3,46$, respectively).

Table 2 shows the characteristic of the caregivers/informants with respect to cognition, burden, depressive, anxiety symptoms. No significant difference between the groups in relation to depressive symptoms, anxiety symptoms and cognitive aspects was observed. However, we observed differences between the groups in relation to the caregiver's burden $(p<0.001)$. It was noted that the caregiver burden for the control group presented significantly lower values than for the other two AD groups (Dunn's test: $p<$ 0.001). However, the mild $A D$ and moderate $A D$ groups did not present significant differences between them. We observed that all domains related to the caregiver's burden were significantly worse in caregivers of subjects with $A D$.

Table 3 show the correlations between emotional evaluation (burden, depressive and anxiety symptoms) and functional assessment in controls, mild $A D$ and moderate $A D$ respectively. . When we correlated the evaluations of individuals assessed by the DAFS-BR with the score obtained in the indirect scales administered by the caregivers/informants, we observed a significant correlation for all the scales. Similarly, we obtained good sensitivity and specificity for mild and moderate AD. We did not find in any group a significant correlation between emotional symptoms and the direct evaluation of functionality. However, the same emotional symptoms of the caregivers/informants exhibited significant correlations with the scores on the indirect scales, particularly in the control group, with the IQCODE exhibiting the lowest correlation and being closer to the direct evaluation of functionality. In the mild AD group, we also observed correlations between indirect scales and emotional symptoms but in smaller numbers, which suggests that the progression of the disease may lead to more accurate estimates of functionality loss by the caregiver/informant. This hypothesis was reinforced by the 
observation that in the moderate $A D$ group all indirect scale results resembled the DAFS-BR results.

Table 4 shows the correlation between burden type domains (timedependent, developmental, physical, emotional and social) and functional domains (Time orientation, comunication skills, dealing with finances,shopping skills, grooming and eating skills). We observed significant negative correlation in both control and mild AD groups, specifically in dealing with finances domains and time-dependent burden $(p<0.05)$. That is, the greater the subject's difficulty with dealing with finances according to the DAFS-BR, the greater was the caregiver's burden with respect to the time required to care for the elderly person. As dementia progressed, i.e., in the moderate phase of AD the burden was more correlated to emotional factors and communication skills. Our findings indicate that the higher that the independence in communication is, the greater the emotional stress. This DAFS-BR item refers to talking on the telephone and sending correspondence, abilities that are maintained only in the most preserved cases of moderate $A D$ so that as the disease severity progresses, the family member is less exposed to this situation.

\section{Discussion}

Our primary finding in the comparison of indirect evaluations and direct functionality evaluations was that the presence of depressive, anxiety and burden symptoms influenced the indirect scales, mainly for the control and mild $A D$ groups. With the progression of $A D$, the caregiver/informant's evaluation of the IADL loses the correlation with the emotional symptoms, approaching direct evaluation. Despite this possible influence, when assessing sensitivity and specificity, all indirect scales presented good results for mild and moderate AD.

It was also observed that all indirect evaluations had at least one item that correlated with a DAFS-BR domain but none that correlated with all domains. The only area that was evaluated in all scales was the dealing with finances, which is identified as a major challenge at the onset of dementia and can be a considerable factor for loss of independence in the elderly. It is interesting to note that this was the only domain that had no correlation with one 
of the scales (DAFS-BR dealing finances $\times$ B-ADL). The B-ADL scale asks whether the elderly person could count money without making a mistake. The caregiver/informant is required to score on a scale of 0 to 10 the degree of difficulty that the subject exhibits. In turn, in the DAFS-BR domain related to dealing finances the subject must identify coins, count them, perform the mental calculations required to make change, write a check and calculate the bank balance. Thus, these tasks are more complex.

The DAFS-BR is a direct evaluation with day-to-day ecological tasks. The individual being assessed performs the tasks in front of the examiner, thus enabling the observation of the performance of each ADL. When correlating the performance of the individual evaluated by the DAFS-BR with the score obtained on the scales, we observed a significant correlation in all the scales. We did not find in any group a significant correlation between emotional symptoms and the direct evaluation of functionality. However, when correlating the same emotional symptoms of the caregivers/informants with the scores on the indirect scales in the control group, we obtained significant correlations, whereby the IQCODE displayed the lowest correlation and was closer to the direct evaluation of the relevant functionality. This fact can be explained by the way in which one compares current functionality and past functionality in the IQCODE. . Our findings are in line with the results of Pereira et al. (2010), who observed a significant correlation between DAFS-BR and IQCODE $(r=0.61, p$ $<0.001)$. In the mild AD group, we also observed correlations between indirect scales and emotional symptoms but to a lesser extent. This outcome suggests that disease progression may lead to a more accurate estimate of functionality loss by the caregiver/informant. This hypothesis was reinforced when in the moderate $A D$ group all the indirect scales were similar to those evaluated by the DAFS-BR. One can suggest that as the impairment of functionality worsens and involves different domains the emotional symptoms of the caregiver/informant interfere less in the perception of each domain. A limitation of our study was that we did not include indirect scales that evaluate BADL. Therefore, it was impossible to assess whether this is the case in these cases. Future studies that address BADL may complement our findings. 
Our findings corroborate previous studies that find that caregiver burden may be correlated with time of care and greater dependence on ADL (Cruz e Hamdan, 2008; Yu et al., 2015; Cesário et al., 2017). Küçükgüçlü et al. (2017) concluded that the factor that most affects the caregiver's burden is the decline in the performance of the ADL and neuropsychological symptoms, which primarily affect the time-dependent burden domain.

Regarding the caregiver characteristics, it is interesting to note that a large majority were female (77\%) of various ages (from 22 to 80 years old; median: 59.00 years). These facts suggest that women tend to assume the role of caregiver more often and that these women are usually wives or daughters of the care recipient. We also observed that in the control and mild AD groups, most of the caregivers/informants did not live with the elderly but spent time with them on a daily basis. In turn, in the moderate AD group, the majority lived with the assisted elderly individual. Therefore, we can infer that as the need for help increases there is a greater tendency to remain longer with the elderly person. In addition, in many cases, living in the same household can facilitate more constant supervision and care. Araújo e Fernandes (2015) reviewed the characteristics of the elderly caregiver profile and reported that the majority of the caregivers were female (85\%) aged from $26-86$ years (mean: 50 years), a total of $95 \%$ were informal caregivers, of whom an estimated $75 \%$ were the daughter or spouse of the elderly care recipient and $80 \%$ lived with the assisted elder. Many studies note the prevalence of women aged 50 and 80 years as caregivers, with schooling varying according to the level of development and culture of their country (Yu et al., 2015; Custodio et al., 2017; Wolff et al., 2017).

Regarding the cognitive and emotional aspects of the caregivers/informants, cognitive screening as well as depressive and anxiety symptoms did not exhibit any difference among the groups. However, we observed a difference between the controls and the mild and moderate $A D$ groups relative to the caregiver's burden. However, unlike the literature, we did not observe a difference in burden between caregivers of mild and moderate $A D$. One possible explanation is that although the patients with $A D$ were at different stages of severity, none had impairment in BADL, which causes higher stress levels for the caregiver (Cruz e Hamdan, 2008). The observation that the 
control informants presented less burden than the $A D$ caregivers agrees with recent studies that find that factors related to the caregiver's burden may increase with dementia and the degree of dependence of the elderly individual(Cruz e Hamdan, 2008; Pinto e Barham, 2014; Yu et al., 2015).

When we analyzed the demographic profile of the evaluated elderly, we found no significant difference between the three groups in relation to age, gender, marital status and employment situation. Regarding schooling, despite the significant difference between the control group (older) and the mild $A D$ group, when we compared the mild and moderate $A D$ groups, there was no significant difference. Education is a recognized protective factor for AD (Herrera Jr et al., 2002; Bottino et al., 2008; Nitrini et al., 2009). This difference has a potential influence, particularly on cognitive assessments, which may be schooling-dependent. However, functional evaluations, the object of this study, are less influenced, and the definition of dementia was based on the total CDR score, taking into account possible influences of schooling. Regarding the cognitive and functional profile, all the evaluated tests revealed significant differences between the control and AD groups, as expected, characterizing the functional and cognitive loss inherent to dementia's progression.

In conclusion, the presence of emotional symptoms influences indirect evaluation in mild cases of cognitive decline, in which the functional impairment is subtle. In such cases, direct evaluation would be preferable if possible. Among the indirect evaluation methods, the IQCODE was less influenced by caregiver emotional factors and most closely approximated direct evaluation. In moderate $A D$, in which functional impairment is evident, indirect evaluation was less influenced by caregiver burden.

Conflict of interest declaration:

None

\section{Description of authors' roles}

$\mathrm{J} . \mathrm{H}$ is responsable for recruitng and organizing the data collection, all analisys presented in this paper and writiing this manuscript, P.B.N ; P.C. H.M ; A.D.B.V. colaborated with clinical and functional data collection ; A.M O was responsable for assisting in patients recruitment and supervised the study 
design in the selection of functional scales, finaly T.C.T.F. A was responsable for study design; supervison for all phases and for the writting this paper..

\section{Acknowledgements}

TCTFA \& JH are suported by a research grant of Conselho Nacional de Desenvolvimento Cientifico e Tecnológico (CNPq) ( 301460/2015-9 \& 830744/1991-6 respectvely) 
Reference:

Almeida M L, M. L., J. C. Leite, A. P. S. Avalhais, B. R. d. S. Melo, C. C. Thomaz, Z. R. M. Botan, C. S. S. Manzini and F. A. C. Vale (2016). "Instrumentos mais utilizados na avaliação da funcionalidade de idosos com demência: uma revisão sistemática." Revista de Atenção à Saúde (antiga Rev. Bras. Ciên. Saúde) 14(48): 76-85.

Amorim, P. (2000). "Mini International Neuropsychiatric Interview (MINI): validação de entrevista breve para diagnóstico de transtornos mentais." $\underline{\text { Rev }}$ Bras Psiquiatr 22(3): 106-115.

Araújo, F., J. Pais Ribeiro, A. Oliveira, C. Pinto and T. Martins (2008). Validação da escala de Lawton e Brody numa amostra de idosos não isntitucionalizados. Leal, J., Silva, I. \& Marques, S. Actas do $7^{\circ}$ congresso Nacional de psicologia da saúde. Lisboa: ISPA.

Araújo, F. N. F. d. and M. J. P. Fernandes (2015). "PERFIL DE CUIDADORES DE IDOSOS NO BRASIL."

Argüelles, S., D. A. Loewenstein, C. Eisdorfer and T. Argüelles (2001). "Caregivers' judgments of the functional abilities of the Alzheimer's disease patient: impact of caregivers' depression and perceived burden." Journal of Geriatric Psychiatry and Neurology 14(2): 91-98.

Arrighi, H. M., I. Gélinas, T. P. McLaughlin, J. Buchanan and S. Gauthier (2013). "Longitudinal changes in functional disability in Alzheimer's disease patients." International Psychogeriatrics 25(6): 929-937.

Association, A. P. (2014). DSM-5: Manual diagnóstico e estatístico de transtornos mentais, Artmed Editora.

Bahia, V. S., M. T. Carthery-Goulart, M. M. Novelli, E. M. Kato-Narita, R. ArezaFegyveres, P. Caramelli and R. Nitrini (2010). "Functional disability in Alzheimer disease: a validation study of the Brazilian version of the Disability Assessment for Dementia (DAD-Br)." Alzheimer Disease \& Associated Disorders 24(3): 291295.

Bahls, S.-C. (1999). "Depressão: uma breve revisão dos fundamentos biológicos e cognitivos." Interação em Psicologia 3(1).

Beck, A., N. Epstein, G. Brown and R. Steer (1988). "An inventory for measuring clinical anxiety: Psychometrie properties." Journal ofConsulting and Clinical Psychology 56(6): 893-897.

Beck, A. T., C. H. Ward, M. Mendelson, J. Mock and J. ERBAUGH (1961). "An inventory for measuring depression." Archives of general psychiatry 4(6): 561571.

Bentvelzen, A., L. Aerts, K. Seeher, J. Wesson and H. Brodaty (2017). "A Comprehensive Review of the Quality and Feasibility of Dementia Assessment 
Measures: The Dementia Outcomes Measurement Suite." Journal of the American Medical Directors Association.

Bertolucci, P. H., S. Brucki, S. R. Campacci and Y. Juliano (1994). "O miniexame do estado mental em uma populaçäo geral: impacto da escolaridade." Arq. Neuropsiquiatr 52(1): 1-7.

Boff, M. S., F. S. Sekyia and C. Bottino (2015). "Prevalence of dementia among brazilian population: systematic review." Rev Med (São Paulo) 94(3): 154-161.

Bottino, C., A. Stoppe Jr, A. Scalco, R. Ferreira, S. Hototian and M. Scalco (2001). "Validade e confiabilidade da versão brasileira do CAMDEX." Arq Neuropsiquiatr 59(Supl 3): 20.

Bottino, C. M., D. Azevedo Jr, M. Tatsch, S. R. Hototian, M. A. Moscoso, J. Folquitto, A. Z. Scalco, M. C. Bazzarella, M. A. Lopes and J. Litvoc (2008). "Estimate of dementia prevalence in a community sample from São Paulo, Brazil." Dementia and Geriatric Cognitive Disorders 26(4): 291-299.

Bravell, M. E., S. H. Zarit and B. Johansson (2011). "Self-reported activities of daily living and performance-based functional ability: a study of congruence among the oldest old." European Journal of Ageing 8(3): 199-209.

Bressan, L. A., F. d. A. C. Vale and J. G. Speciali (2007). "The daily life of patients with dementia: a comparative study between the information provided by the caregiver and direct patient assessment." Dementia \& Neuropsychologia 1(3): 288-295.

Brigola, A. G., B. Moretti Luchesi, E. Serafim Rossetti, E. Mioshi, K. Inouye and S. C. lost Pavarini (2017). "Perfil de saúde de cuidadores familiares de idosos e sua relação com variáveis do cuidado: um estudo no contexto rural." Revista Brasileira de Geriatria e Gerontologia 20(3).

Brucki, S. M., R. Nitrini, P. Caramelli, P. H. F. Bertolucci and I. H. Okamoto (2003). "Sugestões para o uso do mini-exame do estado mental no Brasil." Arquivos de Neuro-psiquiatria.

BUCKS, R. S., D. Ashworth, G. Wilcock and K. Siegfried (1996). "Assessment of activities of daily living in dementia: development of the Bristol Activities of Daily Living Scale." Age and ageing 25(2): 113-120.

Burlá, C., A. A. Camarano, S. Kanso, D. Fernandes and R. Nunes (2013). "Panorama prospectivo das demências no Brasil: um enfoque demográfico." Ciência \& Saúde Coletiva 18(10): 2949-2956.

Burton, C. L., E. Strauss, D. Bunce, M. A. Hunter and D. F. Hultsch (2009). "Functional abilities in older adults with mild cognitive impairment." Gerontology 55(5): 570-581.

Bustamante, S. E. Z., C. M. Bottino, M. A. Lopes, D. Azevedo, S. R. Hototian, J. Litvoc and W. Jacob Filho (2003). "Instrumentos combinados na avaliação de 
demência em idosos: resultados preliminares." Arq Neuropsiquiatr 61(3A): 601606.

Canedo, B. d. S. (2014). "Mini-exame do estado mental como instrumento de avaliação cognitiva: uma revisão bibliográfica."

Canon, M. B. F., M. H. M. de Alemieda and M. M. P. C. Novelli (2016). "Escala de avaliação de incapacidade na demência-versão longa (DADL-BR)/Disability assessment scale for dementia-long version (DADL-BR)." Cadernos de Terapia Ocupacional da UFSCar 24(2).

Canon, M. B. F. and M. M. P. C. Novelli (2012). "Estudo dos instrumentos de avaliação funcional em demência comumente utilizados no Brasil." Journal of Occupational Therapy of University of São Paulo/Revista de Terapia Ocupacional da Universidade de São Paulo 23(3).

Caporicci, S. and M. Neto (2011). "Estudo comparativo de idosos ativos e inativos através da avaliação das atividades da vida diária e medição da qualidade de vida." Motricidade 7(2).

Caramellia, P. and M. T. Barbosa (2002). "Como diagnosticar as quatro causas mais freqüentes de demência? How to diagnose the four most frequent causes of dementia?" Rev Bras Psiquiatr 24(Supl I): 7-10.

Carthery-Goulart, M. T., R. Areza-Fegyveres, R. R. Schultz, I. Okamoto, P. Caramelli, P. H. F. Bertolucci and R. Nitrini (2007). "Cross-cultural adaptation of the Disability Assessment for Dementia (DAD)." Arquivos de Neuro-psiquiatria 65(3B): 916-919.

Cecato, J. F., J. M. Montiel, D. Bartholomeu and J. E. Martinelli (2014). "Poder preditivo do MoCa na avaliação neuropsicológica de pacientes com diagnóstico de demência." Revista Brasileira de Geriatria e Gerontologia 17(4): 707-719.

Cesário, V. A. C., M. C. C. Leal, A. P. d. O. Marques and K. A. Claudino (2017). "Estresse e qualidade de vida do cuidador familiar de idoso portador da doença de Alzheimer." Saúde em Debate 41: 171-182.

Chaves, M. L., C. C. Godinho, C. S. Porto, L. Mansur, M. T. Carthery Goulart, M. S. Yassuda and R. Beato (2011). "Doença de Alzheimer. Avaliação cognitiva, comportamental e funcional." Dementia \& Neuropsychologia 5(1).

Cornelis, E., E. Gorus, I. Beyer, I. Bautmans and P. De Vriendt (2017). "Early diagnosis of mild cognitive impairment and mild dementia through basic and instrumental activities of daily living: Development of a new evaluation tool." PLoS medicine 14(3): e1002250.

Costa, A. J. L. (2006). "Metodologias e indicadores para avaliação da capacidade funcional: análise preliminar do Suplemento Saúde da Pesquisa Nacional por Amostra de Domicílios-PNAD, Brasil, 2003." Ciência \& Saúde Coletiva 11(4): 927-940. 
Costa, E. C., A. Y. Kyosen Nakatani and M. M. Bachion (2006). "Capacidade de idosos da comunidade para desenvolver Atividades de Vida Diária e Atividades Instrumentais de Vida Diária." Acta paulista de enfermagem 19(1).

Cruz, M. d. N. and A. C. Hamdan (2008). "O impacto da doença de Alzheimer no cuidador." Psicol. estud.[serie en Internet].

Cruz V T, V. T., J. Pais, A. Teixeira and B. Nunes (2004). "Sintomas iniciais de demência de Alzheimer: a percepção dos familiares." Acta Med Port 17: 435444.

Cunha, F. C. M. d., M. T. G. Cintra, J. M. Dornelas, M. G. Assis, J. G. Cassiano, R. Nicolato, L. F. Malloy-Diniz, E. N. d. Moraes and M. A. C. Bicalho (2015). "Declínio funcional em idosos com comprometimento cognitivo leve."

Cunha, J. A. (2001). "Manual da versão em português das Escalas Beck." São Paulo: Casa do Psicólogo: 11-13.

Custodio, N., A. Wheelock, D. Thumala and A. Slachevsky (2017). "Dementia in latin america: epidemiological evidence and implications for public policy." Frontiers in aging neuroscience 9: 221.

Dash, T., Y. Joanette and (2016). Neurocognitive Markers of Aging Encyclopedia of Geropsychology. Springer.

Dias, E. G., Y. A. de Oliveira Duarte, M. H. Morgani and M. L. Lebrão (2014). "As Atividades avançadas de vida diária como componente da avaliação funcional do idoso." Revista de Terapia Ocupacional da Universidade de São Paulo 25(3): 225-232.

Dutra, M. C., R. d. S. Ribeiro, S. B. Pinheiro, G. F. d. Melo and G. d. A. Carvalho (2015). "Accuracy and reliability of the Pfeffer Questionnaire for the Brazilian elderly population." Dementia \& Neuropsychologia 9(2): 176-183.

Fagundes, T. A., D. A. G. Pereira, K. M. P. Bueno and M. G. Assis (2017). "Incapacidade funcional de idosos com demência/Functional disability in elderly with dementia." Cadernos Brasileiros de Terapia Ocupacional 25(1).

Farias, N. and C. M. Buchalla (2005). "A classificação internacional de funcionalidade, incapacidade e saúde da organização mundial da saúde: conceitos, usos e perspectivas." Revista brasileira de epidemiologia 8(2): 187193.

Faul, F., E. Erdfelder, A.-G. Lang and A. Buchner (2007). "G* Power 3: A flexible statistical power analysis program for the social, behavioral, and biomedical sciences." Behavior research methods 39(2): 175-191.

Ferreira, N. C. L. Q. (2017). "• As dificuldades dos familiares que atuam no cuidado dos idosos portadores da doença de Alzheimer: uma revisão bibliográfica." REVISTA CIÊNCIA ET PRAXIS 8(15): 35-42. 
Fjell, A. M., L. McEvoy, D. Holland, A. M. Dale, K. B. Walhovd and A. s. D. N. Initiative (2014). What is normal in normal aging? Effects of aging, amyloid and Alzheimer's disease on the cerebral cortex and the hippocampus.

Folquitto, J. C., S. E. Bustamante, S. B. Barros, D. Azevedo, M. A. Lopes, S. R. Hototian, W. Jacob Filho, J. Litvoc and C. Bottino (2007). "The Bayer: Activities of Daily Living Scale (B-ADL) in the differentiation between mild to moderate dementia and normal aging." Revista Brasileira de Psiquiatria 29(4): 350-353.

Folstein, M. F., S. E. Folstein and P. R. McHugh (1975). "'Mini-mental state": a practical method for grading the cognitive state of patients for the clinician." Journal of psychiatric research 12(3): 189-198.

Fuchs, J., C. Scheidt-Nave, T. Hinrichs, A. Mergenthaler, J. Stein, S. G. RiedelHeller and E. Grill (2013). "Indicators for healthy ageing-a debate." International journal of environmental research and public health 10(12): 66306644.

Gallucci Neto, J., M. S. C. Júnior and C. von Krakauer Hübner (2001). "Escala de Depressão de Hamilton (HAM-D): revisão dos 40 anos de sua utilização." Revista da Faculdade de Ciências Médicas de Sorocaba. ISSN eletrônico 1984-4840 3(1): 10-14.

Garrido, R. and P. R. Menezes (2004). "Impacto em cuidadores de idosos com demência atendidos em um serviço psicogeriátrico." Revista de Saúde Pública 38(6): 835-841.

Gauthier L, Gélinas I, McIntyre M, Gauthier S, Laberge H and D. SW (1994). "Disability Assessment for Dementia (DAD) user's guide, 1994.".

Gomes-Oliveira, M. H., C. Gorenstein, F. L. Neto, L. H. Andrade and Y. P. Wang (2012). "Validation of the Brazilian Portuguese version of the Beck Depression Inventory-II in a community sample." Revista Brasileira de Psiquiatria 34(4): 389-394.

Gomes, P. S. and J. B. Pamplona (2015). "ENVELHECIMENTO POPULACIONAL, MERCADO DE TRABALHO E POLÍTICA PÚBLICA DE EMPREGO NO BRASIL." Economia \& Gestão 15(41): 206-230.

Granger, C. V., B. B. Hamilton, R. A. Keith, M. Zielezny and F. S. Sherwin (1986). "Advances in functional assessment for medical rehabilitation." Topics in geriatric rehabilitation 1(3): 59-74.

Gutierrez, L. L. P., N. R. M. Fernandes and M. Mascarenhas (2017). "Caracterização de cuidadores de idosos da região metropolitana de Porto Alegre (RS): perfil do cuidado." Saúde em Debate 41: 885-898.

Hamilton, M. (1960). "A rating scale for depression." Journal of neurology, neurosurgery, and psychiatry 23(1): 56. 
Herrera Jr, E., P. Caramelli, A. S. B. Silveira and R. Nitrini (2002). "Epidemiologic survey of dementia in a community-dwelling Brazilian population." Alzheimer Disease \& Associated Disorders 16(2): 103-108.

Hindmarch, I., H. Lehfeld, P. de Jongh and H. Erzigkeit (1998). "The Bayer activities of daily living scale (B-ADL)." Dementia and geriatric cognitive disorders 9(Suppl. 2): 20-26.

Hopkins, R. O., M. R. Suchyta, B. B. Kamdar, E. Darowski, J. C. Jackson and D. M. Needham (2017). "Instrumental Activities of Daily Living after Critical Illness: A Systematic Review." Annals of the American Thoracic Society(ja).

Hughes, C. P., L. Berg, W. L. Danziger, L. A. Coben and R. Martin (1982). "A new clinical scale for the staging of dementia." The British journal of psychiatry 140(6): 566-572.

IBGE. (2014). "Brasil é reconhecido por políticas públicas em favor de idosos." Retrieved 08/2013, 2014, from http://ibege.gov.br

Jacinto, A. F. (2008). Alterações cognitivas em pacientes idosos atendidos em ambulatório geral de clínica médica, Universidade de São Paulo.

Jefferson, A. L., L. K. Byerly, S. Vanderhill, S. Lambe, S. Wong, A. Ozonoff and J. H. Karlawish (2008). "Characterization of activities of daily living in individuals with mild cognitive impairment." The American Journal of Geriatric Psychiatry 16(5): 375-383.

Jekel, K., M. Damian, C. Wattmo, L. Hausner, R. Bullock, P. J. Connelly, B. Dubois, M. Eriksdotter, M. Ewers and E. Graessel (2015). "Mild cognitive impairment and deficits in instrumental activities of daily living: a systematic review." Alzheimer's research \& therapy 7(1): 17.

Johnson, N., A. Barion, A. Rademaker, G. Rehkemper and S. Weintraub (2004). "The Activities of Daily Living Questionnaire: a validation study in patients with dementia." Alzheimer disease \& associated disorders 18(4): 223230.

Jorm, A. and P. Jacomb (1989). "The Informant Questionnaire on Cognitive Decline in the Elderly (IQCODE): socio-demographic correlates, reliability, validity and some norms." Psychological medicine 19(4): 1015-1022.

Katz, N. (2011). "Cognition, Occupation, and Participation Across the Life Span." Bethesda: The American Occupational Therapy Association.

Katz, S., A. B. Ford, R. W. Moskowitz, B. A. Jackson and M. W. Jaffe (1963). "Studies of illness in the aged: the index of ADL: a standardized measure of biological and psychosocial function." Jama 185(12): 914-919.

Küçükgüçlü, Ö., B. A. Söylemez, G. Yener, C. D. Barutcu and M. A. Akyol (2017). "Examining Factors Affecting Caregiver Burden: A Comparison of Frontotemporal Dementia and Alzheimer's Disease." American Journal of Alzheimer's Disease \& Other Dementias 8 32(4): 200-206. 
Lara, J., R. Cooper, J. Nissan, A. T. Ginty, K.-T. Khaw, I. J. Deary, J. M. Lord, D. Kuh and J. C. Mathers (2015). "A proposed panel of biomarkers of healthy ageing." BMC medicine 13(1): 222.

Lawton, M. P. and E. M. Brody (1970). "Assessment of older people: selfmaintaining and instrumental activities of daily living." Nursing Research 19(3): 278.

Lima-Silva, T. B., V. S. Bahia, V. A. Carvalho, H. C. Guimarães, P. Caramelli, M. L. F. Balthazar, B. Damasceno, C. M. d. C. Bottino, S. M. D. Brucki and R. Nitrini (2015). "Direct and indirect assessments of activities of daily living in behavioral variant frontotemporal dementia and Alzheimer disease." Journal of geriatric psychiatry and neurology 28(1): 19-26.

Lin, A., J. Brook, J. D. Grill and E. Teng (2017). "Participant-Informant Relationships Affect Quality of Life Ratings in Incipient and Clinical Alzheimer Disease." The American Journal of Geriatric Psychiatry 25(3): 297-307.

Lino, V. T. S., S. R. M. Pereira, L. A. B. Camacho, S. T. Ribeiro Filho and S. Buksman (2008). "Cross-cultural adaptation of the independence in activities of daily living index (Katz index)." Cadernos de Saúde Pública 24(1): 103-112.

Loewenstein, D. A., E. Amigo, R. Duara, A. Guterman, D. Hurwitz, N. Berkowitz, F. Wilkie, G. Weinberg, B. Black, B. Gittelman and C. Eisdorfer (1989). "A New Scale for the Assessment of Functional Status in Alzheimer's Disease and Related Disorders." Journal of Gerontology 44(4): P114-P121.

Lopes dos Santos, R. and J. S. Virtuoso Júnior (2008). "Confiabilidade da versão brasileira da escala de atividades instrumentais da vida diária." Revista Brasileira em Promoção da Saúde 21(4).

Mahoney, F. I. and D. W. Barthel (1965). "Functional evaluation: the Barthel Index: a simple index of independence useful in scoring improvement in the rehabilitation of the chronically ill." Maryland state medical journal.

Mapi, R. I. (1999). Cultural Adaptation of the Bayer Activities of Daily Living Scale (B-ADL) into Brazilian Portuguese, Mapi Research Institute Lyon-France.

Marigliano, R. X., J. F. da Silva, M. L. de Jesus Miranda, G. M. Rodrugues and C. A. Gil (2015). "Estratégias de autocuidado usadas por cuidadores de idosos: análise de produção científica." Mudanças-Psicologia da Saúde 23(2): 37-45.

Marra, T. A., L. S. Pereira, C. D. C. d. M. Faria, D. S. Pereira, M. A. A. Martins and M. G. Tirado (2007). "Avaliação das atividades de vida diária de idosos com diferentes níveis de demência." Revista Brasileira de Fisioterapia 11(4).

Marshall, G. A., S. L. Aghjayan, M. Dekhtyar, J. J. Locascio, K. Jethwani, R. E. Amariglio, K. A. Johnson, R. A. Sperling and D. M. Rentz (2017). "Activities of daily living measured by the Harvard Automated Phone Task track with cognitive decline over time in non-demented elderly." The journal of prevention of Alzheimer's disease 4(2): 81. 
McKhann, G., D. Drachman, M. Folstein, R. Katzman, D. Price and E. M. Stadlan (1984). "Clinical diagnosis of Alzheimer's disease Report of the NINCDS-ADRDA Work Group* under the auspices of Department of Health and Human Services Task Force on Alzheimer's Disease." Neurology 34(7): 939939.

Medeiros, M. and R. Guerra (2009). "Translation, cultural adaptation and psychometric analysis of the Activities of Daily Living Questionnaire (ADLQ) for functional assessment of patients with Alzheimer's disease." Brazilian Journal of Physical Therapy 13(3): 257-266.

Mlinac, M. E. and M. C. Feng (2016). "Assessment of activities of daily living, self-care, and independence." Archives of Clinical Neuropsychology 31(6): 506516.

Montaño, M. B. M. M. and L. R. Ramos (2005). "Validity of the Portuguese version of clinical dementia rating." Revista de Saude Publica 39(6): 912-917.

Moura Minosso, J. S., F. Amendola, M. R. Martins Alvarenga and M. A. de Campos Oliveira (2010). "Validação, no Brasil, do Índice de Barthel em idosos atendidos em ambulatórios." Acta Paulista de Enfermagem 23(2).

Nagaratnam, N., K. Nagaratnam and D. O'Mara (2013). "Bayer-activities of daily living scale in mild and moderate dementia of the Alzheimer type." American Journal of Alzheimer's Disease \& Other Dementias® 28(8): 784-789.

Nasreddine, Z. S., N. A. Phillips, V. Bédirian, S. Charbonneau, V. Whitehead, I. Collin, J. L. Cummings and H. Chertkow (2005). "The Montreal Cognitive Assessment, MoCA: a brief screening tool for mild cognitive impairment." Journal of the American Geriatrics Society 53(4): 695-699.

Neubern, P. C. B. (2018). Funcioalidade e funçoes executivas em idosos saudáveis e portadores de demências na doença de Alzheimer: um estudo de validação do Executive Functiona Performance Teste- BR. Phd, USP.

Nitrini, R., C. M. Bottino, C. Albala, N. S. C. Capuñay, C. Ketzoian, J. J. L. Rodriguez, G. E. Maestre, A. T. A. Ramos-Cerqueira and P. Caramelli (2009). "Prevalence of dementia in Latin America: a collaborative study of populationbased cohorts." International Psychogeriatrics 21(4): 622-630.

Nitrini, R., P. Caramelli, C. Bottino, B. P. Damasceno, S. M. D. Brucki and R. Anghinah (2005). "Diagnóstico de doença de Alzheimer no Brasil: avaliação cognitiva e funcional." Arq neuropsiquiatr 63(3-A): 720-727.

Nitrini, R., P. Caramelli, C. Bottino, B. P. Damasceno, S. M. D. Brucki and R. Anghinah (2005). "Diagnóstico de doença de Alzheimer no Brasil: critérios diagnósticos e exames complementares." Arq Neuropsiquiatr 63(3-A): 713-719.

Nitrini, R., P. Caramelli, E. Herrera Jr, V. Bahia, L. Caixeta, M. Radanovic, R. Anghinah, H. Charchat-Fichman, C. Porto and M. Carthery (2004). "Incidence of dementia in a community-dwelling Brazilian population." Alzheimer Disease \& Associated Disorders 18(4): 241-246. 
Novak, M. and C. Guest (1989). "Application of a multidimensional caregiver burden inventory." The gerontologist 29(6): 798-803.

Novelli, M. M. P. C., R. Nitrini and P. Caramelli (2010). "Cuidadores de idosos com demência: perfil sociodemográfico e impacto diário." Revista de terapia ocupacional da Universidade de São Paulo 21(2): 139-147.

Nyberg, L., M. Lövdén, K. Riklund, U. Lindenberger and L. Bäckman (2012). "Memory aging and brain maintenance." Trends in cognitive sciences 16(5): 292-305.

Paixão Jr, C. M. and M. E. Reichenheim (2005). "Uma revisão sobre instrumentos de avaliação do estado funcional do idoso A review of functional status evaluation instruments in the elderly." Cad. Saúde Pública 21(1): 7-19.

Paradela, E. M. P., C. de Souza Lopes and R. A. Lourenço (2009). "Adaptação para o português do Cambridge Cognitive Examination-Revised aplicado em um ambulatório público de geriatria Portuguese adaptation of the Cambridge Cognitive Examination-Revised in." Cad. Saúde Pública 25(12): 2562-2570.

Pereira, F. S., A. M. Oliveira, B. S. Diniz, O. V. Forlenza and M. S. Yassuda (2010). "Cross-cultural adaptation, reliability and validity of the DAFS-R in a sample of Brazilian older adults." Archives of Clinical Neuropsychology 25(4): 335-343.

Pereira J K, J. K., J. Oliveira Araújo Firmo and K. C. Giacomin (2014). "Maneiras de pensar e de agir de idosos frente às questões relativas à funcionalidade/incapacidade." Ciência \& Saúde Coletiva 19(8).

Perroco, T. R., A. E. Damin, N. A. Frota, M.-N. M. Silva, V. Rossi, R. Nitrini and C. Bottino (2008). "Short IQCODE as a screening tool for $\mathrm{MCl}$ and dementia: preliminary results." Dementia \& Neuropsychologia 2(4): 300-304.

Pfeffer, R., T. Kurosaki, C. Harrah Jr, J. Chance and S. Filos (1982). "Measurement of functional activities in older adults in the community." Journal of gerontology 37(3): 323-329.

Pinto, F. N. F. R. and E. J. Barham (2014). "Bem estar psicológico: Comparação entre cuidadores de idosos com e sem demência." Psicologia, Saúde \& Doenças 15(3): 635-655.

Quintão, S., A. R. Delgado and G. Prieto (2013). "Estudo de validade da versao portuguesa do Beck Anxiety Inventory mediante o modelo Rasch Rating Scale." Psicologia: Reflexao \& Critica 26(2): 305-311.

Ramos, L. R. (2003). "Fatores determinantes do envelhecimento saudável em idosos residentes em centro urbano: Projeto Epidoso, São Paulo." Cadernos de Saúde Pública.

Razani, J., B. Kakos, C. Orieta-Barbalace, J. T. Wong, R. Casas, P. Lu, C. Alessi and K. Josephson (2007). "Predicting caregiver burden from daily 
functional abilities of patients with mild dementia." Journal of the American Geriatrics Society 55(9): 1415-1420.

Riberto, M., M. H. Miyazaki, S. S. Jucá, H. Sakamoto, P. P. N. Pinto and L. R. Battistella (2016). "Validação da versão brasileira da Medida de Independência Funcional." Acta fisiátrica 11(2): 72-76.

Roth, M., E. Tym, C. Mountjoy, F. A. Huppert, H. Hendrie, S. Verma and R. Goddard (1986). "CAMDEX. A standardised instrument for the diagnosis of mental disorder in the elderly with special reference to the early detection of dementia." The British journal of psychiatry 149(6): 698-709.

Rowe, J. W. and R. L. Kahn (1987). "Human aging: usual and successful." Science 237(4811): 143-149.

Sanchez, M. A. d. S., P. C. R. Correa and R. A. Lourenço (2011). "Crosscultural Adaptation of the" Functional Activities Questionnaire-FAQ" for use in Brazil." Dementia \& Neuropsychologia 5(4): 322-327.

Sanchez, M. A. d. S. and R. A. Lourenço (2009). "Informant Questionnaire on Cognitive Decline in the Elderly (IQCODE): cross-cultural adaptation for use in Brazil." Cadernos de saude publica 25(7): 1455-1465.

Santos, M. D. d. and S. d. Melo Borges (2015). "Percepção da funcionalidade nas fases leve e moderada da doença de Alzheimer: visão do paciente e seu cuidador." Revista Brasileira de Geriatria e Gerontologia 18(2): 339-349.

Sarmento, A. L. R. (2009). "Apresentação e aplicabilidade da versão brasileira da MoCA (Montreal Cognitive Assessment) para rastreio de comprometimento cognitivo leve."

Saúde, O. M. d. (2004). CIF: classificação internacional de funcionalidade, incapacidade e saúde, Edusp São Paulo.

Scazufca, M. (2002). "Brazilian version of the Burden Interview scale for the assessment of burden of care in carers of people with mental illnesses." Revista brasileira de psiquiatria 24(1): 12-17.

Silva Falcão, D. V. and J. S. Nobre Ferro Bucher-Maluschke (2009). "Cuidar de familiares idosos com a doença de alzheimer: uma reflexão sobre aspectos psicossociais." Psicologia em Estudo 14(4).

Silva Talmelli, L. F. d., A. C. Martins Gratão, L. Kusumota and R. A. Partezani Rodrigues (2010). "Nível de independência funcional e déficit cognitivo em idosos com doença de Alzheimer." Revista da Escola de Enfermagem da USP 44(4).

Souza Mendes, R., C. Novelli and M. M. Pires (2015). "Perfil cognitivo e funcional de idosos moradores de uma instituição de longa permanência para idosos." Cadernos de Terapia Ocupacional da UFSCar 23(4).

Souza, S., A. C. L. F. Camacho, F. L. Joaquim and F. H. do Espírito Santo (2016). "O planejamento do autocuidado para o cuidador de idosos: revisão 
integrativa." Revista de enfermagem UFPE on line-ISSN: 1981-8963 10(5): 1866-1872.

Sposito, G., A. L. Neri and M. S. Yassuda (2016). "Atividades avançadas de vida diária (AAVDs) e o desempenho cognitivo em idosos residentes na comunidade: Dados do Estudo FIBRA Polo UNICAMP." Revista Brasileira de Geriatria e Gerontologia 19(1): 7-20.

Trindade, A. P. N. T. d., M. A. Barboza, F. B. de Oliveira and A. P. O. Borges (2017). "Repercussão do declínio cognitivo na capacidade funcional em idosos institucionalizados e não institucionalizados." Fisioterapia em Movimento 26(2).

Valer, D. (2012). "Adaptação do instrumento Caregiver Burden Inventory para uso com cuidadores de pessoas idosas no Brasil [dissertação]." Porto Alegre (RS): Escola de Enfermagem, Universidade Federal do Rio Grande do Sul.

Valer, D. B., M. Aires, F. L. Fengler and L. M. G. Paskulin ( 2015). "Adaptação do instrumento Caregiver Burden Inventory para uso com cuidadores de pessoas idosas no Brasil" " Rev. Latino-Am. Enfermagem 23: 130-138.

Vallejo, V., P. Wyss, L. Rampa, A. V. Mitache, R. M. Müri, U. P. Mosimann and T. Nef (2017). "Evaluation of a novel Serious Game based assessment tool for patients with Alzheimer's disease." PloS one 12(5): e0175999.

Viñas-Diez, V., O. Turró-Garriga, C. Portellano-Ortiz, J. Gascón-Bayarri, R. Reñé-Ramírez, J. Garre-Olmo and J. L. Conde-Sala (2017). "Kinship and cohabitation in relation to caregiver burden in the context of Alzheimer's disease: a 24-month longitudinal study." International journal of geriatric psychiatry.

WHO, W. H. O. (2015). Relatório Mundial de Envelhecimento e Saúde, Luxemburg: WHO/FWC/ALC.

Wolff, J. L., J. Mulcahy, J. Huang, D. L. Roth, K. Covinsky and J. D. Kasper (2017). "Family Caregivers of Older Adults, 1999-2015: Trends in Characteristics, Circumstances, and Role-Related Appraisal." The Gerontologist: gnx093-gnx093.

Yu, H., X. Wang, R. He, R. Liang and L. Zhou (2015). "Measuring the caregiver burden of caring for community-residing people with Alzheimer's disease." PloS one 10(7): e0132168.

Zanetti, O., C. Geroldi, G. B. Frisoni, A. Bianchetti and M. Trabucchi (1999). "Contrasting results between caregiver's report and direct assessment of activities of daily living in patients affected by mild and very mild dementia: the contribution of the caregiver's personal characteristics." Journal of the American Geriatrics Society 47(2): 196-202.

Zarit, S. and J. Zarit (1983). "The memory and behavior problems checklist and the burden interview-Penn State Gerontology Center." University Park. 


\section{Table}

Table 1 - Demographic and clinical characterization of the sample according to groups (mild $A D$, moderate $A D$ and Controls)

\begin{tabular}{|c|c|c|c|c|c|}
\hline & & & Grups & & \\
\hline & & $\begin{array}{l}\text { Controls } \\
(\mathrm{n}=41)\end{array}$ & $\begin{array}{l}\text { Mild AD } \\
(\mathrm{n}=26)\end{array}$ & $\begin{array}{c}\text { Moderate AD } \\
(n=14)\end{array}$ & $P$ \\
\hline Age & & & & & $0.054^{(3)}$ \\
\hline & $60-69$ & $12(29.3 \%)$ & $5(19.2 \%)$ & $0(0.0 \%)$ & \\
\hline & $70-79$ & $19(46.3 \%)$ & $11(42.3 \%)$ & $5(35.7 \%)$ & \\
\hline & $>=80$ & $10(24.4 \%)$ & $10(38.5 \%)$ & $9(64.3 \%)$ & \\
\hline Gender & & & & & $0.580^{(3)}$ \\
\hline & Male & $11(26.8 \%)$ & $10(38.5 \%)$ & $5(35.7 \%)$ & \\
\hline & Female & 30 (73.2\%) & $16(61.5 \%)$ & $9(64.3 \%)$ & \\
\hline Marital st & atus & & & & $0.223^{(3)}$ \\
\hline & With partner & $15(36.6 \%)$ & $14(53.9 \%)$ & $4(28.6 \%)$ & \\
\hline & Without partner & $26(63.4 \%)$ & $12(46.1 \%)$ & $10(71.4 \%)$ & \\
\hline Schoolin & (in years) & $11.95 \pm 4,34$ & $7.58 \pm 4,62$ & $9.71 \pm 5,38$ & $<0.001^{(1)}$ \\
\hline Work situ & ation & & & & $0.205^{(4)}$ \\
\hline & Retired & 29 (70.7\%) & 22 (84.6\%) & $14(100.0 \%)$ & \\
\hline & Working & $6(14.6 \%)$ & $1(3.9 \%)$ & $0(0.0 \%)$ & \\
\hline & From home & $6(14.6 \%)$ & 3 (11.5\%) & $0(0.0 \%)$ & \\
\hline Retireme & tt time (in years) & $15.13 \pm 12,98$ & $13.85 \pm 9,60$ & $15.36 \pm 12,12$ & $0.995^{(2)}$ \\
\hline MEEM & & $27.44 \pm 2.25$ & $22.12 \pm 3.88$ & $15.93 \pm 2.73$ & $<0.001^{(1)}$ \\
\hline CAMCOC & & $92.85 \pm 8.37$ & $69.69 \pm 11.03$ & $52.36 \pm 10.00$ & $<0.001^{(1)}$ \\
\hline DAFS-BF & & $96.41+7.39$ & $74.23+10.54$ & $58.29+10.05$ & $<0.001^{(1)}$ \\
\hline B-ADL & & $1.29 \pm 0.90$ & $4.96 \pm 2.00$ & $6.64 \pm 2.10$ & $<0.001^{(1)}$ \\
\hline Lawton-B & rody & $20.12 \pm 1.74$ & $13.73 \pm 3.14$ & $10.93 \pm 2.65$ & $<0.001^{(1)}$ \\
\hline IQCODE & & $2.71 \pm 0.78$ & $3.35 \pm 0.56$ & $3.64 \pm 0.50$ & $<0.001^{(1)}$ \\
\hline FAQ & & $0.46 \pm 1.29$ & $12.04 \pm 7.76$ & $23.75 \pm 5.76$ & $<0.001^{(2)}$ \\
\hline $\begin{array}{l}\text { Note: MM } \\
\text { Functional } \\
\text { Informant } \\
\text { living (1) } \\
\text { Kruskal-W } \\
\text { descriptive }\end{array}$ & Mini Mental State & $\begin{array}{l}\text { CAMCOG: Cam } \\
\text { es Questionnair } \\
\text { awton-Brody: La } \\
\text { lysis of Varianc } \\
\text { ive level of prc } \\
\text { onparametric te } \\
\text { est. }\end{array}$ & $\begin{array}{l}\text { ridge Cognitive T } \\
\text { B-ADL: Bayer - } \\
\text { on and Brody's So } \\
\text { at one factor, (2) } \\
\text { ability of Analysis } \\
\text { (3) descriptive ley }\end{array}$ & $\begin{array}{l}\text { t DAFS-BR: Dire } \\
\text { tivities of Daily Li } \\
\text { le of Instrumental } \\
\text { lescriptive level o } \\
\text { of Variance at } \\
\text { l of probability of }\end{array}$ & $\begin{array}{l}\text { Assessment } \\
\text { ig; IQCODE: } \\
\text { ctivities Daily } \\
\text { orobability of } \\
\text { factor, (2) } \\
\text {-square test, }\end{array}$ \\
\hline
\end{tabular}


Table 2 - Cognitive and emotional characterization of the caregivers / informants according to the AD group of the respective patients

\begin{tabular}{|c|c|c|c|c|}
\hline \multicolumn{5}{|c|}{ Group of caregiveres/informants } \\
\hline & $\begin{array}{c}\text { Controls } \\
(n=41)\end{array}$ & $\begin{array}{c}\text { Mild AD } \\
(n=26)\end{array}$ & $\begin{array}{c}\text { Moderate AD } \\
(n=14)\end{array}$ & $P$ \\
\hline $\begin{array}{l}\text { Zarit } \\
\text { BDI }\end{array}$ & $\begin{array}{c}8.51 \pm 10.74 \\
7.98 \pm 9.06\end{array}$ & $\begin{array}{c}28.19 \pm 16.99 \\
8.73 \pm 8.48\end{array}$ & $\begin{array}{c}30.14 \pm 13.13 \\
9.50 \pm 8.75\end{array}$ & $\begin{array}{c}<0.001^{(2)} \\
0.224^{(2)}\end{array}$ \\
\hline BAI & $5.78 \pm 6.27$ & $9.92 \pm 12.56$ & $8.50 \pm 7.41$ & $0.608^{(2)}$ \\
\hline $\mathrm{MoCa}$ & $25.39 \pm 2.80$ & $24.00 \pm 3.59$ & $23.21 \pm 4.84$ & $0.084^{(1)}$ \\
\hline CBI & $5.20 \pm 10.41$ & $27.00 \pm 24.41$ & $36.21 \pm 18.88$ & $<0.001^{(2)}$ \\
\hline CBI - time-dependence & $0.95 \pm 1.90$ & $6.73 \pm 6.17$ & $11.57 \pm 4.57$ & $<0.001^{(2)}$ \\
\hline CBI - developmental & $0.88 \pm 2.29$ & $7.38 \pm 6.34$ & $8.71 \pm 7.08$ & $0.001^{(2)}$ \\
\hline CBI - physical & $1.15 \pm 2.73$ & $4.42 \pm 6.13$ & $7.57 \pm 7.64$ & $<0.001^{(2)}$ \\
\hline CBI -social & $1.20 \pm 3.03$ & $4.77 \pm 6.09$ & $6.29 \pm 5.12$ & $0.002^{(2)}$ \\
\hline CBI - emotional & $1.05 \pm 2.66$ & $4.19 \pm 4.87$ & $2.07 \pm 2.56$ & $<0.001^{(2)}$ \\
\hline
\end{tabular}

Note:MoCa : Montreal Cognitive Assessment, Zarit: ZaritBurden Interview; CBI: Caregiver burden inventory; BDI: Beck Depression Inventory; BAI: Beck anxiety inventory; (1) descriptive level of probability of the Analysis of Variance at one factor; (2) descriptive level of probability of Kruskal-Wallis nonparametric test; (3) descriptive level of probability of the test chi-square, (4) descriptive level of probability of Fisher's exact test 
Table 3 - Correlation coefficient of emotional factors of the informant with functional scales for the control group, Mild AD and Moderate AD group.

Control $(n=41)$

Mild $A D(n=26)$

Moderate $A D(n=14)$

DAFS- IQCODE B-ADL LAWTON FAQ DAFS- IQCODE B-ADL LAWTON FAQ DAFS- IQCODE B-ADL $B R$

$B R$

\begin{tabular}{|c|c|c|c|c|c|c|c|c|c|c|c|c|c|c|c|c|}
\hline \multirow[t]{2}{*}{ Zarit } & $\mathrm{R}$ & -0.040 & 0.666 & 0.795 & -0.523 & 0.522 & -0.068 & 0.474 & 0.452 & -0.341 & 0.209 & -0.189 & 0.223 & 0.376 & -0.354 & 0.259 \\
\hline & $p$ & 0.803 & $<0.001$ & $<0.001$ & $<0.001$ & $<0.001$ & 0.741 & 0.014 & 0.020 & 0.088 & 0.306 & 0.517 & 0.442 & 0.185 & 0.214 & 0.371 \\
\hline \multirow[t]{2}{*}{ BDI } & $\mathrm{R}$ & 0.037 & 0.138 & 0.528 & -0.520 & 0.576 & -0.022 & 0.337 & 0.277 & -0.366 & 0.208 & 0.150 & -0.132 & 0.355 & -0.517 & 0.261 \\
\hline & $p$ & 0.819 & 0.388 & $<0.001$ & $<0.001$ & $<0.001$ & 0.916 & 0.092 & 0.170 & 0.066 & 0.308 & 0.608 & 0.653 & 0.213 & 0.058 & 0.368 \\
\hline \multirow[t]{2}{*}{ BAI } & $\mathrm{R}$ & 0.215 & 0.227 & 0.436 & -0.308 & 0.335 & -0.224 & 0.390 & 0.368 & -0.514 & 0.605 & 0.204 & -0.042 & -0.237 & -0.446 & -0.115 \\
\hline & $p$ & 0.177 & 0.154 & 0.004 & 0.050 & 0.032 & 0.271 & 0.049 & 0.065 & 0.007 & 0.001 & 0.485 & 0.887 & 0.414 & 0.110 & 0.695 \\
\hline \multirow[t]{2}{*}{ CBI total } & $\mathrm{R}$ & -0.096 & 0.491 & 0.822 & -0.650 & 0.713 & -0.229 & 0.176 & 0.460 & -0.569 & 0.430 & 0.144 & 0.176 & 0.420 & -0.496 & 0.223 \\
\hline & $p$ & 0.552 & 0.001 & $<0.001$ & $<0.001$ & $<0.001$ & 0.259 & 0.547 & 0.018 & 0.002 & 0.028 & 0.624 & 0.547 & 0.134 & 0.071 & 0.444 \\
\hline \multirow{4}{*}{$\begin{array}{l}\text { CBI } \\
\text { (time } \\
\text { dependence) } \\
\text { CBI } \\
\text { (developmental) }\end{array}$} & $\mathrm{R}$ & -0.425 & 0.132 & 0.349 & -0.348 & 0.327 & -0.427 & 0.448 & 0.611 & -0.759 & 0.708 & -0.088 & 0.448 & 0.040 & -0.200 & 0.048 \\
\hline & $p$ & 0.006 & 0.409 & 0.025 & 0.026 & 0.037 & 0.030 & 0.108 & 0.001 & $<0.001$ & $<0.001$ & 0.766 & 0.108 & 0.891 & 0.493 & 0.871 \\
\hline & $\mathrm{R}$ & -0.184 & 0.469 & 0.736 & -0.581 & 0.630 & -0.260 & 0.150 & 0.492 & -0.576 & 0.424 & 0.140 & 0.150 & 0.538 & -0.618 & 0.361 \\
\hline & $p$ & 0.248 & 0.002 & $<0.001$ & $<0.001$ & $<0.001$ & 0.200 & 0.609 & 0.011 & 0.002 & 0.031 & 0.634 & 0.609 & 0.047 & 0.019 & 0.205 \\
\hline \multirow{2}{*}{$\begin{array}{l}\text { CBI } \\
\text { (physical) }\end{array}$} & $\mathrm{R}$ & -0.111 & 0.476 & 0.755 & -0.620 & 0.644 & -0.105 & 0.102 & 0.293 & -0.385 & 0.309 & 0.116 & 0.102 & 0.288 & -0.388 & 0.158 \\
\hline & $p$ & 0.491 & 0.002 & $<0.001$ & $<0.001$ & $<0.001$ & 0.611 & 0.729 & 0.146 & 0.052 & 0.124 & 0.693 & 0.729 & 0.317 & 0.171 & 0.589 \\
\hline \multirow{2}{*}{$\begin{array}{l}\mathrm{CBI} \\
\text { (emotional) }\end{array}$} & $\mathrm{R}$ & 0.065 & 0.277 & 0.668 & -0.538 & 0.695 & -0.210 & 0.104 & 0.245 & -0.432 & 0.355 & 0.297 & 0.104 & 0.216 & -0.180 & -0.063 \\
\hline & $p$ & 0.689 & 0.079 & $<0.001$ & $<0.001$ & $<0.001$ & 0.302 & 0.723 & 0.227 & 0.028 & 0.075 & 0.302 & 0.723 & 0.457 & 0.538 & 0.830 \\
\hline \multirow{2}{*}{$\begin{array}{l}\text { CBI } \\
\text { (social) }\end{array}$} & $\mathrm{R}$ & 0.134 & 0.620 & 0.804 & -0.542 & 0.562 & -0.003 & -0.425 & 0.324 & -0.213 & 0.082 & -0.109 & -0.425 & 0.253 & -0.079 & 0.216 \\
\hline & $p$ & 0.405 & $<0.001$ & $<0.001$ & $<0.001$ & $<0.001$ & 0.987 & 0.130 & 0.107 & 0.295 & 0.689 & 0.712 & 0.130 & 0.383 & 0.789 & 0.457 \\
\hline
\end{tabular}

Note: Note: $r$ = Pearson's correlation coefficient, $p=$ descriptive level of probability, Zarit: Zarit Burden Interview; BDI : Beck Depression Inventory; BAI: Beck Anxiety Inventory; CBI: Caregiver Burden

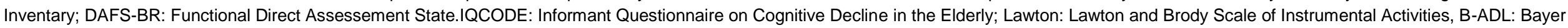
Activities of the Daily Living Scale; Pfeffer Functional Activities FAQ:Questionnaire 
Table 04- Correlation coefficient between the domains of the $\mathrm{CBI}$ scales and the DAFS-BR domains for the control group, mild AD and moderate AD group

\begin{tabular}{|c|c|c|c|c|c|c|c|c|c|c|c|c|c|c|c|c|}
\hline & & \multicolumn{5}{|c|}{ Control $(n=41)$} & \multicolumn{5}{|c|}{ Mild AD $(n=26)$} & \multicolumn{5}{|c|}{ Moderate $A D(n=14)$} \\
\hline & & $\begin{array}{l}\text { DAFS } \\
\text { Time } 0 .\end{array}$ & $\begin{array}{l}\text { DAFS } \\
\text { Com. } \\
\text { Skills }\end{array}$ & $\begin{array}{l}\text { DAFS } \\
\text { D.F. }\end{array}$ & $\begin{array}{l}\text { DAFS } \\
\text { Shop. } \\
\text { Skills }\end{array}$ & $\begin{array}{l}\text { DAFS } \\
\text { G.E. } \\
\text { Skills }\end{array}$ & $\begin{array}{l}\text { DAFS } \\
\text { Time } O .\end{array}$ & $\begin{array}{l}\text { DAFS } \\
\text { Com. } \\
\text { Skills }\end{array}$ & $\begin{array}{l}\text { DAFS } \\
\text { D.F. }\end{array}$ & $\begin{array}{l}\text { DAFS } \\
\text { Shop. } \\
\text { Skills }\end{array}$ & $\begin{array}{l}\text { DAFS } \\
\text { G.E. } \\
\text { Skills }\end{array}$ & $\begin{array}{l}\text { DAFS } \\
\text { Time } O .\end{array}$ & $\begin{array}{l}\text { DAFS } \\
\text { Com. } \\
\text { Skills }\end{array}$ & $\begin{array}{l}\text { DAFS } \\
\text { D.F. }\end{array}$ & $\begin{array}{l}\text { DAFS } \\
\text { Shop. } \\
\text { Skills }\end{array}$ & $\begin{array}{l}\text { DAFS } \\
\text { G.E. } \\
\text { Skills }\end{array}$ \\
\hline \multirow{2}{*}{$\begin{array}{l}\text { CBI Time } \\
\text { dependence }\end{array}$} & $\mathrm{R}$ & 0,053 & 0,148 & $-0,334$ & $-0,638$ & - & -0.156 & -0.189 & -0.296 & -0.411 & - & -0.232 & -0.234 & 0.124 & -0.124 & \\
\hline & $p$ & 0,741 & 0,355 & 0,033 & $<0,001$ & - & 0.447 & 0.356 & 0.141 & 0.037 & - & 0.424 & 0.421 & 0.674 & 0.674 & $\begin{array}{l}0.290 \\
0.302\end{array}$ \\
\hline \multirow{2}{*}{$\begin{array}{l}\mathrm{CBI} \\
\text { Developmental }\end{array}$} & $\mathrm{R}$ & 0,110 & $-0,036$ & $-0,191$ & $-0,283$ & - & -0.133 & -0.099 & -0.274 & -0.315 & - & -0.268 & 0.489 & 0.407 & -0.388 & - \\
\hline & $p$ & 0,493 & 0,823 & 0,232 & 0,073 & - & 0.516 & 0.632 & 0.176 & 0.117 & - & 0.355 & 0.076 & 0.149 & 0.171 & $\begin{array}{l}0.0 / 8 \\
0.791\end{array}$ \\
\hline \multirow[t]{2}{*}{ CBI Phisical } & $\mathrm{R}$ & 0,153 & 0,008 & $-0,097$ & $-0,188$ & - & -0.014 & 0.117 & -0.092 & -0.285 & - & -0.238 & 0.433 & 0.402 & -0.350 & 0.103 \\
\hline & $p$ & 0,340 & 0,962 & 0,546 & 0,238 & - & 0.947 & 0.571 & 0.655 & 0.158 & - & 0.413 & 0.122 & 0.155 & 0.220 & 0.726 \\
\hline \multirow[t]{2}{*}{ CBI Emociotal } & $\mathrm{R}$ & 0,101 & 0,107 & 0,119 & $-0,129$ & - & -0.314 & 0.009 & -0.259 & -0.146 & - & 0.017 & 0.595 & 0.409 & -0.265 & 0.204 \\
\hline & $p$ & 0,529 & 0,507 & 0,457 & 0,421 & - & 0.118 & 0.965 & 0.201 & 0.478 & - & 0.953 & 0.025 & 0.147 & 0.359 & 0.485 \\
\hline \multirow[t]{2}{*}{ CBI Social } & $\mathrm{R}$ & 0,140 & 0,093 & 0,022 & 0,066 & - & 0.075 & -0.074 & -0.103 & -0.002 & - & -0.284 & 0.281 & $\begin{array}{l}- \\
0.083\end{array}$ & -0.409 & $\begin{array}{l}- \\
0.083\end{array}$ \\
\hline & $p$ & 0,383 & 0,562 & 0,893 & 0,680 & - & 0.716 & 0.718 & 0.618 & 0.993 & - & 0.325 & 0.331 & 0.779 & 0.147 & 0.779 \\
\hline
\end{tabular}

NOTE: DAFS-BR: Functional Direct State Assessment DAFS Time O.: Time Orientation; DAFS Com. Skills: Comunication Skills; DAFS D.F.: Dealing with Finances ;DAFS Shop. Skills: Shopping Skills; DAFS G.E. skills: Grooming and Eating skills; $r$ = Pearson correlation coefficient, $\mathbf{p}=$ descriptive level of probability, CBI: Caregiver Burden Inventary; 